Diogo dos Santos Scelza Cavalcanti

\&

Gustavo Parente Duarte Ferreira

\title{
AVALIAÇÃO QUALITATIVA DAS INCERTEZAS DA MEDIÇÃO ÓTICA DO COMPRIMENTO DA TRINCA EM TESTE DE FADIGA
}

\author{
PROJETO DE GRADUAÇÃO
}

Professor Orientador: Jaime Tupiassú Pinho de Castro

Departamento de Engenharia Mecânica

Rio de Janeiro, 12 de Dezembro de 2005 
Diogo dos Santos Scelza Cavalcanti

\&

Gustavo Parente Duarte Ferreira

\section{QUALITATIVE EVALUATION OF THE UNCERTAINTIES OF OPTICS MEASUREMENTS OF CRACK SIZE IN FATIGUE TEST}

\section{DISSERTATION FOR UNDERGRADUATION DEGREE}

Professor Advisor: Jaime Tupiassú Pinho de Castro, Ph.D.

Departamento de Engenharia Mecânica

Rio de Janeiro, December 12, 2005 


\section{'Agradecimentos}

Gostaríamos de agradecer a Deus, autor e criador de todas as coisas. Ele que por vontade livre, no primeiro dia da criação, disse um verbo em hebraico reservado somente às suas ações. "Bará"! "Faça-se"! O universo se fez, a primeira lei da termodinâmica foi quebrada e inúmeros casos de estudos científicos ficaram sem solução para nós, pobres criaturas. Por outro lado nos deu como engenheiros, meios de ganhar o "pão nosso de cada dia". Agora nos cabe a tarefa de buscar a Deus em suas sutilezas, tanto na ciência quanto na vida.

A nossa família, em especial nossos pais Vera e Bianor, Pedro e Evane, que desde sempre nos acompanharam, educaram, motivaram e nos guiaram nessa conquista que foi concretizada com o suor do nosso rosto, mas que sem o amor de vocês certamente não seríamos capazes.

Eu Diogo, gostaria de agradecer a minha querida namorada Danielli, que tanta força me deu nesses momentos difíceis. E eu Gustavo, a minha querida amiga Carol. Enfim, a todos amigos, nossa família escolhida, pelo apoio e companheirismo que tiveram durante esses longos e cansativos anos, em nossos momentos de nervosismo, insegurança, e também por terem dividido as alegrias de nossas conquistas. Eis aqui mais uma!

Aos nossos colegas de faculdade, que muitas vezes passamos horas a fio tentando entender "aquela equação" que acabou não caindo na prova.

A todos os nossos professores, pois nos deram uma formação sólida e profunda, digna da melhor escola de Engenharia Mecânica do Brasil. Em especial ao professor Jaime Tupiassú Pinho de Castro, que nos orientou neste trabalho e ao 
professor Ronaldo Vieira, que nos transmitiu calma e tranqüilidade durante o nosso agradável convívio no laboratório.

Um agradecimento especial ao Jaiminho, filho do prof. Jaime e ao Dr. Antônio Carlos por terem nos dado todo suporte para a realização dos nossos testes e por serem tão pacientes ao sanarem nossas dúvidas operacionais. E ao Senhor Garcia (vulgo Bigode), que com suas histórias e mágicas descontraía o ambiente e tornava nossa estadia no laboratório mais alegre.

Não poderíamos deixar de agradecer aos nossos amigos padres. Pe. Jorjão, por sentir junto conosco nossas angustias e alegrias, e ao Pe. Frederico, que há muito tempo é mais que um padre, mas um amigo para todas as horas.

Enfim, a todos que deixamos de estar juntos e esperaram pacientemente nossas ausências devido a trabalhos, provas, estudos... o nosso Muito Obrigado! 
Área de concentração: Mecânica da Fratura e Fadiga

\title{
Sumário
}

O trabalho apresenta uma avaliação qualitativa das incertezas da medição ótica do comprimento da trinca em teste de fadiga da/dN. Além disso, descreve-se o equipamento necessário para esse tipo de teste, a metodologia para aplicação de cargas dinâmicas e a realização das medições utilizando-se um telescópio, baseandose nas recomendações da norma ASTM E 647.

Palavras chave: fadiga, propagação de trinca, medição

\begin{abstract}
This research presents a qualitative evaluation of the uncertainties of optics measurements of crack size in da/dN fatigue tests. Moreover, it describes the necessary equipment for this kind of test, the methodology of dynamic load application and how to measure using a telescope, according to the ASTM E 647 standard.
\end{abstract}

Key words: fatigue, crack propagation, measurement 


\section{ÍNDICE}

2.1 MECÂNICA da Fratura 2

$\begin{array}{lll}2.2 & \text { ConcentraçÃo de Tensões } & 3\end{array}$

$\begin{array}{lll}\text { 2.3 Propagação de Trincas por Fadiga } & 4\end{array}$

2.3.1 Método $d a / d N$ de Projeto À FAdiga (Regra de Paris) 6

$\begin{array}{lll}2.3 .2 & \text { VANTAgENS DA REgRA DE PARIS } & 7\end{array}$

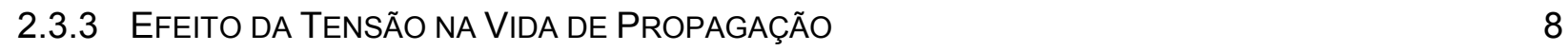

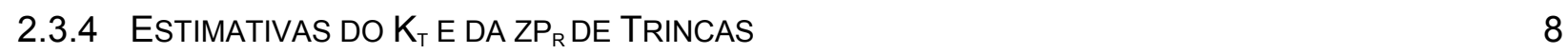

$\begin{array}{lll}\text { 2.3.5 } & \text { FECHAMENTO DAS TRINCAS DE FADIGA } & 10\end{array}$

$\begin{array}{lll}\text { 2.3.6 OS LIMITES DA REGRA DE PARIS } & 11\end{array}$

2.4 As Fases da Curva de Propagação de Trincas típicas 12

$\begin{array}{llr}2.4 .1 & \text { AFASEI } & 12\end{array}$

$\begin{array}{lll}2.4 .2 & \text { A FASE II } & 14\end{array}$

2.4.2.1 Estimativas de Barsom para a Fase II das Curvas $d a / d N$ dos Aços 16

$\begin{array}{lll}2.4 .3 & \text { A FASE III } & 16\end{array}$

$\begin{array}{lll}\text { 2.4.4 } & \text { Regras } d a / d N \text { MaIs Precisas } & 17\end{array}$

2.4.4.1 Regra de Elber Modificada $\quad 17$

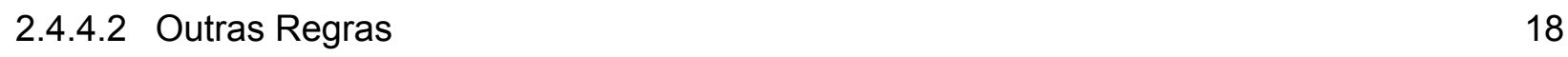

$\begin{array}{ll}\text { 2.4.4.3 Regra de Forman-Newman } & 19\end{array}$

$\begin{array}{ll}\text { 2.4.4.4 Limites das Regras Tradicionais } & 19\end{array}$

$\begin{array}{lll}2.5 & \text { Fechamento IndUZIDO PoR Plasticidade } & 20\end{array}$

2.5.1 FECHAMENTO PARCIAL DAS TRINCAS 22 
$\begin{array}{lll}2.6 & \text { Outros Mecanismos de Fechamento } & 23\end{array}$

2.7 INCOMPATIBILIDADE DE ORIENTAÇÃo DA FRENTE DA TRINCA 25

2.8 Mecanismos de Retardo localizados na Vizinhança da Ponta da Trinca 25

2.9 Tensões e Deformações Residuais $\quad 29$

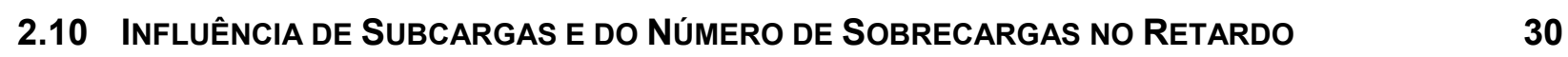

2.11 Modelagem dos Efeitos de Retardo 33

2.11.1 RETARdo BASEAdo NA VARIAÇÃo dE R 33

2.11.2 RETARDO BASEAdo NA VARIAÇÃO DE DA/DN 36

2.11.3 Retardo Baseado no DeCRÉscimo de $\Delta \mathrm{K}$

2.11.4 Retardo Baseado Na VARIaçÃo de $\mathrm{K}_{\mathrm{AB}} \quad 40$

$\underline{3} \quad$ PROCEDIMENTO EXPERIMENTAL

$\begin{array}{lll}3.1 & \text { EQUIPAMENTOS E MATERIAIS } & 43\end{array}$

$\begin{array}{lll}3.2 & \text { Metodologia do Teste } & 45\end{array}$

3.2.1 PreparaçÃo do Corpo de Prova $\quad 45$

3.2.2 Planilha de Monitoramento e CÁlculo do Teste 47

$\begin{array}{lll}\text { 3.2.3 } & \text { MONTAGEM DO SISTEMA } & 48\end{array}$

3.2.4 Metodologia de MediçÃo 49

$\begin{array}{lll}3.2 .5 & \text { FREQÜÊNCIA } & 50\end{array}$

$\begin{array}{lll}\text { 3.2.6 LiMITES E CONTROLE DO TESTE } & 50\end{array}$

$\begin{array}{lll}\text { 3.2.7 CALIBRAÇÃo da MÁQUina de TESTES } & 50\end{array}$

3.2.8 ABERTURA DA PRÉ-TRINCA

$\begin{array}{lll}\text { 3.2.9 PROPAGAÇÃO DA TRINCA } & 51\end{array}$

$\begin{array}{lll}\text { 3.2.9.1 K-Decrescente } & 51\end{array}$

$\begin{array}{lll}\text { 3.2.9.2 K-Crescente } & 52\end{array}$ 
$\begin{array}{lll}4.1 & \text { INCERTEZAS NAS MEDIÇÕES } & 53\end{array}$

$\begin{array}{lll}4.2 & \text { OUTRAS INCERTEZAS } & 54\end{array}$

$\begin{array}{lll}4.3 & \text { ANÁLISE dOS DADOS } & 55\end{array}$

$\underline{5}$ CONCLUSÃO $\quad 59$

\begin{tabular}{lr} 
BIBLIOGRAFIA & 61 \\
\hline
\end{tabular}

APÊNDICE I: TABELA DE DADOS $\quad 65$

APÊNDICE II: ROTINA MATLAB PARA EXIBIR A NUVEM DE PONTOS

69

APÊNDICE III: TÓPICOS DA NORMA ASTM E 647-2000 UTILIZADOS 74

APÊNDICE IV: GRÁFICOS 78 


\section{ÍNDICE DE FIGURAS}

Figura 1 - Experimento de Paris 06

Figura 2 - Curva da/dN típica 12

$\begin{array}{ll}\text { Figura } 3 \text { - Estrias na fase II } & 14\end{array}$

Figura 4 - Fechamento parcial das trincas $\quad 22$

Figura 5 - Fechamento induzido por rugosidade $\quad 24$

Figura 6 - Gráfico "fatores de intensidade de tensão X ângulo da dobra, a" 26

Figura 7 - Gráfico "fatores de intensidade de tensão X ângulo de bifurcação, $2 \alpha$ " 27

Figura 8 - Bifurcação $\quad 28$

Figura 9 - Caminho da trinca bifurcada $\quad 28$

Figura 10 - Tensões residuais compressivas $\quad 30$

$\begin{array}{ll}\text { Figura } 11 \text { - Sobrecargas e subcargas } & 31\end{array}$

Figura 12 - Efeitos de sobrecargas e subcargas 31

Figura 13 - Número de ciclos de retardo 32

Figura 14 - Retardo segundo Wheeler $\quad 37$

Figura 15 - Ajuste experimental do expoente de Wheeler 38

Figura 16 - Os 4 regimes de propagação segundo o modelo KN 43

Figura 17 - Esquema da fixação do corpo de prova na máquina de teste $\quad 45$

Figura 18 - Corpo de prova utilizado no teste 46

Figura 19- Gráfico a X N 56

Figura 20 - Gráfico da/dN X a $\quad 57$

Figura 21 - Gráfico da/dN X a $\quad 58$

Figura $22-$ Gráfico da/dN X $\Delta \mathrm{K}$ 
ÍNDICE DE TABELAS

Tabela 1 - Dimensões do corpo de prova

Tabela 2 - Identificação dos pontos do teste 


\section{Lista de Símbolos}

a Tamanho da trinca atual $[\mathrm{mm}]$

A Constante da curva da/dN

$\mathrm{a}_{0} \quad$ Tamanho inicial de trinca $[\mathrm{mm}]$

ac Tamanho de trinca crítico $[\mathrm{mm}]$

asc Tamanho de trinca na sobrecarga $[\mathrm{mm}]$

b Expoente elástico da curva de Coffin-Manson

CP Corpo de Prova

CTOD Abertura de ponta de trinca (crack tip openning displacement)

d Diâmetro [mm]

da/dN Taxa de propagação de trinca [mm/ciclo ou $\mathrm{m} /$ ciclo]

E Módulo de elasticidade à tração (módulo de Young) [GPa]

$E^{\prime} \quad$ Módulo de Young efetivo $\left(E^{\prime}=E\right.$ em tensão plana e $E^{\prime}=E /(1-v 2)$ em deformação plana) [GPa]

$\mathrm{f}(\mathrm{a} / \mathrm{w}) \quad$ função adimensional da geometria do fator de intensidade de tensão

G Módulo de elasticidade ao cisalhamento [GPa]

HV Dureza Vickers

I Momento de inércia da seção reta [mm4]

$\mathrm{K}_{\mathrm{ab}} \quad$ Fator de intensidade de tensão de abertura de trinca $[\mathrm{MPa}(\mathrm{m}) 1 / 2]$

$\mathrm{K}_{\mathrm{c}} \quad$ Tenacidade à fratura $[\mathrm{MPa}(\mathrm{m}) 1 / 2]$

$\mathrm{K}_{\mathrm{I}} \quad$ Fator de intensidade de tensão em modo I [MPa $\left.(\mathrm{m}) 1 / 2\right]$

K IC Fator de intensidade de tensão crítico em modo I [MPa(m)1/2]

$\mathrm{K}_{\max } \quad$ Fator de intensidade de tensão máxima $[\mathrm{MPa}(\mathrm{m}) 1 / 2]$

$\mathrm{K}_{\min } \quad$ Fator de intensidade de tensão mínimo (incluindo compressão) [MPa(m)1/2] 
$\mathrm{K}_{\mathrm{SC}} \quad \mathrm{Kmax}$ da mais recente sobrecarga [MPa(m)1/2]

$\mathrm{K}_{\text {sub }} \quad \mathrm{Kmin}$ da mais recente subcarga $[\mathrm{MPa}(\mathrm{m}) 1 / 2]$

Ir Comprimento do ligamento residual de uma peça [mm]

m Expoente da curva da/dN

MFLE Mecânica da Fratura Linear Elástica

N Número de ciclos

NSC Número consecutivos de ciclos de sobrecarga

$\mathrm{p} \quad$ expoente de (1-R) da curva da/dN (Walker, Hall)

$\mathrm{P}_{\mathrm{ab}} \quad$ Carga de abertura de trinca $[\mathrm{N}]$

R Razão de tensão Kmin/Kmax

$\mathrm{R}_{\mathrm{pt}} \quad$ Razão de parada de trinca (KSC/Kmax)

RsC Razão de sobrecarga (KSCmin/KSCmax)

$\mathrm{S}_{\mathrm{C}} \quad$ Resistência à fluência [MPa]

$\mathrm{S}_{\mathrm{E}} \quad$ Resistência ao escoamento [MPa]

$\mathrm{S}_{\mathrm{Ec}} \quad$ Resistência ao escoamento cíclico [MPa]

$\mathrm{S}_{\mathrm{R}} \quad$ Resistência à ruptura [MPa]

TND Teste não destrutivo

$\mathrm{zp}, \mathrm{zp}_{\mathrm{i}} \quad$ Tamanho da zona plástica atual [mm]

zpsc Tamanho da zona plástica de sobrecarga [mm]

a Coeficiente multiplicador da carga média para cálculo de $\Delta K$ th

$\beta \quad$ Expoente de Wheeler para retardo de trinca (modifica da/dN) ou Coeficiente do efeito da carga média em $\Delta \mathrm{kth}=\Delta \mathrm{K} 0(1-\beta R)$

Y Expoente de Wheeler modificado para retardo de trinca

$\delta \quad$ Abertura de ponta de trinca 
$\Delta \mathrm{K} \quad$ Gama do fator de intensidade de tensão $[\mathrm{MPa}(\mathrm{m}) 1 / 2]$

$\Delta \mathrm{K}_{0} \quad$ Limiar de propagação de trinca para $\mathrm{R}=0[\mathrm{MPa}(\mathrm{m}) 1 / 2]$

$\Delta \mathrm{K}_{\mathrm{ef}} \quad$ Gama efetiva do fator de intensidade de tensão [MPa(m)1/2]

$\Delta \mathrm{k}_{\text {th }} \quad$ Limiar de propagação de trinca $[\mathrm{MPa}(\mathrm{m}) 1 / 2]$

$\Delta \mathrm{P} \quad$ Gama de forças aplicadas à peça $[\mathrm{N}]$

$\Delta \varepsilon \quad$ Gama das deformações atuantes no ponto crítico da peça

$\Delta \sigma \quad$ Gama das tensões atuantes no ponto crítico da peça [MPa]

$\varepsilon \quad$ Deformação [\% ou $\mu$ e]

o $\quad$ Tensão [MPa]

$\sigma_{\max } \quad$ Tensão máxima [MPa]

$\sigma_{\mathrm{n}} \quad$ Tensão nominal [MPa]

$\sigma_{\mathrm{R}} \quad$ Tensão real de ruptura [MPa] 


\section{INTRODUÇÃO}

A fadiga é um mecanismo de falha causada pela variação de um carregamento em uma determinada peça ou estrutura. Muitos dos componentes mecânicos estão submetidos a estas condições de carregamento, o que torna o estudo da fadiga uma área de fundamental importância para o desenvolvimento de projetos de engenharia mecânica.

A falha por fadiga começa com uma pequena trinca. Em geral esta trinca nasce na superfície da peça, normalmente a região mais solicitada da peça. A geração das trincas é muito influenciada por entalhes, mudanças na seção transversal, furos, corrosão, marcas de inspeção e estampagem, trincas internas devido ao processo de fabricação ou mesmo irregularidades causadas pela usinagem da peça que podem concentrar localmente as tensões na peça.

A trinca inicial é tão pequena que é invisível a olho nu e difícil de localizar utilizando-se qualquer método de inspeção. Isso pode representar um sério problema para materiais frágeis, os quais têm pouca resistência à propagação da trinca. marcas de inspeção e estampagem, trincas internas devido ao processo de fabricação ou mesmo irregularidades causadas pela usinagem da peça.

Uma vez que a trinca é iniciada, o efeito de concentração de tensão se torna maior e a trinca se propaga mais rapidamente. À medida que a área tensionada diminui em tamanho, a tensão aumenta em magnitude até que, finalmente, a área remanescente frature repentinamente. Consequentemente, a falha por fadiga é caracterizada por duas regiões distintas. A primeira é devido ao desenvolvimento progressivo da trinca, enquanto a segunda, à fratura repentina. 
Quando componentes mecânicos falham estaticamente, estes normalmente apresentam deflexões muito grandes, permitindo que o componente possa ser trocado antes que a fratura ocorra de fato. Assim muitas falhas estáticas nos dão "alertas" visíveis quando estão avançadas, mas o mesmo não ocorre com falhas finais por fadiga; que são repentinas e, portanto, perigosas.

Sabendo-se que, na prática, a fadiga é na maioria dos casos o mais importante dentre todos os vários mecanismos indutores de falhas mecânicas, e tendo em vista que a modelagem do crescimento da trinca de fadiga se dá analisando corpos de prova em laboratório através de testes dinâmicos, este trabalho tem por objetivo primário avaliar qualitativamente as incertezas da medição ótica do comportamento da trinca em testes de fadiga. E assim dar o primeiro passo em direção a responder questões atuais que pairam no meio cientifico. Por exemplo: Qual o parâmetro controlador da propagação de trincas por fadiga: $\Delta \mathbf{K}$ ou $\Delta \mathbf{K}_{\mathrm{ef}}$ ?

Além disso, faz-se mister deixar novamente o Laboratório de Ensaios Mecânicos do DEM em condições de produzir resultados, pois ele acabou de passar por obras.

\section{REVISÃO TEÓRICA}

\subsection{Mecânica da Fratura}

O uso do modelo para propagação de trincas baseado no fator de intensidade de tensões é a aplicação de engenharia mais bem sucedida para a mecânica da fratura. Em contraste com a tradicional abordagem da relação tensão-vida e carga-vida, dentro do contexto da mecânica da fratura, supõe-se que trincas existem em materiais e estruturas. Parâmetros de fratura podem ser usados para caracterizar as tensões e 
cargas perto da ponta da trinca. Um entendimento fundamental da mecânica da fratura e do limite do uso dos parâmetros de fratura é necessário para aplicações da mecânica da fratura para modelar propagação de trincas por fadiga.

Primeiramente será apresentado o conceito de concentração de tensões. Em seguida, serão introduzidos os fatores de intensificação de tensões, zonas plásticas e exigências da mecânica da fratura linear elástica. Finalmente serão expostas as leis de propagação de trincas por fadiga baseadas na mecânica da fratura linear elástica.

\subsection{Concentração de Tensões}

A fórmula:

$$
\sigma=\frac{M \cdot y}{I}
$$

usada para calcular as tensões lineares elásticas induzidas pelo momento fletor $\mathbf{M}$ no ponto que dista y do eixo neutro numa viga de momento de inércia I, só é válida ${ }^{12}$ nos trechos onde a seção reta permaneça uniforme. Logo, as fórmulas clássicas só servem para se calcular as chamadas tensões nominais $\sigma_{n}$, as quais desprezam os efeitos localizados nas transições geométricas. Mas a maioria das peças reais tem entalhes (como furos, rasgos, ombros ou outros detalhes geométricos similares, onde a seção varia de forma brusca), que são em geral indispensáveis para a fixação e/ou a operação da peça, e estes entalhes concentram (aumentam) localmente as tensões nominais que atuam na peça.

O fator de concentração de tensões $\mathbf{K}_{\mathbf{t}}$ é definido pela razão entre a máxima tensão que atua numa dada seção (entalhada) $\sigma_{\max }$ e a tensão nominal $\sigma_{\mathrm{n}}$ que atuaria naquela seção se o entalhe nela não causasse qualquer efeito: 


$$
K_{t}=\frac{\sigma_{\max }}{\sigma_{n}}
$$

Na modelagem dos problemas de fadiga (e também nos de fratura de peças frágeis), o efeito dos entalhes é de primordial importância e o uso dos $\mathrm{K}_{\mathrm{t}} \mathrm{s}$ é indispensável.

\subsection{Propagação de Trincas por Fadiga}

Queremos estudar a propagação de trincas por fadiga seguindo as técnicas da mecânica da fratura linear elástica (MFLE). Para isso devemos demonstrar que o parâmetro que controla a taxa de propagação das trincas $d a / d N$ é a gama $\Delta \mathrm{K}$ do fator de intensidade de tensões e não gama de tensões $\Delta \sigma$. Além disso, devemos para que o estudo se torne consistente, devemos avaliar as vantagens das regras $d a / d N \times \Delta \mathrm{K} \mathrm{e}$, sobretudo as suas limitações.

A fadiga é o tipo de falha mecânica que é caracterizada pela geração e/ou pela propagação paulatina de uma trinca, causada primariamente pela aplicação repetida de varias caras variáveis. A trinca é gerada pela gama de deformações $\Delta \varepsilon$ ou das tensões $\Delta \sigma$ atuantes no ponto critico da peça e a propagação da trinca é geralmente perpendicular à máxima tensão normal trativa e é controlada por $\Delta \mathrm{K}$, a gama do fator de intensidade de tensões, e que descreve a o tamanho do campo de tensões em torno da trinca. Como no caso da geração, a modelagem do problema de propagação de trincas requer estudo e informações em seis áreas complementares e que afetam o objeto de estudo, são elas:
a) Geometria
b) Carregamento
c) Propriedades do material 
d) Análise das tensões

e) Análise das trincas

f) Análise do dano

A confiabilidade e a precisão das informações levantadas devem ser similares, pois, todos os parâmetros enumerados acima são de igual importância.

A taxa de propagação das trincas é controlada principalmente pela gama do fator de intensidade de tensão no modo I $\left.\Delta K_{I}=\left[\Delta \sigma_{I}\right][\sqrt{\pi a}] f(a / w)\right]$, cresce perpendicular a maior gama de tensão $\Delta \sigma_{I}$, esta função depende também do comprimento da trinca 'a' e uma função adimensional $\mathrm{f}(\mathrm{a} / \mathrm{w})$ que quantifica o efeito de todos os outros fatores geométricos que afetam o campo de tensões na peça trincada.

Em 1961 Paris $^{44}$ propôs que a taxa de propagação das trincas por fadiga dependia da gama do fator de intensidade de tensões $\Delta \mathrm{K}$ e depois demonstrou convincentemente que é $\Delta \mathrm{K}$ que controla $d a / d N$. No seu trabalho Paris ${ }^{43}$ analisou a propagação de trincas por fadiga em duas placas trincadas idênticas (de mesma geometria e material) submetidas à mesma gama de tensões $\Delta \sigma=\frac{\Delta P}{w t}$. Na primeira placa a carga foi aplicada na borda da trinca por um pino bipartido inserido na trinca e a outra a carga foi induzida na sua borda.

Se a gama de tensões controlasse a propagação das trincas, a taxa $d a / d N$ deveria ser a mesma nas duas placas. Contudo Paris observou que a que quando a carga foi aplicada na borda da placa, a taxa $d a / d N$ cresceu com o tamanho da trinca 'a' mas quando a carga foi aplicada na face de trinca, $d a / d N$ decresceu com 'a'. Podemos concluir que a taxa de propagação por fadiga não pode estar sendo controlada pela gama das tensões $\Delta \sigma$, que era a mesma nos dois casos descritos 
acima. Por outro lado pode-se observar que as curvas $d a / d N \times \Delta \mathrm{K}$ medidas nas duas placas coincidiram, pois as equações referentes às placas são:

Placa com a força aplicada no furo:

$$
\Delta K=\frac{\Delta \sigma w}{\sqrt{\pi a}}
$$

Placa com a força aplicada na borda da placa:

$$
\Delta K=\Delta \sigma \sqrt{\pi a}
$$

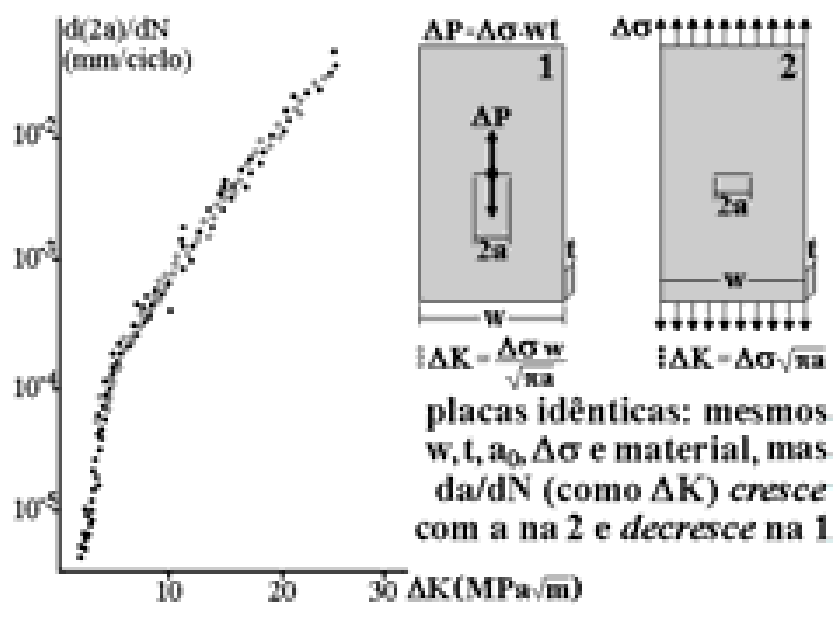

Figura 1 - Experimento de Paris

\subsubsection{Método $d a / d N$ de Projeto à Fadiga (Regra de Paris)}

O método $d a / d N$ de projeto a fadiga é usado para prever a vida residual de peças trincadas a partir da integração da curva de propagação $d a / d N \times \Delta \mathrm{K}$ do material. ${ }^{47,53}$

Este método teve inicio com a proposição da regra de Paris a qual prevê a relação abaixo:

$$
\frac{d a}{d N}=A \Delta K^{m}
$$


Onde A e m são propriedades do material que devem ser medidas em testes de propagação de trincas por fadiga, sendo m um número tipicamente entre 2 e 5 . Como as trincas preferem crescer em modo I, para minimizar o trabalho gasto na zona plástica e no atrito entre suas faces, e comum usar o índice I e somente usá-lo quando os outros modos tiverem alguma importância.

\subsubsection{Vantagens da Regra de Paris}

Uma das principais vantagens é que a regra reconhece a presença de trinca e quantifica a sua propagação por fadiga. Desde a época de Wöhler esta foi a primeira idéia revolucionária, além disso, e muito simples usar tanto em projeto quanto na avaliação de integridade estrutural.

Se a taxa de propagação é dada pela equação acima onde $A$ e $m$ são propriedades do material e $\Delta \mathrm{K}$ é a gama do fator de intensidade de tensões e $\mathrm{N}$ o numero de ciclos, temos:

$$
N=\int_{a_{0}}^{a_{f}} \frac{d a}{A \Delta K^{m}}=\frac{1}{A(\Delta \sigma \sqrt{\pi})^{m}} \int_{a_{0}}^{a_{f}} \frac{d a}{[\sqrt{a} f(a / w)]^{m}}
$$

Devemos enfatizar que nas estruturas reais, nas quais não se pode garantir total inexistência de trincas, a grande vantagem dos materiais de alta tenacidade é o aumento da trinca critica e não da vida residual da peça. Como as trincas grandes são muito mais facilmente detectáveis que as pequenas em TND (testes não destrutivos) as estruturas tenazes são mais seguras que as frágeis. É por isso que boas inspeções periódicas nas áreas criticas são muito importantes na gerencia da confiabilidade das peças que trabalham a fadiga.

Assim, podemos calcular o tamanho da trinca critica do material fazendo algumas manipulações na formula de acordo com o resultado abaixo: 


$$
K_{c}=\sigma \sqrt{\pi a_{c}} f\left(a_{c} / w\right)
$$

O cálculo da vida residual muitas vezes é complicado sem um programa de integração numérica, contudo, existem no mercado inúmeros programas que fazem essa conta, como o "ViDa" que é especifico para projeto de fadiga a carregamentos complexos, ou programas matemáticos como o MatLab ou Maple.

\subsubsection{Efeito da Tensão na Vida de Propagação}

A vida $\mathrm{N}$ de propagação pode ser relacionada à gama de tensão $\Delta \sigma$ de uma forma semelhante à curva SN.

$$
N \Delta \sigma^{m}=\int_{a_{0}}^{a_{f}} \frac{d a}{A[\sqrt{\pi a} f(a / w)]^{n}}=c t e
$$

Com $a_{0}, a_{f}$ e a regra de Paris o termo a direita é uma constante equivalente ao coeficiente $\mathrm{C}$ de Wöhler. $\mathrm{O}$ expoente de tensa é igual ao $\mathrm{m}$ de Paris, tipicamente da ordem de 3 para metais, um valor muito menor que o expoente B do método SN, que em media é igual a 11. Também podemos observar que o método $\varepsilon N$ corrobora este valor, pois se $b \approx-0,09$, então o expoente da tensão é estimado por $-1 / b \approx 11,1$.

Dessa forma observa-se que a iniciação da trinca é muito mais sensível à $\Delta \sigma$ que a propagação (na região onde a equação de Paris é valida).

\subsubsection{Estimativas do $\mathrm{K}_{\mathrm{t}}$ e da $\mathrm{zp}_{\mathrm{r}}$ de Trincas}

Pode-se usar Inglis ${ }^{27}$ para estimar $0 \mathrm{~K}_{\mathrm{t}}$ de uma trinca de fadiga a partir da abertura de sua ponta $(\mathrm{CTOD})^{8}$ que é dada por $\delta \cong \frac{K_{I}^{2}}{E S_{E}}$, então temos:

$$
K_{t}=1+2 \sqrt{\frac{a}{\rho} \cong 2 \sqrt{\frac{2 a}{\delta}}} \cong \sqrt{\frac{4 a}{K_{I}^{2} / 2 E S_{E}}}=\frac{2 \sqrt{2 a E S_{E}}}{\sigma \sqrt{\pi a} f(a / w)} \cong \frac{1.6 \sqrt{E S_{E}}}{\sigma f(a / w)}
$$


A estimativa do $K_{t}$ das trincas de fadiga decresce com $\sigma$ (as trincas ficam menos afiadas, pois $\delta$ cresce sob carga) mas ainda sim é muito alta $\left(10^{2}<K_{t}<10^{3}\right){ }^{8}$ Logo, as cargas que causam fadiga (cujas gamas típicas são maiores que $S_{E} / 10$ ) sempre geram zonas plásticas reversas $\mathrm{zp}_{\mathrm{r}}$ em torno das pontas de trincas visto que com $\mathrm{K}_{\mathrm{t}}$ 's tão altos elas sempre causam $\Delta \sigma>2 \mathrm{~S}_{\mathrm{Ec} .}{ }^{7}$

Dessa forma, as "trincas matemáticas" não simulam muito bem uma trinca de fadiga, que não propagam em um material isento de deformações plásticas e sempre crescem "cortando" uma parte da peça que já tenha sido deformada pelos dois tipos de zonas plásticas que acompanham as suas pontas:

a) A zona plástica monotônica máxima: $z p_{\max }=z p$, e pode ser estimada através da seguinte relação ${ }^{7}$ :

$$
\sigma_{y}(x=0)=\frac{K_{I}}{\sqrt{2 \pi z p}}=S_{E} \Rightarrow z p \cong \frac{K_{I_{\max }}^{2}}{2 \pi S_{E}^{2}}
$$

b) A zona plástica reversa $\mathrm{zp}_{\mathrm{r}}$, na qual o material escoa tanto na carga quanto na descarga pode ser estimada pela seguinte relação:

$$
\Delta \sigma_{y}(x=0)=\frac{\Delta K_{I}}{\sqrt{2 \pi z p_{r}}}=2 S_{E} \Rightarrow z p_{r} \cong \frac{1}{2 \pi} \frac{\Delta K_{I}^{2}}{4 S_{E_{c}}^{2}}
$$

Estas estimativas são simplistas, porém descrevem de maneira bem razoável os valores esperados. $A z_{r}$, na maioria das vezes é pequena em relação às outras dimensões das estruturas nos problemas reais de fadiga. Dessa forma podemos concluir que toda a propagação paulatina de trincas por fadiga ocorre sob condições elásticas dominantes, e é por isto que ela é controlada $\Delta K$ durante a maior parte da vida da maioria das peças. ${ }^{8}$ 


\subsubsection{Fechamento das Trincas de Fadiga}

Elber ${ }^{17-18}$ descobriu o fechamento das trincas de fadiga medindo a rigidez de uma placa trincada que variava de acordo com a carga; decrescia à medida que a carga crescia a partir do zero, até a uma chamada carga de abertura da trinca $\mathrm{P}_{\mathrm{ab}}>0 \mathrm{a}$ partir desse valor a rigidez da placa trincada e permanecia constante para qualquer $\mathrm{P}>\mathrm{P}_{\mathrm{ab}}$. E a rigidez da peça com uma dada trinca $\mathrm{a}_{0}$ é o inverso da sua flexibilidade $\mathrm{C}\left(\mathrm{a}_{0}\right)$ e pode ser calculada de acordo com a seguinte equação:

$$
G=\left(\frac{P^{2}}{2 t}\right)\left(\frac{d C}{d a}\right)=\frac{\left(K_{I}\right)^{2}}{E^{\prime}}
$$

Então:

$$
\frac{d C}{d a}=\frac{2 t K_{I}^{2}}{P^{2} E^{\prime}}=\frac{2 t \sigma^{2} \pi}{P^{2} E^{\prime}}\left[a f^{2}(a / w)\right] \therefore C\left(a_{0}\right)=\frac{2 t \sigma^{2} \pi}{P^{2} E^{\prime}} \int_{0}^{a_{0}}\left[a f^{2}(a / w)\right] d a+C(0)
$$

Onde $\mathrm{C}(0)$ é a flexibilidade da peça sem a trinca ${ }^{8}$.

A carga de abertura $P_{a b}$ é medida no inicio do trecho linear da curva $P(\delta)$ (ou da parte horizontal de $\mathrm{P}(\bar{\delta})-\mathrm{k}(\bar{\delta})$, onde $\mathrm{P}$ é a carga aplicada, $\delta$ é o deslocamento que ela induz na peça trinada e $\mathrm{k}$ é a sua rigidez quando a trinca esta toda aberta ${ }^{10}$.

A esteira de deformações residuais trativas que envolve as faces das trincas de fadiga é a principal causa do seu fechamento. O resto da peça ao ser descarregado, induz forças compressivas através das faces da trinca ao tentar voltar à sua configuração inicial. Dessa forma as faces da trinca vão se abrindo paulatinamente à medida que a carga vai crescendo ate que se abram totalmente (em $P>P_{a b}$ ). Assim, segundo o esquema de Elber, as trincas de fadiga crescem embutidas numa esteira de deformações plásticas trativas e os ligamentos residuais das peças (que permanecem elásticos) tendem a comprimir as faces das trincas descarregadas. 
Deve-se enfatizar que a rigidez inicialmente decrescente observada nas peças trincadas por fadiga ao carregá-las a partir do zero não é devida à sua plastificação macroscópica, já que quando $\mathbf{P}>\mathbf{P}_{\mathbf{a b}}$ a rigidez das peças permanece constante. Supondo que a trinca só possa crescer após estar toda aberta, então a taxa da/dN deveria ser controlada pela gama efetiva $\Delta \mathbf{K}_{\mathrm{ef}}=\mathbf{K}_{\max }-\mathbf{K}_{\mathrm{ab}}$ (e não por $\Delta \mathrm{K}$ ).

Segundo o esquema de Elber, as trincas de fadiga crescem embutidas numa esteira de deformações plásticas trativas e os ligamentos residuais das peças (que permanecem elásticos) tendem a comprimir as faces das trincas descarregadas.

\subsubsection{Os Limites da Regra de Paris}

As curvas $d a / d N \times \Delta \mathrm{K}$ típicas não são parabólicas, pois os limites físicos das taxas de propagação induzem-nas a ter uma forma sigmoidal característica (em loglog) que pode ser separada em três fases bem distintas ${ }^{16,53}$.

A fase I que parte de um limiar de propagação $\Delta \mathrm{K}_{\text {th }}\left(\Delta \mathrm{K}<\Delta \mathrm{K}_{\text {th }}\right.$ então da/dN=0 e $\Delta \mathrm{K}>\Delta \mathrm{K}_{\text {th }}$ então da/dN $\rightarrow 0$ se $\Delta \mathrm{K} \rightarrow \Delta \mathrm{K}_{\mathrm{th}}$ ) com derivada decrescente à medida que $\Delta \mathrm{K}$ cresce, e termina quando esta se estabiliza.

A fase II, onde a derivada de $\log (\mathrm{da} / \mathrm{dN}) \times \log (\Delta \mathrm{K})$ é aproximadamente constante e $\frac{d a}{d N} \cong A \Delta K^{m}$

A fase III, onde a derivada cresce com $\Delta \mathrm{K}$ ate que a peça frature quando $\mathrm{K}_{\max }=\Delta \mathrm{K} /(1-\mathrm{R})=\mathrm{K}_{\mathrm{c}}$

A regra de Paris só descreve bem a fase II e só pode ser usada para prever vidas à fadiga nesta fase. A figura a seguir mostra as três fases da curva $d a / d N \times \Delta \mathrm{K} \mathrm{e}$ esquematiza correlacionando às taxas $d a / d N$ típicas dos metais estruturais com o diâmetro atômico (dátomo), com o tamanho do grão ( $\left.d_{\text {grão }}\right)$ e com a zpr. 


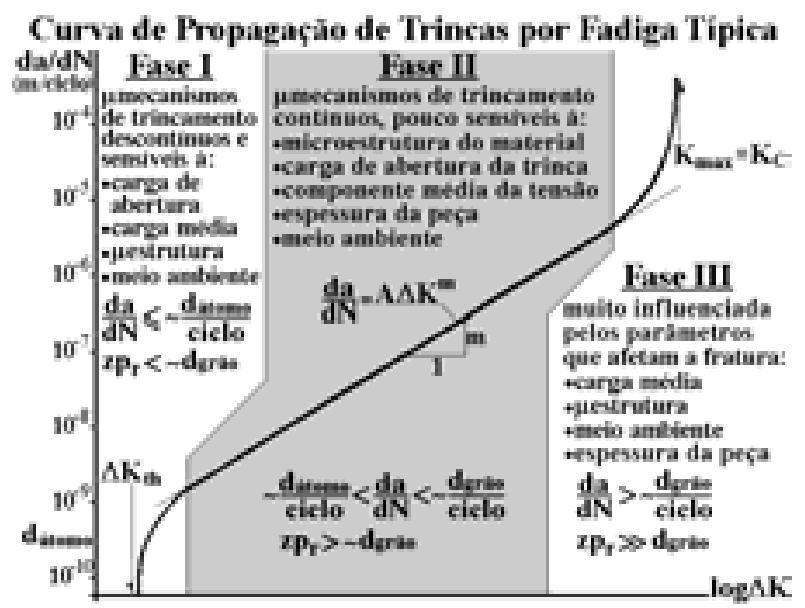

Figura 2 - Curva da/dN típica

Como as trincas de fadiga são concentradores de tensão muito severos, a sua propagação é sempre acompanhada de uma região de $\mathrm{zp}_{\mathrm{r}}$ em torno da sua ponta onde ocorrem deformações plásticas reversas, com já mencionado no texto acima.

\subsection{As Fases da Curva de Propagação de Trincas Típicas}

\subsubsection{A Fase I}

Corresponde a cauda da curva log $(\mathrm{da} / \mathrm{dN}) \times \log (\Delta \mathrm{K})$ e vai do limiar $\Delta \mathrm{K}_{\text {th }}$ até as taxas da ordem de $10^{-9} \mathrm{~m} /$ ciclo. Como o diâmetro atômico dos metais é da ordem de $0,3 \times 10^{-9}$ na fase I as taxas da/dN são (na média) menores ou da ordem de um espaçamento atômico por ciclo. Nesta fase a propagação da frente da trinca é descontinua e muito lenta, pois em uma rede cristalina as trincas devem crescer em cada ponto pelo menos um diâmetro atômico. O crescimento das trincas é intragranular e é sensível à carga média, à microestrutura do material, ao meio ambiente e à carga de abertura da trinca. Além disso, na fase I a zona plástica reversa que sempre acompanha as trincas de fadiga é menor que o tamanho do grão típico das ligas estruturais metálicas; que varia de 10 a $100 \mu \mathrm{m}$. 
As cargas médias trativas ajudam a separar as faces das trincas, logo tendem a aumentar as taxas da/dN, mas as cargas médias compressivas tendem a fechar as trincas e em geral retardam a sua propagação.

Como as trincas precisam expor suas pontas às cargas de serviço para que possam crescer a fadiga, é comum desprezar-se a parte compressiva das cargas de fadiga nos cálculos mais simples da vida residual de peças trincadas. Contudo, deve-se tomar cuidado com cargas compressivas, pois estas tendem a acelerar o crescimento da trinca. Quando a peça é submetida a esse tipo de carregamento cria-se uma zona plástica reversa trativa, este evento diminui $\mathbf{K}_{\mathbf{a b}}$ facilitando abertura de sua ponta. $\mathrm{O}$ $\Delta \mathrm{K}_{\text {th }}$ é a maior gama do fator de intensidade de tensões que é incapaz de propagá-las, ou seja, se $\Delta \mathrm{K}<\Delta \mathrm{K}_{\text {th }}$ então da/dN=0. $\mathrm{E}$ por essa mesma razão podemos observar que quando $\Delta \mathrm{K}$ é um pouco maior que $\Delta \mathrm{K}_{\text {th }}$ a taxa de propagação é muito pequena. Assim, as taxas de propagação na fase I são muito sensíveis a qualquer parâmetro que possa alterar tanto a curvatura e a localização da cauda da curva da/dN x $\Delta \mathrm{K}$ quando o valor de $\Delta \mathrm{K}_{\text {th }}$.

Os parâmetros que podem alterar $\Delta \mathrm{K}_{\text {th }}$ são ${ }^{32,57}$ :

A carga média, pois $\Delta K_{\text {th }}(R)$ decresce quando $R$ cresce, assim temos $\Delta K_{\text {th }}$ $(\mathrm{R}>0)<\Delta \mathrm{K}_{\text {th }}(\mathrm{R}=0)=\Delta \mathrm{K}_{0}<\Delta \mathrm{K}_{\text {th }}(\mathrm{r}<0)$.

A microestrutura do material, pois obstáculos no caminho da trinca como vazios e inclusões podem nas taxas de propagação muito baixas ancorar ou cegar a ponta da trinca, e assim, dificultar o seu progresso e aumentar $\Delta \mathrm{K}_{\mathrm{th}}$, por exemplo ${ }^{9}$.

Meio ambiente, pois a oxidação das faces da trinca pode entupi-la e aumentar $\Delta \mathrm{K}_{\mathrm{th}}{ }^{53}$

Fechamento das trincas de fadiga como já discutido. 
Dessa forma, vemos que a modelagem da fase I a partir de propriedades mecânica macroscópicas não é eficiente. E como esse estudo não faz parte do escopo desse texto não se vai aprofundar essa questão.

\subsubsection{A Fase II}

As taxas de propagação típicas da fase II do trincamento por fadiga de ligas estruturais metálicas são da ordem de $10^{-9}$ a $10^{-8}<$ da/dN $<10^{-6}$ a $10^{-5} \mathrm{~m} /$ ciclo, o que equivale a uma propagação da entre a ordem do diâmetro do átomo e do diâmetro do grão da microestrutura.

As zonas plásticas reversas são em geral maiores que o tamanho do grão. Então a plasticidade cíclica à frente da trinca é policristalina e seus incrementos são grandes em relação aos espaçamentos da rede cristalina. Dessa forma o trincamento na fase II tende a ser contínuo e uniforme ao longo da frente da trinca. Essas observações podem ser corroboradas pelas estrias que são observadas por microscopia eletrônica na superfície das trincas de fadiga. Essa é a característica mais importante fratográfica da propagação na fase II $^{19,38}$

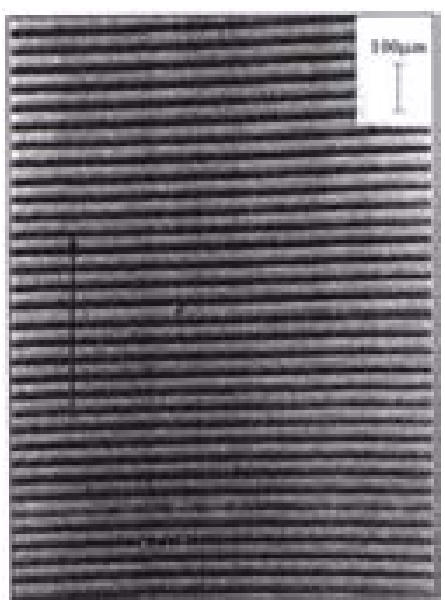

Figura 3 - Estrias na fase II 
As estrias indicam que o mecanismo de propagação das trincas por fadiga na fase II é causado por cegamentos de afiações sucessivas da sua ponta. Por outro lado, nem todos os materiais deixam estrias bem marcadas nas superfícies das trincas. Todavia quando identificadas, constituem a mais forte evidência fratográfica que a falha foi causada por fadiga. As estrias às vezes podem ser usadas para investigar as cargas e a historia de serviço da peça ${ }^{35}$, logo as faces das trincas devem ser protegidas para não mascarar essas evidencias, em particular, não esfregando as duas metades de uma peça quebrada ou mesmo tentando "encaixar" novamente os dois lados da peça. Essa prática pode danificar as estrias prejudicando um estudo posterior.

A sensibilidade do trincamento na fase II aos efeitos dos parâmetros que afetam $\Delta \mathrm{K}_{\text {th }}$ decresce à medida que as taxas afastam da cauda a curva $d a / d N \times \Delta \mathrm{K}$. Assim, a fase II é pouco sensível a:

a) carga media

b) microestrutura e meio ambiente enquanto esses não afetarem muito a resistência e a ductilidade do material

c) carga de abertura da trinca $\mathrm{K}_{\mathrm{ab}}$ (pequenas variações em $\Delta \mathrm{K}$ só podem influir muito nas taxas $d a / d N$ baixas)

d) Espessura da peça.

A ASTM $^{42}$ não restringe a espessura dos corpos de prova usados no levantamento das curvas $d a / d N \times \Delta \mathrm{K}$

Alguns autores ${ }^{41}$ questionam esta decisão já que $K_{a b}$, a carga de abertura da trinca seria maior quando ela cresce sob tensão plana dominante, e assim, $d a / d N$ teria que ser menos nas peças cuja espessura não é muito maior que a zp. Quer-se fazer esse estudo após concluir o trabalho inicial que está sendo apresentado neste texto. 


\subsubsection{Estimativas de Barsom para a Fase II das Curvas $d a / d N$ dos Aços}

Como nos métodos $S N$ e $\varepsilon N$, na ausência de resultados experimentais confiáveis, é importante dispor de regras para estimar tão precisamente quanto possível as curvas da/dN $\times \Delta \mathrm{K}$ dos principais materiais estruturais. A estimativa de Barsom $^{2}$ para a regra de Paris dos aços é muito popular $(d a / d N$ em $\mathrm{m} /$ ciclo, $\Delta \mathrm{K}$ em $\operatorname{MPa} \sqrt{m})$ :

$$
\begin{aligned}
& \text { Ferrítico-perlítico:...............da/dN }=6,9.10^{-12} \Delta \mathrm{K}^{3} \\
& \text { Martensíticos:.................. } d a / d N=1,35 \cdot 10^{-10} \Delta \mathrm{K}^{2,25} \\
& \text { Austeníticos:................... da/dN }=5,6 \cdot 10^{-12} \Delta \mathrm{K}^{3,25}
\end{aligned}
$$

Estas estimativas são muito usadas na pratica, contudo além das limitações das regras de Paris, podem diferir muito dos resultados experimentais.

\subsubsection{A Fase III}

$\mathrm{Na}$ fase III a trinca se propaga acompanhada de muita plasticidade em torno

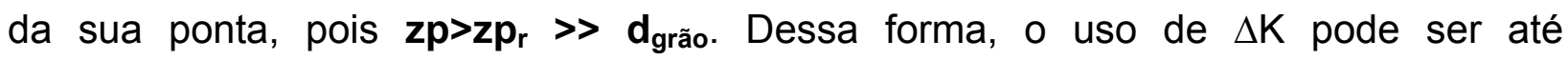
questionável em peças pequenas, mas mesmo quando a falha final ocorre sob plasticidade generalizada, em geral $\Delta \mathrm{K}$ controla as fases I e II.

Como há fraturamento quando $K_{\max }=K_{c}$, a fase III é sensível à carga média, à microestrutura e à espessura da peça. $\mathrm{K}_{\mathrm{c}}(\mathrm{t})$ varia com a espessura "t" da peça, e em geral $\mathbf{K}_{\mathbf{c}}>\mathbf{K}_{\mathbf{l c}}$ que só depende do material, mas requer uma zona plástica critica $\mathbf{z p}_{\mathbf{c}}$ muito menor que todas as dimensões da peça.

Quando $\mathbf{K}_{\max }$ é da mesma ordem que $\mathbf{K}_{\mathbf{c}}$, os mecanismos de fraturamento dúcteis (cavitação ou coalescência de vazios) ou frágeis (clivagem) superpõem-se aos do trincamento por fadiga. 
A maior taxa de propagação é limitada pela abertura da ponta da trinca $d a / d N<\mathrm{CTOD}_{\mathrm{c}}=\mathrm{K}_{\mathrm{c}} d\left(\mathrm{E} . \mathrm{S}_{\mathrm{E}}\right)$. Como o $\mathrm{CTOD}_{\mathrm{c}}$ das ligas metálicas mais tenazes é da ordem de $1 \mathrm{~mm}$ a maior taxa de crescimento de trincas por fadiga é da ordem de $0.1 \mathrm{~mm} /$ ciclo e acima deste valor, o problema deixa de ser de trincamento e passar a ser de fraturamento.

\subsubsection{Regras $d a / d N$ Mais Precisas}

Visando contornar as limitações da regra de Paris, varias outras regras foram propostas para melhor descrever a forma da curva $d a / d N \times \Delta \mathrm{K}$ e os efeitos de $\Delta \mathbf{K}_{\mathbf{t h}}$, de $\mathbf{K}_{\mathbf{c}}$ da carga de abertura $\mathbf{K}_{\mathbf{a b}}$ e da carga média.

A regra mais simples adapta a idéia do $\Delta \mathrm{K}_{\mathrm{ef}}$ de $\operatorname{Elber}^{18}\left(\Delta \mathrm{K}_{\mathrm{ef}}=\mathrm{K}_{\max }-\mathrm{K}_{\mathrm{ab}}\right)$ para modelar a cauda da fase I e supõe como da/dN= se $\Delta \mathrm{K}<\Delta \mathrm{K}_{\mathrm{th}}$, então a taxa da/dN deve variar com $\Delta \mathrm{K}-\Delta \mathrm{K}_{\text {th }}$ para atingir o limiar corretamente:

$$
\frac{d a}{d N}=A_{e}\left(\Delta K-\Delta K_{t h}\right)^{m_{e}}
$$

Esta regra é fácil de usar e pode descrever bem as fases I e II, mas gera previsões não conservativas em $\Delta \mathbf{K}$ altos e também em $\Delta \mathbf{K}$ baixos de $\mathbf{R}$ alto, caso $\Delta \mathbf{K}_{\mathrm{th}}(\mathbf{R})$ seja simplificado por $\Delta \mathbf{K}_{\mathbf{0}}$, o que não é valido para $\mathbf{R} \gg \mathbf{0}$.

\subsubsection{Regra de Elber Modificada}

Caso não se conheça o valor de $\Delta \mathbf{K}_{\text {th }}(\mathbf{R})$, para evitar as previsões não conservativas deve-se supor na regra de Elber modificada que:

$$
\Delta \mathbf{K}_{\mathrm{th}}(\mathbf{R})=\Delta \mathbf{K}_{\mathbf{0}}(\mathbf{1}-\mathbf{R})
$$

Então temos: 


$$
\frac{d a}{d N}=A_{e}\left(\Delta K-\Delta K_{0}(1-\mathrm{R})\right)^{m_{e}}
$$

As várias curvas de Elber modificadas tendem a coincidir quando $\Delta \mathbf{K}$ cresce, e como o único parâmetro que as diferencia é o limiar $\Delta \mathbf{K}_{\mathrm{th}}(\mathbf{R})$, elas refletem sua influência $\left(\Delta \mathrm{K}_{\mathrm{th}}(\mathrm{R})\right)$ na taxa $d a / d N$. Desta forma pode-se justificar a pouca influência que a carga média e todos os outros fatores que influem em $\Delta \mathbf{K}_{\text {th }}$ têm na região de Paris, mas também se pode concluir que $\Delta \mathbf{K}_{\text {ef }}$ não explica toda a complexidade do problema de propagação, já que R tem alguma influência na fase II.

A regra de Elber modificada não modela o efeito de $K_{c}$ e só prevê a influência de R na fase I.

\subsubsection{Outras Regras}

Existem outras regras de dois ou mais parâmetros, mas o estudo delas não esta dentro do escopo deste trabalho. No entanto vale a pena mencionar seus autores e as referencias para um eventual aprofundamento. Os principais autores das regras de dois parâmetros são:

- Forman ${ }^{22} \rightarrow$ Mais popular de todas

- Priddle ${ }^{46} \rightarrow$ Mais versátil, porém não reconhece efeito da carga média nas fases I e II.

E de três parâmetros

- Walker ${ }^{56} \rightarrow$ Pode ser considerada uma extensão da regra de Paris, pois não modela as fases I e III.

- Hall ${ }^{26} \rightarrow$ Modela as fases I e II e descreve o efeito da carga média, mas não modela a fase III. 


\subsubsection{Regra de Forman-Newman}

Existem inúmeras regras para descrever a forma da curva $d a / d N \times \Delta \mathbf{K}$ dentre elas se destaca a regra de Forman-Newman ${ }^{21}$ usada pela NASA, pois apresenta uma equação que depende de $\mathbf{K}_{\mathrm{ab}}$.

$$
\frac{d a}{d N}=A_{f n}\left(\frac{1-f}{1-R} \Delta K\right)^{m_{f n}} \frac{\left(1-\Delta K_{t h} / \Delta K\right)^{p_{f n}}}{\left(1-K_{\max } / K_{C}\right)^{q_{f n}}}
$$

Onde:

$$
f=\frac{K_{a b}}{K_{\max }}
$$

É bom lembrar que a norma E-647 da $\mathrm{ASTM}^{42}$ aceita corpos de prova de qualquer espessura t na medição de $d a / d N$. Nesta mesma norma, é afirmado que a espessura $\mathbf{t}$ pode influir em $\mathbf{K}_{\mathbf{a b}}$, mas não se posiciona de como esses efeitos acontecem. A ASTM não diferencia o trincamento por fadiga por $\varepsilon$-plana ou sob $\sigma$ plana, nem qualquer outro efeito de tipo do corpo de prova ou do comprimento de trinca em $\mathbf{K}_{\mathbf{a b}}$. Dessa forma não se torna evidente qual mecanismo controla a propagação das trincas por fadiga, se $\Delta \mathbf{K}$ ou $\Delta \mathbf{K}_{\text {ef. }}$ Esta área do conhecimento está sob conflito de filosofias entre a ASTM e a NASA.

\subsubsection{Limites das Regras Tradicionais}

Todas as regras descritas podem ser chamadas de fenomenológicas, pois são úteis para ajustar as curvas $d a / d N \times \Delta \mathbf{K}$. Contudo, elas não podem prever o seu comportamento. Apesar disso, elas tem grande importância pratica, pois a previsão da vida residual das estruturas trincadas, que é o objetivo do estudo daquelas curvas, depende da sua precisão. 
Por outro lado, as regras tradicionais em geral não ajustam bem o comportamento completo das curvas $d a / d N \times \Delta \mathbf{K}$, logo não se pode esperar uma boa precisão das previsões de vida residual a fadiga feitos a partir de sua integração. Entretanto é fácil alterar estas regras para diminuir suas deficiências.

\subsection{Fechamento Induzido por Plasticidade}

As trincas de fadiga não crescem em material virgem, pois elas se propagam cortando as zonas plásticas que sempre acompanham as suas pontas. Estas zonas plásticas causam o fechamento (i.e., as forças compressivas transmitidas através das faces) induzido por plasticidade das trincas de fadiga quando totalmente descarregadas $^{17-18,55}$. O fechamento da trinca é forçado pelo resto da peça que permanece elástico e que, quando a peça é descarregada, tende a comprimir a esteira plástica que sempre envolve as trincas de fadiga (assim, é preciso primeiro aliviar as faces das trincas ao recarregar a peça, e elas em geral só se abrem totalmente numa carga de abertura $\mathbf{K}_{\mathrm{ab}}>\mathbf{0}$ ). $\mathrm{O}$ fechamento das trincas e as tensões residuais em raízes de entalhes têm grande influência em fadiga e ambos são causados por gradientes de deformação plástica. Contudo, as tensões residuais não podem justificar os efeitos locais nas pontas de trincas, pois elas sempre escoam tanto na carga quanto na descarga da peça (i.e., alterações na $\mathbf{z p}_{\mathbf{r}}$ não podem causar variação significativa nas tensões que lá atuam, as quais sempre oscilam entre $-\sigma_{R}<\sigma<\sigma_{R}$ ). Supondo que as pontas das trincas de fadiga só sejam de novo solicitadas após sua total abertura quando $\mathrm{K}>\mathrm{K}_{\mathrm{ab}}\left(\Delta \mathrm{K}=\mathrm{K}_{\max }-\mathrm{K}_{\min } \geq \Delta \mathrm{K}_{\mathrm{ef}}=\mathrm{K}_{\max }-\mathrm{K}_{\mathrm{ab}}\right)$, é razoável argumentar que $\Delta \mathbf{K}_{\text {ef }}$ e não $\Delta \mathbf{K}$ deveria controlar $\mathbf{d a} / \mathbf{d N}$.

Na realidade, este argumento é implicitamente usado pela maioria dos modelos de retardo usados para prever a vida à fadiga de peças trincadas sujeitas a cargas 
complexas, mas, exceto pelo de Forman-Newman ${ }^{21}$, todos os modelos usados para ajustar as curvas da/dN $\times \mathbf{\Delta K}$ estudados até agora independem de $\mathbf{K}_{\mathrm{ab}} . \mathbf{\Delta K}-\Delta \mathbf{K}_{\mathrm{th}}(\mathbf{R})$ se comporta como, mas não é igual a $\Delta \mathbf{K}_{\mathrm{ef}}$, pois $\Delta \mathbf{K}_{\mathbf{0}}$ é uma propriedade do material, mas $K_{a b}$ não é. Além disso, se for $\Delta K_{\text {ef }}$ e não $\Delta \mathbf{K}$ que controla da/dN então, para poder continuar usando a Mecânica da Fratura Linear Elástica (MFLE) e as taxas medidas em pequenos corpos de prova (CPs) no projeto estrutural, deve-se demonstrar que $\mathbf{K}_{\mathbf{a b}}$, como $\Delta \mathbf{K}$, é quantificável pelos mesmos parâmetros $(\boldsymbol{\sigma}, \mathbf{a}$ e $\mathbf{f}(\mathbf{a} / \mathbf{w}))$ que definem o fator de intensidade de tensões $\mathbf{K}$. Mas o fechamento das trincas é causado pela reação de tensões elásticas atuantes no ligamento residual da peça sobre o envelope de deformações residuais (trativas) que envolve as faces das trincas, o qual por sua vez é gerado pela zona plástica que depende do estado de tensões dominantes na ponta da trinca. Ou seja, da espessura $\mathbf{t}$ da peça. Por isso, espera-se que o fechamento seja maior em:

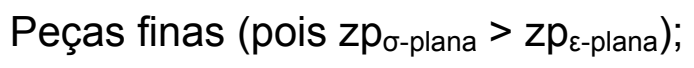

Materiais com baixo $S_{E}$ (pois a $z p$ varia com $1 / S_{E}^{2}$ );

Níveis mais altos de tensão (pois a $\mathbf{z p}$ varia com $\mathbf{K}_{\max }{ }^{2}$ ).

E que o fechamento diminua quando:

As tensões $\boldsymbol{\sigma}_{\max }$ forem tão altas que gerem escoamento significativo no ligamento residual Ir, o que relaxa a restrição elástica imposta pelo resto da peça;

A trinca for profunda, i.e., for associada a um pequeno Ir que não consiga comprimi-la eficientemente.

Assim se, para $\mathbf{\Delta K}$ e $\mathbf{R}$ dados, $\Delta \mathbf{K}_{\text {ef }}$ variar como esperado com a espessura $\mathbf{t}$ da peça ou o comprimento a da trinca, deve-se verificar qual parâmetro controla a propagação das trincas por fadiga medindo, sob $\mathbf{R}$ fixo, $\mathbf{K}_{\mathbf{a b}}$ e $\mathbf{d a} / \mathbf{d N}$ em várias 
combinações de $\mathbf{\Delta K}$, a e $\mathbf{t}$, para demonstrar se as taxas correlacionam melhor com $\Delta \mathbf{K}$ ou com $\Delta \mathbf{K}_{\text {ef. }}$ É lamentável que este argumento lógico seja muitas vezes (impropriamente) ignorado quando se argumenta implícita ou explicitamente, que as taxas de propagação da/d $\mathbf{N}$ devem depender de $\Delta \mathbf{K}_{\text {ef }}\left(\operatorname{logo}\right.$ de $\mathbf{K}_{\mathbf{a b}}, \mathbf{t}$, Ir, etc.).

De fato, ao não diferenciar o trincamento por fadiga sob $\varepsilon$-plana do sob $\sigma$ plana, a ASTM implicitamente aceita que é a gama $\Delta \mathbf{K}$ e não $\Delta \mathbf{K}_{\text {ef }}$ o parâmetro controlador do trincamento (ou que $\mathbf{K}_{\mathrm{ab}}$ dependeria apenas de $\Delta \mathbf{K}$ e de $\mathbf{K}_{\max }$ ou $\mathbf{R}$, o que tornaria $\Delta \mathbf{K}_{\mathrm{ef}}$ equivalente ao conjunto destes dois parâmetros).

\subsubsection{Fechamento Parcial das Trincas}

Paris $^{45}$ sugeriu que o fechamento das trincas apenas ocorreria a partir de uma pequena distância d atrás das suas pontas, e assim, mesmo com a peça descarregada, a cunha $\mathbf{2 h}$ causaria o fechamento parcial da trinca e provocaria um valor mínimo de $\Delta \mathbf{K}_{\text {ef }}$ não nulo, o qual valeria:

$$
K_{e f_{\min }}=\frac{E^{\prime} h}{\sqrt{2 \pi d}}
$$

Onde $E^{\prime}=\mathbf{E}$ sob um estado de $\sigma$-plana e $E^{\prime}=E /\left(1-v^{2}\right)$ sob um estado de $\varepsilon$ plana.

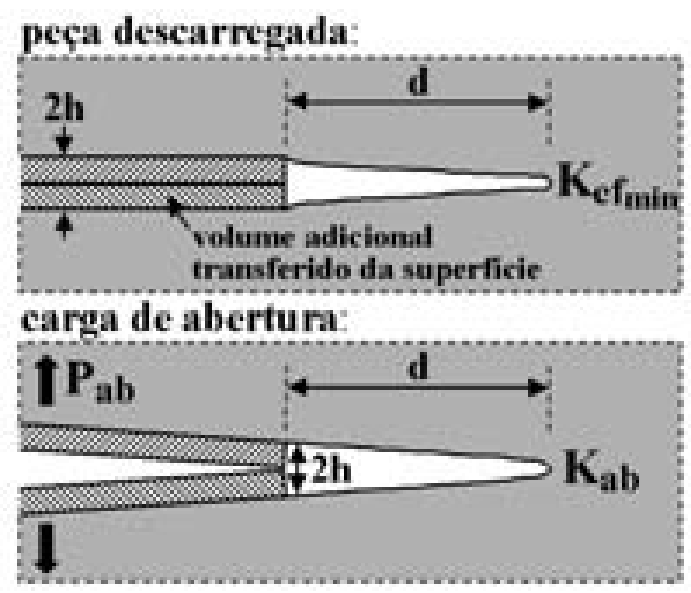

Figura 4 - Fechamento parcial das trincas 
Além disso, o $\mathbf{K}_{\mathbf{a b}}$ que abre esta cunha precisa gerar uma abertura COD (crack opening displacement) em $\mathbf{d}$ igual às $\mathbf{2 h}$, logo:

$$
C O D=\frac{4 K_{a b}}{E^{\prime}} \sqrt{\frac{2 d}{\pi}}=2 h \Rightarrow K_{e f_{\min }}=\frac{E^{\prime}}{\sqrt{2 \pi d}} \frac{2 K_{a b}}{E^{\prime}} \sqrt{\frac{2 d}{\pi}}=\frac{2}{\pi} K_{a b}
$$

Conclui-se assim que sob fechamento parcial a carga de abertura diminui de $\mathrm{K}_{\mathrm{ab}}$ para $(2 / \pi) \mathrm{K}_{\mathrm{ab}} \cong 0.64 \cdot \mathrm{K}_{\mathrm{ab}}, \operatorname{logo}:$

$$
\Delta K_{e f}=K_{\max }-\frac{2}{\pi} K_{a b}
$$

O fechamento parcial independe de $\mathbf{h}$ ou $\mathbf{d}$ e a expressão supõe $\mathbf{K}_{\min } \leq \mathbf{0}$, mas se $0<K_{\min } \leq K_{a b}$ então $K_{\max }-(2 / \pi) K_{a b}-(1-2 / \pi) K_{\min } \leq \Delta K_{\text {ef }} \leq K_{\max }-(2 / \pi) K_{a b}$. $O$ $\Delta \mathbf{K}_{\text {ef }}$ proposto acima ajustou bem a fase I de ligas de Al, porém é um pouco disperso na fase $\mathrm{II}^{45}$. Um melhor ajuste foi obtido substituindo-se o fator $2 / \mathbf{m}$ por um parâmetro $0 \leq p \leq 1$, que varia de $p=2 / \pi$ próximo de $\Delta K_{\text {th }}$ até $p=1$ na região de Paris. ${ }^{28,31}$

\subsection{Outros Mecanismos de Fechamento}

O fechamento da trinca também pode ser induzido pela oxidação das suas faces, e por isso as taxas da/dN em $\mathbf{R}$ baixo podem ser menores em ambientes agressivos do que nos inertes ${ }^{53}$. Isto ocorre porque os óxidos podem ter um volume muito maior que o do metal que lhes deu origem e, caso não sejam removidos, podem acabar por entupir a trinca, funcionado como uma cunha entre as suas faces, o que aumenta $\mathbf{K}_{\mathbf{a b}}$.

Os retardos inicialmente gerados por outros mecanismos podem aumentar o tempo de contato do material com o meio oxidante, logo a quantidade de óxido nas faces da trinca, retardando-a ainda mais. 
O fechamento induzido por rugosidade ocorre quando as faces das trincas de fadiga, que podem ser serrilhadas e não planas, sofrem um deslocamento relativo em modo II e/ou III que force a interferência entre os picos do serrilhado na descarga da peça, aumentando assim $\mathbf{K}_{\mathbf{a b}}$. Estes deslocamentos relativos podem ser aumentados por sobrecargas, causando retardo na propagação da trinca. Abaixo um exemplo do fechamento induzido por rugosidade ${ }^{51}$.

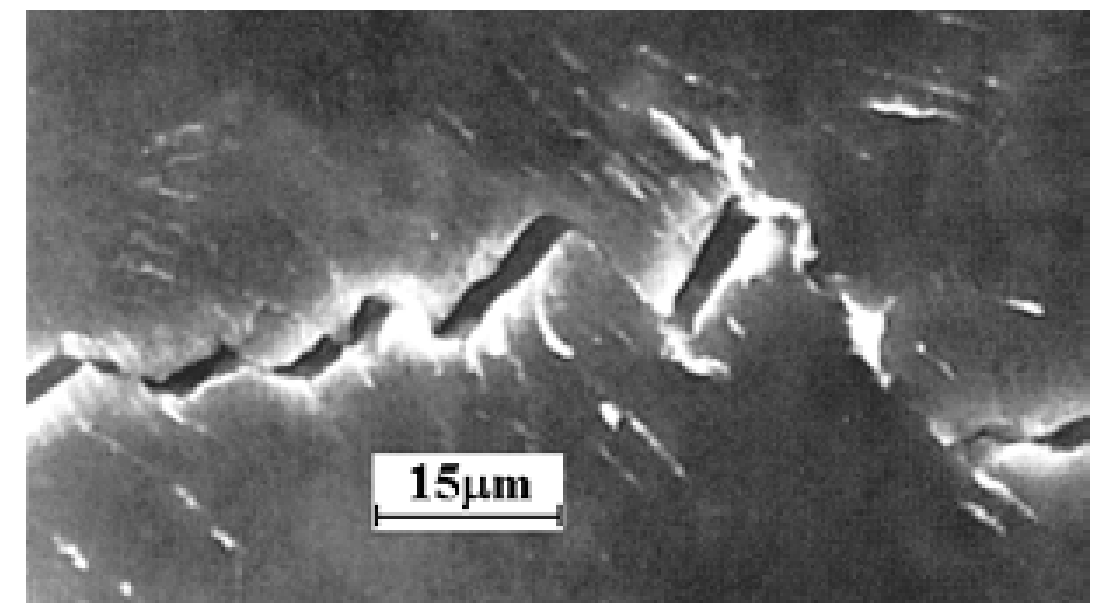

Figura 5 - Fechamento induzido por rugosidade

O fechamento causado por transformação de fase pode ser importante em alguns aços austeníticos metaestáveis nos quais a deformação plástica induz a transformação martensítica ${ }^{53}$. Estes aços são chamados trip, anagrama em inglês de transformation induced (by) plasticity, e podem atingir as maiores razões $\mathbf{K}_{\mathbf{C}} / \mathbf{S}_{\mathbf{R}}$ dentre todos os aços estruturais. Alguns outros materiais menos importantes do ponto de vista estrutural (como cerâmicas contendo zircônio e o estanho cinzento) também apresentam este fenômeno ${ }^{53}$. Como a martensita tem volume cerca de $4 \%$ maior que a austenita que Ihe dá origem (que é cúbica de face centrada, logo compacta), e como a esteira de deformações plásticas que envolve a trinca de fadiga tende a transformar-se em martensita, o efeito das sobrecargas no aumento da carga de abertura $\mathbf{K}_{\mathbf{a b}}$ é potencializado pela sinergia entre estes dois mecanismos. 


\subsection{Incompatibilidade de Orientação da Frente da Trinca}

É um mecanismo que justifica o retardo, e.g., considere taxas $\mathbf{d a} / \mathbf{d N}_{\mathbf{1}}$ e $\mathbf{d a} / \mathbf{d} \mathbf{N}_{\mathbf{2}}$ medidas sob $\Delta \mathbf{K}$ constante em dois níveis $\Delta \mathbf{K}_{\mathbf{1}}$ e $\Delta \mathbf{K}_{\mathbf{2}}\left(\Delta \mathbf{K}_{\mathbf{1}}>\Delta \mathbf{K}_{2}\right)$, e que $\Delta \mathbf{K}_{\mathbf{1}}$ (mas não $\Delta \mathbf{K}_{\mathbf{2}}$ ) gere lábios de cisalhamento a $45^{\circ}$ do plano da trinca, que reduzem o fator de intensidade de tensão ${ }^{3,48}$. Assim, uma carga $\Delta \mathbf{K}_{\mathbf{2}}$ aplicada após um bloco de $\Delta \mathbf{K}_{\mathbf{1}}$ encontrará a frente da trinca numa orientação que lhe é incompatível, o que tende a gerar $\mathbf{d a} / \mathbf{d N}<\mathbf{d a} / \mathbf{d} \mathbf{N}_{\mathbf{2}}$ (que havia sido medida sem os lábios), retardando a trinca até que os lábios desapareçam neste menor nível $\mathbf{\Delta} \mathbf{K}_{\mathbf{2}}$. Por outro lado, se a gama for aumentada de $\Delta \mathbf{K}_{\mathbf{2}}$ para $\Delta \mathbf{K}_{\mathbf{1}}$, a taxa $\mathbf{d a} / \mathbf{d N}$ será maior que $\mathbf{d a} / \mathbf{d} \mathbf{N}_{\mathbf{1}}$ (aceleração de trinca) até que os lábios voltem a surgir neste nível.

\subsection{Mecanismos de Retardo Localizados na Vizinhança da Ponta da Trinca}

O cegamento, a dobra e a bifurcação da ponta da trinca induzidos por sobrecargas são mecanismos de retardo independentes do fechamento, cuja eficácia deve-se à redução local da força motriz que induz a propagação. Como a abertura de ponta de trinca cresce com $\mathbf{K}_{\max }{ }^{2}$, as sobrecargas esgarçam ou cegam significativamente a ponta da trinca, tendendo a dificultar a sua propagação subseqüente. E, ao contrário do fechamento, espera-se que o efeito da sobrecarga seja sentido imediatamente e não sofra atrasos, e que cesse antes que a trinca cresça através de toda a zona plástica da sobrecarga. Mas não se consegue justificar a quantidade do retardo obtido na prática através apenas da diminuição do $\mathbf{K}_{\mathbf{t}}$ da trinca causado pelo cegamento de sua ponta. Já o decréscimo de $\mathbf{K}_{\mathbf{I}}$ gerado por dobras ou bifurcações da ponta da trinca pode justificar retardos significativos, e.g., pequenas dobras ou desvios angulares de tamanho $\mathbf{b}$ na ponta da trinca de tamanho $\mathbf{a}(\mathbf{b} / \mathbf{a} \rightarrow \mathbf{0})$, que façam um ângulo $\alpha$ com ela, transformam o $\mathbf{K}_{\mathbf{I}}$ originalmente atuante na trinca em 
$k_{1}=K_{I} \cdot \frac{[3 \cos (\alpha / 2)+\cos (3 \alpha / 2)]}{4}$

(modo I) e

$k_{2}=K_{I} \cdot \frac{[\sin (\alpha / 2)+\sin (3 \alpha / 2)]}{4}$

$(\text { modo II })^{61}$. Como esta solução só vale para $\mathbf{z p} \ll \mathbf{b}$, Suresh e Shih calcularam os campos de tensão em torno das pontas das dobras e bifurcações considerando os efeitos da zona plástica e do encruamento ${ }^{52}$. Mas como as sobrecargas podem induzir dobras ou bifurcações com $\mathbf{b} \ll \mathbf{a}$ em trincas longas, as quais só podem influir no campo de tensões em função de $\boldsymbol{\alpha}$, o (grande) efeito da amplitude das sobrecargas no retardo subseqüentes só pode ser modelado se $\boldsymbol{\alpha}$ for uma função desta amplitude.

Como a razão $\mathbf{k}_{\mathbf{1}} / \mathbf{K}_{\mathbf{I}}$ decresce com o ângulo $\mathbf{\alpha}$ da (pequena) dobra $\mathbf{b}$ na ponta da trinca, e como da/dN em $\mathbf{b}$ depende de $\mathbf{k}_{\mathbf{1}}$, se $\mathbf{b}$ fosse gerado por uma sobrecarga este mecanismo justificaria os retardos ${ }^{39}$.

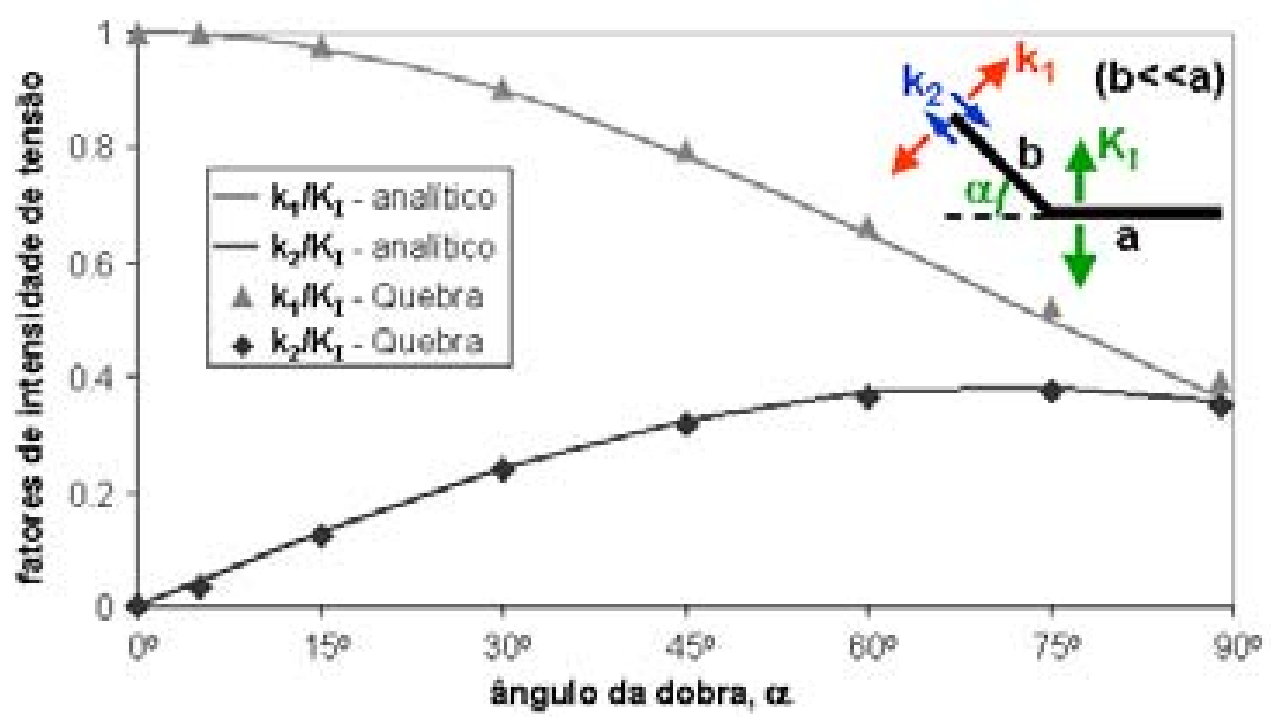

Figura 6 - Gráfico "fatores de intensidade de tensão X ângulo da dobra, a" 


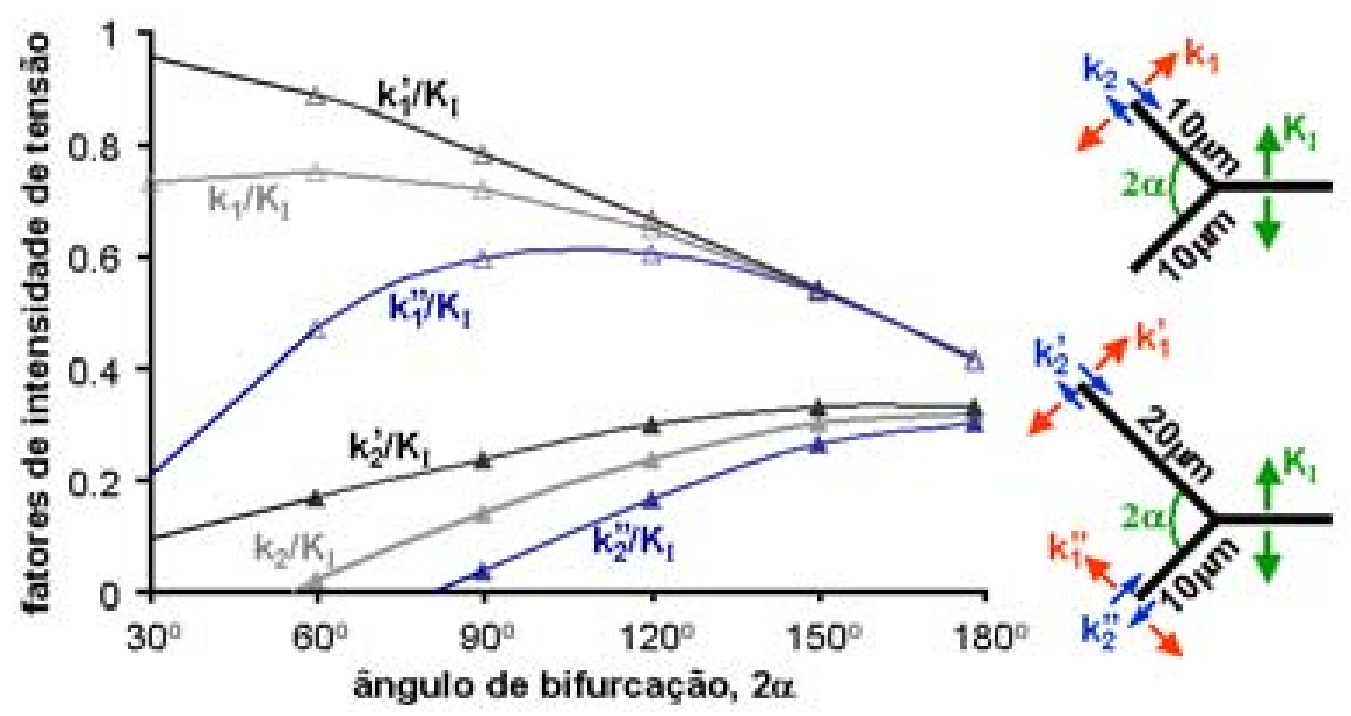

Figura 7 - Gráfico "fatores de intensidade de tensão X ângulo de bifurcação, 2a"

Bifurcações simétricas ou assimétricas também causam diminuição de $\mathbf{k}_{\mathbf{1}}$, gerando retardo ${ }^{39}$. Note que o $\mathbf{k}_{1}$ da ramificação mais curta é sempre menor que o valor da mais longa nas bifurcações assimétricas. Deve-se notar que qualquer pequena assimetria entre os ramos de uma trinca bifurcada é suficiente para garantir que 0 menor deles irá necessariamente parar após uma possível pequena propagação inicial. Já o maior ramo só irá parar se a diminuição do fator de intensidade de tensão for suficiente para atingir o limiar de propagação, caso contrário ele prossegue até sair da zona de influência do menor ramo. Logo, o retardo é máximo logo após a bifurcação da trinca e tende a desaparecer à medida que o maior ramo cresce até se transformar de novo na única frente da trinca. Além disso, simulações por Elementos Finitos feitas no Quebra2D e no ViDa indicam que o efeito de retardo é maior e mais prolongado nas trincas com ângulo de bifurcação de $2 \alpha$ grandes, as quais necessitam de um maior número de ciclos para parar 0 menor ramo (da trinca bifurcada). 

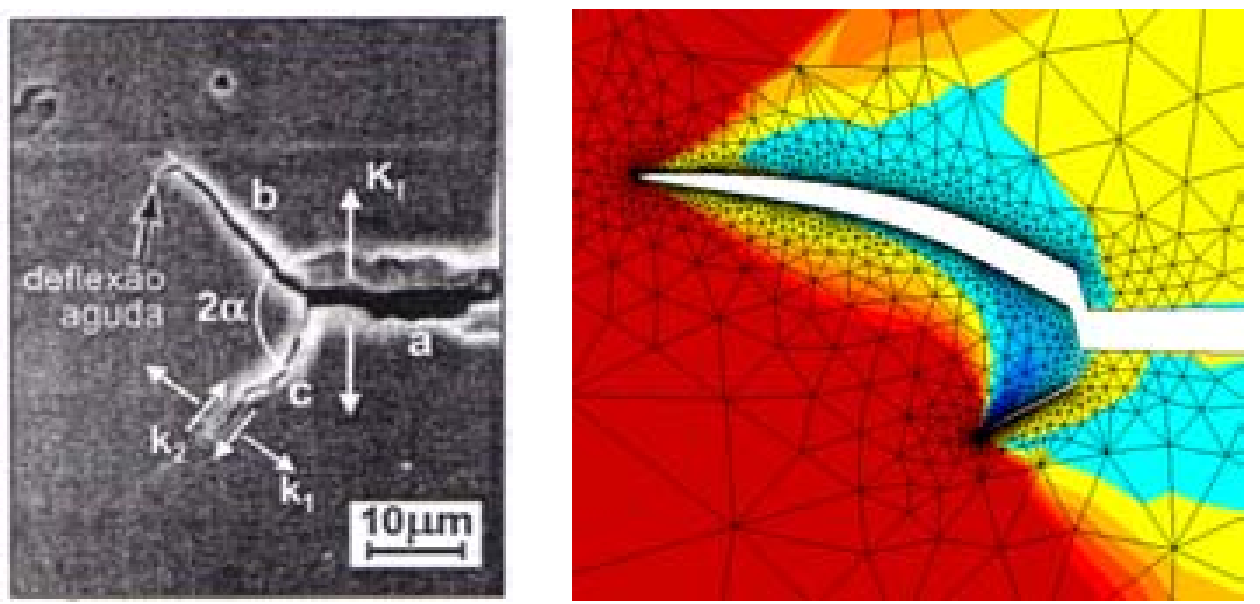

Figura 8 - Bifurcação

Em bifurcações com $2 \alpha$ grande (tipicamente $2 \alpha>120^{\circ}$ ), uma deflexão aguda na ponta do maior ramo da trinca ocorre logo no início da propagação (devido à tendência de crescer em modo I), como observado em testes ${ }^{30}$ e nos cálculos por Elementos Finitos feitos no Quebra2 $\mathbf{D}^{39}$.

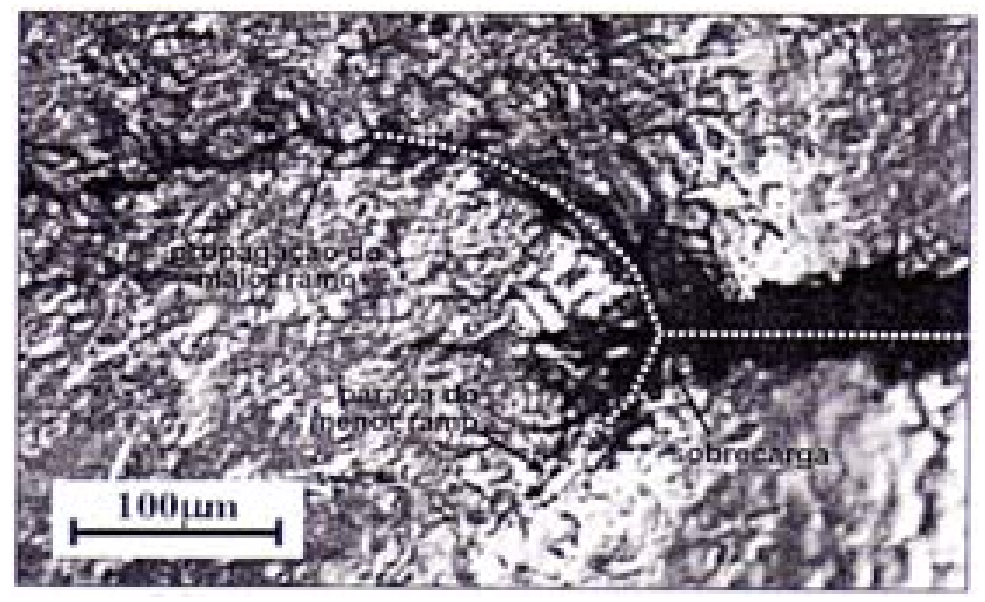

Figura 9 - Caminho da trinca bifurcada

O caminho da trinca bifurcada é muito bem previsto pelo Quebra2D no espécime de aço SAE 1020 acima $^{39}$. 


\subsection{Tensões e Deformações Residuais}

O fechamento induzido por plasticidade é causado por deformações residuais, e as cargas compressivas por ele induzidas através das faces de uma trinca fechada nada mais são do que tensões residuais, já que elas são auto-equilibrantes e persistem com a peça descarregada. Mas isto não implica que as tensões residuais na ponta da trinca sejam uma das causas relevante dos efeitos de retardo após sobrecargas. Mesmo quando se considera a trinca como um entalhe de pequeno raio de ponta (para eliminar a singularidade, uma característica da modelagem e não da física do problema), qualquer carga que propague a trinca por fadiga provoca escoamento cíclico na vizinhança da sua ponta (e gera a zona plástica reserva ou cíclica), eliminando assim a relevância de qualquer tensão residual lá presente. Logo, tensões residuais por ventura presentes na ponta da trinca não podem alterar de forma significativa o $\boldsymbol{\Delta} \boldsymbol{\sigma}$ lá atuante, logo não podem também afetar muito a vida residual do componente trincado. Assim, conclui-se que os efeitos de retardo gerados por sobrecargas podem ser associados a compôs de tensão e/ou deformação residual, mas não podem ser causados por tensões residuais localizadas na própria ponta da trinca. Enfatiza-se novamente que tensões residuais locais são muito importantes na iniciação de trincas em raízes de entalhes quando $\Delta \sigma$ é predominantemente elástico, mas este problema é diferente da propagação das trincas. Assim, campos de tensão residual compressiva podem retardar a propagação das trincas ao reduzir o fator de intensidade de tensões, sem necessariamente provocar o fechamento das faces da trinca $^{29}$.

Um experimento realizado por Blazewicz ${ }^{49}$ permite que se avalie se o efeito do retardo em certo material é causado primariamente pelo campo de tensões residuais (à 
frente da trinca) ou pelo fechamento nas faces (que é um fenômeno que ocorre atrás da ponta da trinca). Antes de iniciar um teste de propagação de trincas sob amplitude constante, quatro identações esféricas são feitas para gerar um campo de tensões residuais compressivas no (futuro) caminho da trinca. Se o retardo ocorrer logo após a trinca atingir a região afetada pelas identações ( $\mathbf{a} \cong \mathbf{a}_{1}$ na figura), então o mecanismo poderá ser o campo de tensões residuais.. Mas um retardo significativo após a trinca superar a região afetada $\left(\mathbf{a} \cong \mathbf{a}_{2}>\mathbf{a}_{1}\right)$ só poderá ser explicado pelo fechamento das faces induzido pelas identações, pois não há tensões residuais significativas à frente da trinca.
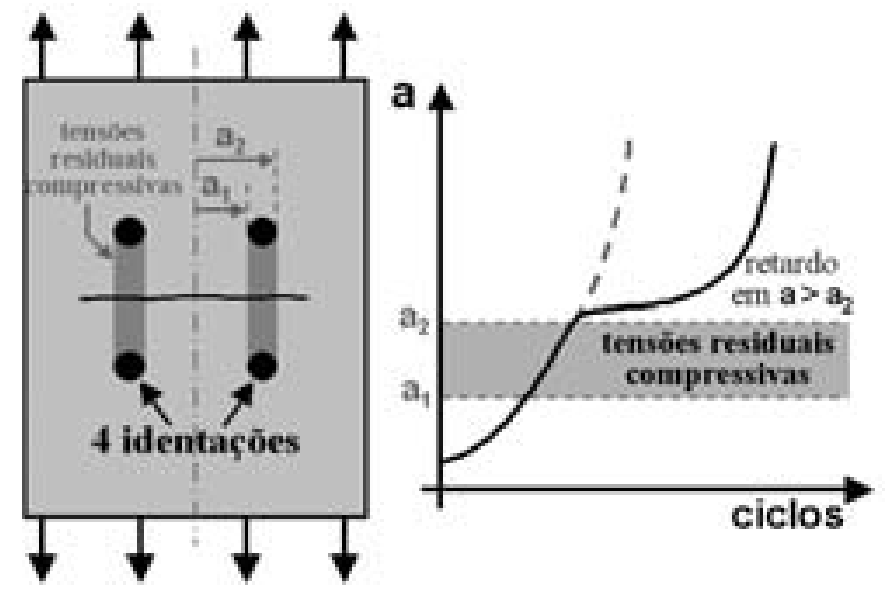

Figura 10 - Tensões residuais compressivas

Experimentos $^{49}$ em um alumínio 2024-T3 sugerem que o retardo (neste caso) foi primariamente causado por fechamento, pois da/dN só foi reduzida quando $\mathbf{a}>\mathbf{a}_{\mathbf{2}}$.

\subsection{Influência de Subcargas e do Número de Sobrecargas no Retardo}

Subcargas reduzem o efeito de retardo ao comprimirem (e até escoarem localmente) as faces da trinca e a zona plástica à sua frente, reduzindo as deformações residuais trativas e/ou as asperezas das faces (diminuindo desse modo o fechamento induzido por plasticidade e/ou rugosidade). Além disso, se a ponta da trinca não estiver 
totalmente fechada, a subcarga $\mathbf{K}_{\text {sub }}$ pode gerar campos de tensões residuais trativas à sua frente, um outro mecanismo que poderia justificar o efeito deletério de $\mathbf{K}_{\text {sub }}$. Subcargas $\mathbf{K}_{\text {sub }}$ aplicadas logo após sobrecargas $\mathbf{K}_{\text {sc }}$ (seqüência sobrecargasubcarga) reduzem muito o efeito de retardo causado pela sobrecarga, como visto nas figuras a seguir. Porém a redução do retardo causada por $\mathbf{K}_{\text {sub }}$ é em geral pequena se aplicada antes da sobrecarga (seqüência sub-sobrecarga).

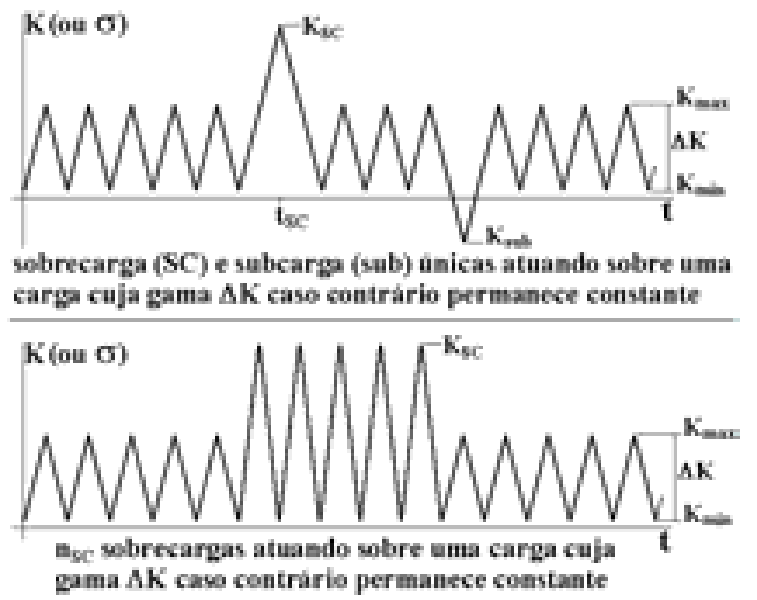

Figura 11 - Sobrecargas e subcargas

Subcargas $\mathbf{K}_{\text {sub }}$ e o número de sobrecargas $\mathbf{n}_{\mathbf{s c}}$ são fatores que podem afetar bastante a taxa da/dN.

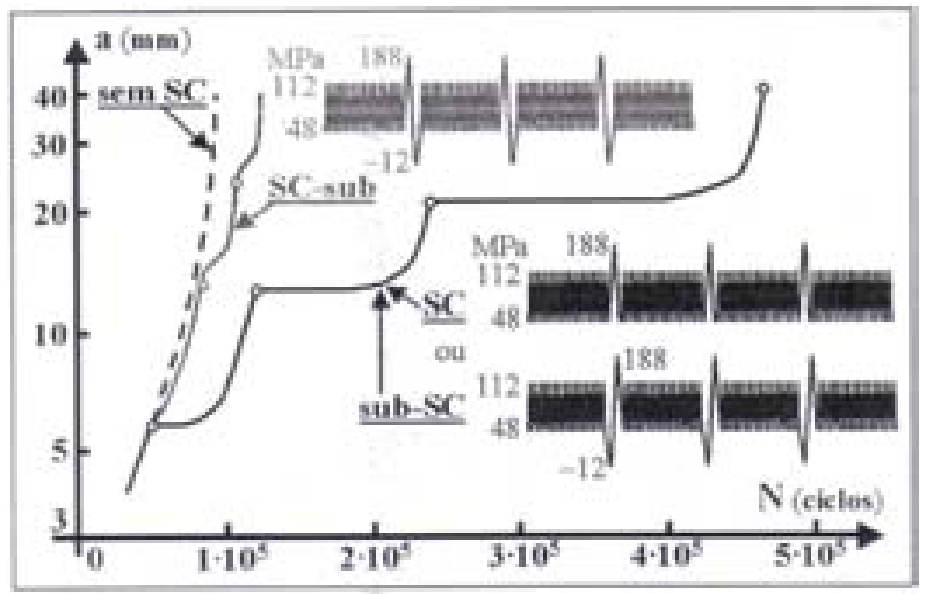

Figura 12 - Efeitos de sobrecargas e subcargas 
Efeito de sobrecargas, de sobrecargas seguidas de subcargas, e de subcargas seguidas de sobrecargas na vida de placas de AL 2024-T3 ${ }^{48}$.

Apesar de reduzir o retardo, $\mathbf{K}_{\text {sub }}$ não necessariamente acelera a trinca acima das taxas obtidas sob amplitude constante, pois uma trinca totalmente fechada não é um concentrador de tensões sob cargas compressivas. Mas $\mathbf{K}_{\text {sub }}$ pode gerar tensões residuais à frente de trincas em entalhes, pois estes sempre permanecem abertos. Outro fator que pode influenciar o retardo é $\mathbf{n}_{\mathbf{s c}}$, o número de sobrecargas consecutivas aplicadas: quanto maior for $\mathbf{n}_{\mathbf{s c}}$, em geral maiores serão a carga de abertura e o retardo (ao menos quando o retardo é controlado por $\mathbf{K}_{\mathrm{ab}}$ ), sendo $\mathbf{K}_{\mathrm{ab}}$ e $K_{a b_{s c}}$ as cargas de abertura que seriam obtidas sob gamas constantes iguais a $\mathbf{K}_{\max }-$ $\mathbf{K}_{\min }$ e $\mathbf{K}_{\mathbf{s c}}-\mathbf{K}_{\min }$, então a $K_{a b_{n}}$ gerada após $\mathbf{n}_{\mathbf{s c}}$ sobrecargas satisfaz $\mathbf{K}_{\mathbf{a b}}<K_{a b_{n}}<$ $K_{a b_{s c}}$, e $K_{a b_{n}}$ cresceria com $\mathbf{n}_{\mathbf{s c}}$ (aumentando assim o retardo subseqüente ao reduzir $\Delta \mathbf{K}_{\text {ef }}$ ) até convergir para $K_{a b_{s c}}$ quando $\mathbf{n}_{\mathbf{s c}} \rightarrow \infty$.

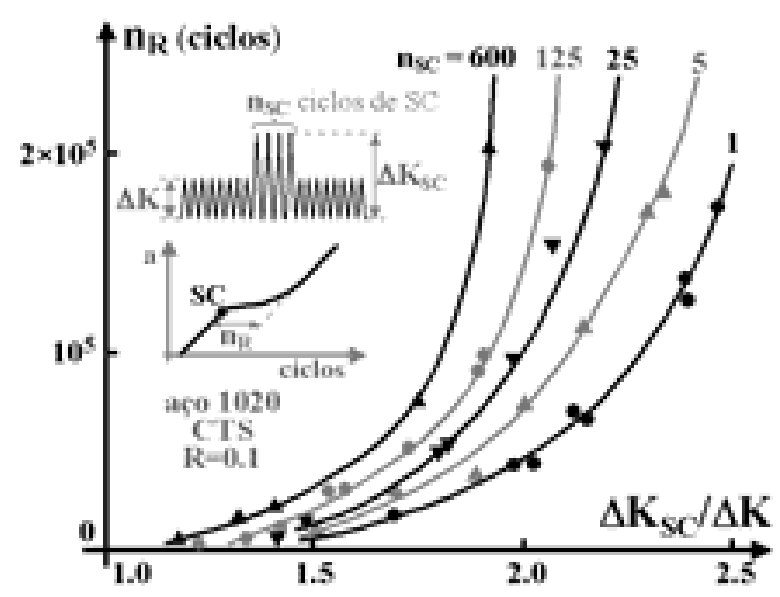

Figura 13 - Número de ciclos de retardo

Nos testes acima, o número de ciclos de retardo $\mathbf{n}_{\mathbf{R}}$ aumentou com o número de sobrecargas $\mathbf{n}_{\mathbf{s c}}$ e com a razão $\Delta \mathbf{K}_{\mathbf{s c}} / \Delta K$. Este gráfico sugere que são necessários 
pelo menos 600 sobrecargas para atingir o retardo máximo nestes corpos de prova deste aço $^{13}$.

\subsection{Modelagem dos Efeitos de Retardo}

É difícil identificar e superpor os vários mecanismos que podem gerar retardo, logo a maioria dos modelos de previsão de vida residual sobre cargas de gama variável é semi-empírica, e pode ser dividida em dois grupos: ${ }^{48}$

Modelos baseados no fechamento: usam estimativas empíricas (DuQuesnay) ou calculadas (Strip Yield) para obter diretamente a carga de abertura $\mathbf{K}_{\mathbf{a b}}$.

Modelos baseados na zona plástica da sobrecarga: correlacionam o retardo ao tamanho da zona plástica da sobrecarga (o que pode capturar tanto os efeitos do fechamento como o de campos de tensões residuais), alterando a razão $\mathbf{R}$ (modelo de Willenborg, e.g.), a taxa da/dN (Wheeler), ou a gama $\Delta \mathbf{K}$ (Wheeler modificado) após as sobrecargas e subcargas para quantificar seus efeitos, como a seguir.

\subsubsection{Retardo Baseado na Variação de R}

Willenborg et al. ${ }^{59}$ supuseram que as sobrecargas retardam as trincas de fadiga porque geram fatores de intensidade de tensões residuais $\mathbf{K}_{\text {res }}\left(\mathbf{a}_{\mathbf{i}}\right)$ variáveis com a distância entre as $\mathbf{z p}_{\mathbf{i}}$ (que avançam com a trinca) e a $\mathbf{z} \mathbf{p}_{s c}$ (fixa na peça) enquanto ( $\mathbf{a}_{\mathbf{i}}$ $\left.+\mathbf{z} \mathbf{p}_{\mathrm{i}}\right)<\left(\mathbf{a}_{\mathrm{sc}}+\mathbf{z} \mathbf{p}_{\mathrm{sc}}\right)$ (i.e., enquanto a $\mathbf{z} \mathbf{p}_{\mathrm{sc}}$ contiver as $\mathbf{z p _ { i }}$, sendo $\mathbf{i}>\mathbf{0}$ se chamarmos de 0 o evento da sobrecarga), e arbitrariamente definiram $\mathbf{K}_{\text {res }}\left(\mathbf{a}_{\mathbf{i}}\right)$ por

$$
K_{r e s}\left(a_{i}\right)=K_{S C} \sqrt{\frac{z p_{S C}+a_{S C}-a_{i}}{z p_{S C}}}-K_{\max }\left(a_{i}\right)
$$

Os $\mathbf{K}_{\text {res }}\left(\mathbf{a}_{\mathrm{i}}\right)$ são subtraídos de $\mathbf{K}_{\max }\left(\mathrm{a}_{\mathrm{i}}\right)$ e $\mathbf{K}_{\min }\left(\mathrm{a}_{\mathbf{i}}\right)$, logo não alteram $\Delta \mathbf{K}\left(\mathrm{a}_{\mathrm{i}}\right)$ porém modificam as razões $\mathbf{R}\left(\mathbf{a}_{\mathbf{i}}\right)$ 


$$
R_{r e t}\left(a_{i}\right)=\frac{K_{\min }\left(a_{i}\right)-K_{r e s}\left(a_{i}\right)}{K_{\max }\left(a_{i}\right)-K_{r e s}\left(a_{i}\right)}
$$

O retardo no crescimento da trinca após a sobrecarga é obtido pela diminuição do valor de $\mathbf{R}\left(\mathbf{a}_{\mathrm{i}}\right)$ para $\mathbf{R}_{\text {ret }}\left(\mathbf{a}_{\mathrm{i}}\right)$, o que reduz o valor da taxa da/dN na região afetada pela sobrecarga se (e somente se) a curva $\mathbf{d a} / \mathbf{d} \mathbf{N} \times \Delta \mathbf{K}$ que descreve a propagação da trinca no material da peça quantificar o efeito da carga média em da/dN. Logo, o modelo de Willenborg não pode ser usado com a regra de Paris, e.g. Outra desvantagem de Willenborg é sempre prever a parada da trinca se $\mathbf{K}_{\max }\left(\mathbf{a}_{\mathbf{1}}\right) \leq \mathbf{K}_{\mathbf{s c}}\left(\mathbf{a}_{\mathbf{0}}\right) / \mathbf{2}$ (i.e., assume uma razão de parada de trinca $\mathbf{R}_{\mathrm{pt}}=2$ ), onde $\mathbf{K}_{\max }\left(\mathbf{a}_{1}\right)$ é o pico da carga logo após a sobrecarga, pois se $K_{s c}\left(a_{0}\right)=2 K_{\max }\left(a_{1}\right) \Rightarrow K_{\text {res }}\left(a_{1}\right)=K_{\max }\left(a_{1}\right) \Rightarrow$ $\mathbf{R}_{\text {ret }}\left(\mathbf{a}_{1}\right)-\infty \Rightarrow \mathbf{d a} / \mathbf{d N}\left(a_{1}\right) \rightarrow 0$. Mas não há justificativa para $\mathbf{R}_{\mathrm{pt}}$ ser constante, já que ela depende do valor de pico e da freqüência das sobrecargas, além da geometria e do material, como já discutido.

Para modelar os valores de $\mathbf{R}_{\mathrm{pt}}$ maiores que 2, podemos-se generalizar Willenborg multiplicando $\mathbf{K}_{\text {res }}\left(\mathbf{a}_{\mathbf{i}}\right)$ por um fator $\boldsymbol{\Phi}\left(\mathbf{a}_{\mathbf{i}}\right)$ dado por: ${ }^{24-25}$

$$
\Phi\left(a_{i}\right)=\frac{1-\Delta K_{t h} / \Delta K\left(a_{i}\right)}{R_{p t}-1}
$$

Valores típicos ${ }^{23}$ de $\boldsymbol{R}_{\mathbf{p t}}$ são 3.5 para ligas de aço e Ni, 2.3-2.7 para ligas de AL, e 2.25 para ligas de Ti.

Apesar da fundamentação física questionável, há vários outros modelos de retardo baseados na idéia da redução de $\mathbf{R}$ proposta originalmente por Willenborg, e.g., o chamado modelo de Willenborg generalizado e modificado ${ }^{1}$ é semelhante ao Willenborg generalizado, porém modela de forma mais cuidadosa o efeito dos valores

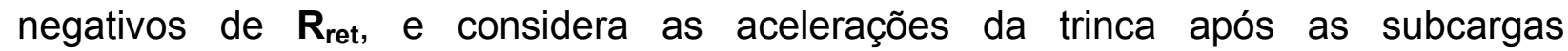
compressivas. 
No Willenborg generalizado e modificado, sendo $\mathbf{K}_{\mathbf{R}}\left(\mathbf{a}_{\mathbf{i}}\right)=\Phi\left(\mathbf{a}_{\mathrm{i}}\right) \cdot \mathbf{K}_{\mathrm{res}}\left(\mathbf{a}_{\mathbf{i}}\right)$ supõese que:

$$
\begin{aligned}
& \left.K_{\text {res }}\left(a_{i}\right)\right|_{\max }=K_{\text {max }}\left(a_{i}\right)-K_{R}\left(a_{i}\right) \\
& \left.K_{\text {res }}\left(a_{i}\right)\right|_{\text {min }}=\left\{\begin{array}{l}
K_{\text {min }}\left(a_{i}\right)-K_{R}\left(a_{i}\right), \text { se } K_{\text {min }}\left(a_{i}\right)>K_{R}\left(a_{i}\right) \\
0, \text { se } 0<K_{\text {min }}\left(a_{i}\right) \leq K_{R}\left(a_{i}\right) \\
K_{\text {min }}\left(a_{i}\right), \text { se } K_{\text {min }}\left(a_{i}\right) \leq 0
\end{array}\right.
\end{aligned}
$$

Onde $\mathbf{K}_{\text {res }}\left(\mathbf{a}_{\mathbf{i}}\right)$ é calculado pelo modelo de Willenborg e $\boldsymbol{\Phi}\left(\mathbf{a}_{\mathrm{i}}\right)$ por:

$$
\Phi\left(a_{i}\right)=\left\{\begin{array}{l}
\min \left(1, \frac{2.523 \cdot \Phi_{0}}{1+3.5\left[0.25-R_{\text {sub }}\left(a_{i}\right)\right]^{0.6}}\right), \text { se } R_{\text {sub }}\left(a_{i}\right)<0.25 \\
1.0, \text { se } R_{\text {sub }}\left(a_{i}\right) \geq 0.25
\end{array}\right.
$$

$\mathbf{R}_{\text {sub }}=K_{\text {min }_{\text {sub }}} / \mathbf{K}_{\text {sc é a razão da subcarga }}\left(\mathbf{R}_{\text {sub }}<\mathbf{0} \Rightarrow\right.$ subcarga compressiva $)$, a qual pode diminuir o efeito de retardo causado por uma sobrecarga prévia (i.e., a subcarga só é considerada efetiva quando atua na região afetada pela sobrecarga), e $\Phi_{0}$ é uma constante, tipicamente ${ }^{23}$ entre 0.2 e 0.8 .

Já o modelo de Walker-Chang-Willenborg ${ }^{11}$ aplica Willenborg generalizado à equação da/dN de Walker-Chang e considera a aceleração da trinca após subcargas compressivas, mas só é aplicável quando subcarga ocorrer imediatamente após a sobrecarga trativa.

A idéia deste modelo é simplesmente diminuir o valor da zona plástica da sobrecarga após a subcarga compressiva que a segue (e cuja razão deve ser $-0.5<R_{\text {sub }}<0$ ), para obter:

$$
z p_{s u b}=\left(1+R_{s u b}\right) \cdot z p_{S C}
$$

Essa menor zona plástica reduz o valor $\Phi\left(\mathbf{a}_{\mathbf{i}}\right) \cdot \mathbf{K}_{\text {res }}\left(\mathbf{a}_{\mathbf{i}}\right)$ diminuindo os efeitos de retardo da sobrecarga trativa prévia calculados por Willenborg generalizado. No 
entanto, mesmo com todas estas modificações, os modelos de retardo baseados na variação da razão $\mathbf{R}$ baseiam-se em hipóteses duvidosas.

\subsubsection{Retardo Baseado na Variação de da/dN}

Wheeler ${ }^{58}$ supôs que sobrecargas retardam as taxas da/dN (em relação às taxas que seriam obtidas caso a sobrecarga não tivesse ocorrido) enquanto a $\mathbf{z p}_{\mathbf{i}}$ do i-ésimo evento subseqüente da carga estiver embutida na $\mathbf{z p s c}$ da sobrecarga, e que as taxas retardadas $(d a / d N)_{\text {ret }_{i}}$ dependem das distâncias entre as fronteiras das $\mathbf{z p}_{\mathbf{i}}$ (que vão avançando com a trinca) e a da $\mathbf{z p}_{\text {sc }}$ (fixa na peça) enquanto $\left(a_{i}+z p_{i}\right)<\left(a_{s c}+z p_{s c}\right)$.

$$
\left(\frac{d a}{d N}\right)_{r e t_{i}}=\left(\frac{d a}{d N}\right)_{i} \cdot\left(\frac{z p_{i}}{z p_{S C}+a_{S C}-a_{i}}\right)^{\beta}
$$

$(\mathbf{d a} / \mathbf{d N})_{i}$ é a taxa que atuaria no i-ésimo evento da carga caso a sobrecarga não retardasse a trinca, e $(d a / d N)_{r t_{i}}$ é a taxa prevista para o crescimento retardado da trinca após a sobrecarga: $(d a / d N)_{r e t_{i}}<(\mathbf{d a} / \mathbf{d N})_{\mathbf{i}}$ se $\left(\mathbf{a}_{\mathbf{i}}+\mathbf{z p}_{\mathbf{i}}\right)<\left(\mathbf{a}_{\mathbf{s c}}+\mathbf{z} \mathbf{p}_{\mathbf{s c}}\right)$. Assim, segundo Wheeler, a taxa de propagação após a sobrecarga deveria sofrer um retardo variável que, de um valor máximo logo no ciclo seguinte à sobrecarga, iria decrescendo à medida que a trinca avançasse pela $\mathbf{z p}_{\mathbf{s c}}$, e terminaria quando a fronteira da zona

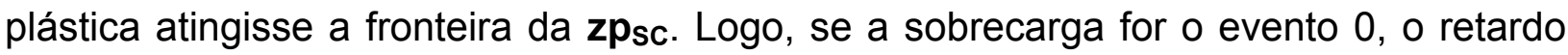

máximo no correria ciclo seguinte, $(d a / d N)_{r e t_{1}}=(\mathbf{d a} / \mathbf{d N})_{1} \cdot\left(\mathbf{K}_{\text {max }} / \mathbf{K}_{\mathbf{s c}}\right)^{2 \beta}=(\mathbf{d a} / \mathbf{d N})_{1} \cdot\left(\boldsymbol{\sigma}_{\max } / \sigma_{\mathbf{s c}}\right)^{2 \beta}$, e terminaria quando $\left(\mathbf{a}_{\mathbf{i}}+\mathbf{z} \mathbf{p}_{\mathbf{i}}\right)=\left(\mathbf{a}_{\mathbf{s c}}+\mathbf{z} \mathbf{p}_{\mathbf{s c}}\right) \Rightarrow(d a / d N)_{r e t_{i}}=(\mathbf{d a} / \mathbf{d N})_{\mathbf{i}}$

Wheeler não pode prever a parada de trincas observada na prática, pois não pode gerar $(d a / d N)_{r e t_{1}}=\mathbf{0}$, mas pode ser usado com cargas de amplitude variáveis ou 
com múltiplas sobrecargas, bastando observar a regra do retardo proporcional à distância entre a fronteira da zona plástica do evento em questão e a fronteira da mais distante dentre as (várias) zonas plásticas das sobrecargas que ainda a estiverem envolvendo.

Abaixo um esquema da região onde a trinca de fadiga é retardada após sobrecargas, segundo o modelo de Wheeler.

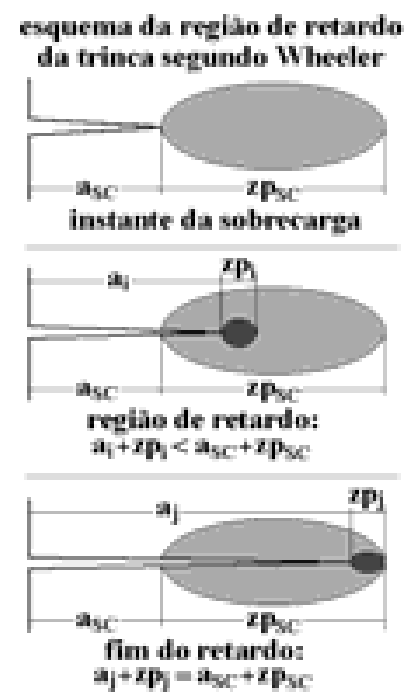

Figura 14 - Retardo segundo Wheeler

A maior zona plástica da sobrecarga seria a causa do retardo da trinca (como no fechamento Elberiano), e a taxa da/dN diminuiria em função da distância entre o fim da zona plástica da carga normal e o fim da zona plástica da sobrecarga:

$$
\begin{aligned}
& \text { retardo } \approx\left(\frac{z p_{i}}{z p_{S C}+a_{S C}-a_{i}}\right)^{\beta} \\
& z p \cong \frac{1}{2 \pi}\left(\frac{K_{\max }}{S_{E}}\right)^{2}
\end{aligned}
$$

$\mathrm{Na}$ prática, o expoente do modelo de Wheeler deve ser ajustado experimentalmente para melhorar a qualidade das previsões de vida à fadiga sob cargas de amplitude variável, como ilustrado abaixo ${ }^{4}$. 


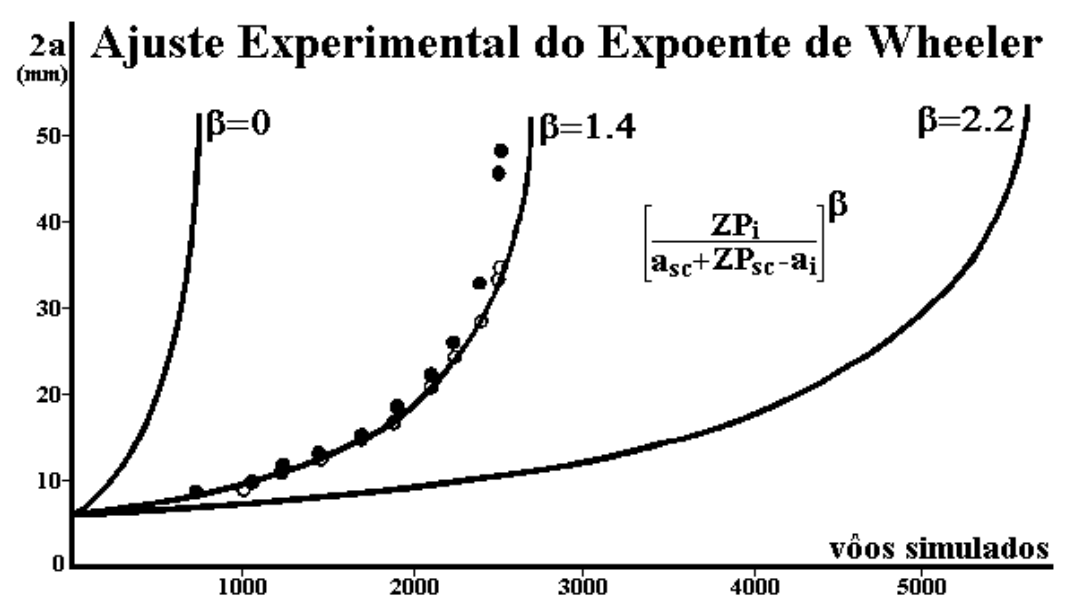

Figura 15 - Ajuste experimental do expoente de Wheeler

\subsubsection{Retardo Baseado no Decréscimo de $\Delta K$}

É trivial eliminar a incapacidade do modelo original de Wheeler de prever as paradas das trincas, sem alterar seu poder de quantificar retardos: basta multiplicar os valores dos $\Delta \mathrm{K}$ s subseqüentes à sobrecarga (em vez das taxas da/dN) pelo parâmetro retardador $^{6}$. Sendo este um modelo totalmente fenomenológico, é até surpreendente que esta não tenha sido a forma escolhida para apresentá-lo e discuti-lo na literatura. Assim, o modelo de Wheeler modificado é dado por: ${ }^{6}$

$$
\Delta K_{r e t}\left(a_{i}\right)=\Delta K\left(a_{i}\right) \cdot\left(\frac{z p_{i}}{z p_{S C}+a_{S C}-a_{i}}\right)^{\gamma}
$$

Enquanto $\left(\mathbf{a}_{\mathbf{i}}+\mathbf{z} \mathbf{p}_{\mathrm{i}}\right)<\left(\mathbf{a}_{\mathrm{sc}}+\mathbf{z} \mathbf{p}_{\mathrm{sc}}\right)($ em geral $\mathbf{y} \neq \boldsymbol{\beta}$, onde $\boldsymbol{\beta}$ é o expoente do modelo original de Wheeler). $\Delta \mathbf{K}\left(\mathbf{a}_{\mathrm{i}}\right)$ é a gama da carga que atuaria no i-ésimo evento caso a sobrecarga não retardasse a trinca, e $\Delta \mathbf{K}_{\text {res }}\left(\mathbf{a}_{\mathbf{i}}\right)$ é a gama prevista para o crescimento retardado da trinca após a sobrecarga: $\Delta K_{\text {res }}\left(a_{i}\right)<\Delta K\left(a_{i}\right)$ se $\left(a_{i}+z_{i}\right)<\left(a_{s c}+z_{s c}\right)$. A trinca pára quando $\Delta K_{\text {res }}\left(a_{i}\right) \leq \Delta K_{t h}\left[R\left(a_{i}\right)\right]$, sendo $R\left(a_{i}\right)=K_{\min }\left(a_{i}\right) / K_{\max }\left(a_{i}\right)$ e $a_{i}$ o comprimento da trinca no i-ésimo evento da carga. 
Wheeler e Wheeler modificado são modelos simples que podem ser usados com qualquer curva $\mathbf{d a} / \mathbf{d} \mathbf{N} \times \mathbf{\Delta K}$, e como Wheeler modificado é mais versátil, vale a pena escolhe-lo quando possível. Além disso, o modelo Wheeler modificado pode ser generalizado para quantificar acelerações nas taxas da/dN retardadas por sobrecargas, que podem ocorrer após subcargas compressivas. Efeitos de subcargas são notados pelo índice sub.

Para modelar os efeitos de retardo após sobrecargas diminuindo aos $\Delta \mathrm{Ks}$ em vez dos da/dNs subseqüentes, e também a diminuição destes efeitos quando a ponta da trinca está dentro da zona plástica da sobrecarga e ocorre uma subcarga compressiva (de $\mathbf{R}_{\text {sub }}<\mathbf{0}$, onde $\mathbf{R}_{\text {sub }}=\mathbf{K}_{\text {sub }} / \mathbf{K}_{\mathbf{s c}}$ ), pode-se usar o modelo de Wheeler modificado e generalizado: $:^{35-37}$

$$
\begin{aligned}
& \Delta K_{\text {ret }}\left(a_{i}\right)=\Delta K\left(a_{i}\right) \cdot\left(\frac{z p_{i}}{\left(1-R_{\text {sub }}^{*}\right) z p_{S C}+a_{S C}-a_{i}}\right)^{\gamma} \\
& \text { Onde } R_{\text {sub }}^{*}=\left\{\begin{array}{l}
0, \text { se } R_{\text {sub }}>0 \\
-\alpha R_{\text {sub }}, \text { se } R^{-}<R_{\text {sub }}<0 \\
-\alpha R^{-}, \text {se } R_{\text {sub }}<R^{-}
\end{array}\right.
\end{aligned}
$$

Sendo a uma constante ajustável e $\mathbf{R}^{-}$um patamar de corte (na falta de informações melhores, $\mathbf{R}^{-}=\mathbf{- 0 . 5}$ ).

Esta redução na zona plástica da sobrecarga foi originalmente proposta para melhorar o modelo de Willenborg como já discutido, e ela foi aqui adaptada para generalizar Wheeler modificado.

Wheeler, Wheeler modificado e Wheeler modificado e generalizado são modelos empíricos, sem boa justificativa teórica, cujo único propósito é descrever a fenomenologia da propagação das trincas sob cargas de amplitude variável da maneira mais simples possível. Em particular, Wheeler modificado e generalizado (após suas 
constantes terem sido ajustadas em testes de referência) pode simular tanto os retardos e paradas como as acelerações nas taxas da/dN causadas pelas mudanças bruscas da carga, característica só encontrada em modelos muito mais complexos. E o ajuste das constantes destes modelos por tentativa e erro usando o ViDa é relativamente simples e rápido, mas o expoente dos modelos depende não só do material como também do tipo de espectro de carga, do nível da tensão e da forma da trinca. $^{50}$

O expoente $\mathbf{y}$ de Wheeler modificado em geral é diferente do $\boldsymbol{\beta}$ de Wheeler, e ambos devem ser ajustados para reproduzir tão bem quanto possível a curva de propagação de referência. É recomendável fazer estas calibrações empíricas usando curvas a $\mathbf{x} \mathbf{N}$ de referência medidas em corpos de prova similares à peça de interesse sob espectros representativos das cargas e das sobrecargas que se espera ter em serviço, para minimizar a influência das variáveis que podem afetar a vida à fadiga.

Modelos tipo Wheeler são mais simples e podem gerar previsões melhores que os tipo Willenborg ou Wheeler modificado e generalizado tendem a se sair melhor que Wheeler, devido ao seu maior potencial de modelagem da física do retardo ${ }^{35-37}$. Caso não se consiga reproduzir adequadamente a curva a $\mathbf{x} \mathbf{N}$ padrão ajustando $\boldsymbol{\beta}$ ou $\mathbf{Y}$, pode-se tentar melhorar as previsões incluindo constantes ajustáveis no parâmetro de Wheeler ${ }^{19}$, pois estes modelos não são leis físicas.

\subsubsection{Retardo Baseado na Variação de $K_{a b}$}

Esta classe de modelos de retardo usa diretamente a carga de abertura de trinca $\mathbf{K}_{\mathrm{ab}}$ a cada ciclo da carga. O modelo da Abertura Constante simplesmente assume que o valor de $\mathbf{K}_{\mathrm{ab}}$ permanece constante após as sobrecargas (entre 30 e $50 \%$ do $K_{\text {sc }}$, tipicamente ${ }^{5}$ ). Este modelo é limitado, e só deve ser usado para prever 
retardos gerados por sobrecargas freqüentes e similares (se não ele pode ser nãoconservativo, pois $\mathbf{K}_{\mathrm{ab}}$ pode diminuir ao sair da zona plástica da sobrecarga), ou por variações da razão $\mathbf{R}$ de blocos de carga de amplitude aproximadamente constante.

Segundo Newman ${ }^{40}$, o valor de $\mathbf{K}_{\mathrm{ab}}$ pode ser estimado a partir da razão $\mathbf{R}_{\mathbf{S c}}=$ $K_{S C_{\min }} / K_{S C_{\max }}$ da sobrecarga por:

$$
\begin{aligned}
& \frac{K_{a b}}{K_{S C}}=\left\{\begin{array}{l}
\max \left(R_{S C}, A_{0}+A_{1} R_{S C}+A_{2} R_{S C}^{2}+A_{3} R_{S C}^{3}\right), R_{S C} \geq 0 \\
A_{0}+A_{1} R_{S C},-2 \leq R_{S C}<0
\end{array}\right. \\
& \text { Onde }\left\{\begin{array}{l}
A_{0}=\left(0.825-0.34 \alpha+0.05 \alpha^{2}\right)\left\{\cos \left[\pi \sigma_{S C} /\left(S_{R}+S_{E}\right)\right]\right\}^{1 / \alpha} \\
A_{1}=(0.83-0.142 \alpha) \cdot \sigma_{S C} /\left(S_{R}+S_{E}\right) \\
A_{2}=1-A_{0}-A_{1}-A_{3} \\
A_{3}=2 A_{0}+A_{1}-1
\end{array}\right.
\end{aligned}
$$

$\alpha$ é a restrição $3 \mathrm{D}$, a razão entre a tensão uniaxial que escoa a peça e $\mathbf{S}_{\mathrm{E}}$, que depende do estado de tensões dominante e varia de $\alpha=1$ em $\sigma$-plana até $\alpha=1 /(1-2 v)$ em $\varepsilon$-plana, e $\sigma_{\mathrm{Sc}}$ é a tensão máxima da sobrecarga.

Essas equações foram desenvolvidas a partir de modelos de Elementos Finitos para modelar efeitos de sobrecargas em placas com trinca central sob cargas de amplitude constante, considerando o fechamento da trinca induzido por plasticidade. Logo, elas são baseadas em resultados numéricos, não em dados experimentais, mas, apesar disso, elas também têm sido utilizadas para prever vida à fadiga de qualquer peça sob cargas de amplitude variável $^{23}$ em conjunto com o modelo da faixa de escoamento de DeKoning-Newman Strip Yield (KN), descrito a seguir.

O modelo chamado de DeKoning-Newman Strip Yield é recente e corroborado pela NASA, mas é mais difícil de usar pois descreve o crescimento de trinca de forma incremental, calculando deferentes taxas para as zonas plásticas primária e cíclica ${ }^{14-}$ ${ }^{15,54}$, e taxa nula se $\mathbf{K}_{\max }<\mathbf{K}_{\mathrm{ab}}+\Delta K_{t h_{i n}}$. O efeito de retardo fica embutido na equação 
da/dN específica do modelo que, para o caso da plasticidade cíclica onde $\mathbf{K}_{\mathrm{ab}}+\Delta K_{t h_{\text {in }}}<\mathbf{K}_{\max }<\mathbf{K}^{*}$, é dada por:

$$
\frac{d a}{d N}=A \cdot\left(K_{\max }-K_{a b}\right)^{n}\left[1-\left(\frac{\Delta K_{\text {thin }}}{K_{\max }-K_{a b}}\right)^{p}\right]
$$

$\mathbf{K}^{*}$ é o nível de transição da plasticidade cíclica para a primária, onde ocorre escoamento de material virgem, o qual deve ser calculado a cada ciclo do carregamento. E para o caso da plasticidade primária (que é a parte da carga que causa o avanço da zona plástica, i.e., que escoa material virgem à frente da ponta da trinca), na qual o valor da carga máxima é $\mathbf{K}^{*}<\mathbf{K}_{\max }<\mathbf{K}_{\mathbf{c}}$, a equação da/dN do modelo DeKoning-Newman Strip Yield é dada por:

$$
\frac{d a}{d N}=A \cdot\left(K^{*}-K_{a b}\right)^{n}\left[1-\left(\frac{\Delta K_{t h i n}}{K^{*}-K_{a b}}\right)^{p}\right]+A_{p} \cdot\left[K_{\max }^{m}-K^{* m}\right]
$$

O efeito de $\Delta K_{t h_{i n}}$ é pequeno sob plasticidade primária, logo o termo à direita vem da lei de Paris, e $\mathbf{A}, \mathbf{n}, \mathbf{p}, \mathbf{A}_{\mathbf{p}}$ e $\mathbf{m}$ são constantes de ajuste dos dados experimentais.

A desvantagem desse modelo é o grande número de constantes experimentais requeridas por essa equação da/dN, e o trabalho não-trivial necessário para calcular numericamente ou medir $\mathbf{K}_{\mathbf{a b}}$ e $\mathbf{K}^{*}$. Abaixo são mostrado os quatro regimes de propagação segundo o modelo DeKoning-Newman Strip Yield: a contribuição do escoamento primário é muito maior que a do secundário no incremento de trinca a cada $1 / 2$ ciclo. 


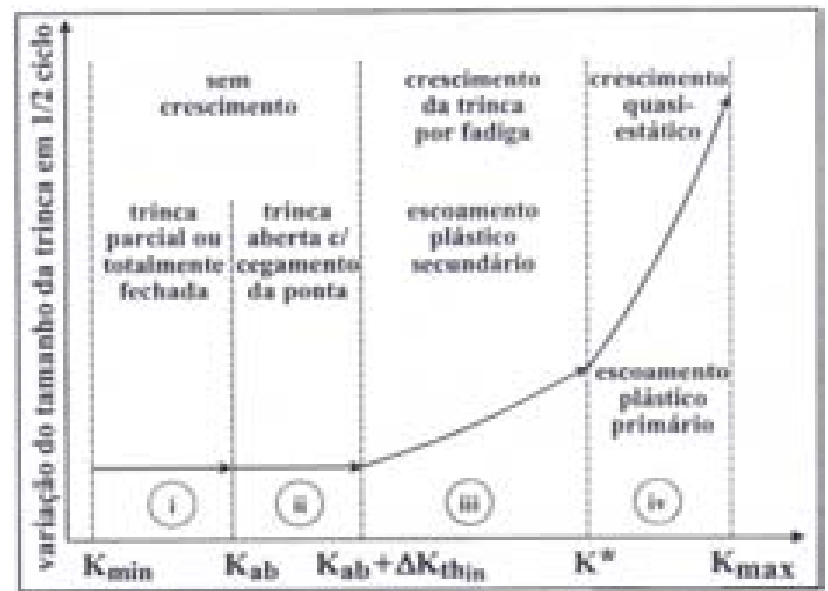

Figura 16 - Os 4 regimes de propagação segundo o modelo KN

\section{PROCEDIMENTO EXPERIMENTAL}

\subsection{Equipamentos e Materiais}

Para a realização da medição do teste de propagação de trinca pelo método $d a / d N$, foram utilizados os seguintes equipamentos e materiais:

- Uma máquina servo hidráulica para ensaios mecânicos dinâmicos MTS 810 Material Test System, com capacidade para 250 kN de carregamento;

- Service Manifold para pressão de 3000 psi;

- Servoválvula MOOG, modelo 760C263A/252.24C-01 para o acionamento hidráulico do pistão;

- Um computador MTS Test Star II, modelo 490.01, para interface entre o computador que controla o teste e a máquina servo hidráulica;

- Um computador Pentium I MMX, 233MHz, 64 MB de RAM, com o programa Test Star II de controle do teste;

- Um osciloscópio marca Tecktronix, modelo TDS 210;

- Uma bomba de óleo INSTRON, refrigerada a água, com vazão de $80 \mathrm{l} / \mathrm{min}$ e pressão de 3000 psi (200 bar); 
- Célula de carga marca ALFA Instrumentos, sensibilidade de 2mV/V e carga máxima de 5 ton;

- Telescópio ótico com lente Nikon - Nikor, zoom F = 43 86 mm, retículo Baucsh\&Lomb com lente $22.7 \mathrm{~mm} 0.17$ 6X, ocular de 9X, com marcação de posição em cruz;

- Micrômetro Newport de $0 \sim 25$ mm e resolução de $1 \mu \mathrm{m}$, e mesa micrométrica Newport modelo M-421;

- Tripé de suporte para o conjunto micrômetro-telescópio;

- Junta universal do tipo Cardam;

- Anéis bipartidos;

- Cabeça de suporte INSTRON com capacidade de $100 \mathrm{kN}$ para fixação das garras;

- Garras de aço ASTM H11 temperadas e revenidas, usinadas conforme norma ASTM E 647;

- Corpo de prova do tipo Forma de Disco de aço 4340;

- Paquímetro com resolução de 0.02 mm;

- Lixa d'água n.220, 400, 600, 800 e 1200.

- Pasta de diamante para metalografia da Arotec.

- Pinos de fixação do corpo de prova nas garras, feitos de aço carbono, com diâmetro nominal de $14 \mathrm{~mm}$;

- Alinhadores artesanalmente manufaturados com papel toalha e fita crepe;

- Computador Pentium III, 650MHz e 354MB de RAM para entrada de dados na planilha de planejamento e cálculo dos testes (Apêndice 1); 
- Lâmpada estroboscópica General Radio Company, modelo 1538-A Strobotac $^{\circledR}$;

- Lâmpada incandescente de 60 W.

A figura abaixo ilustra esquematicamente a montagem do corpo de prova na máquina.

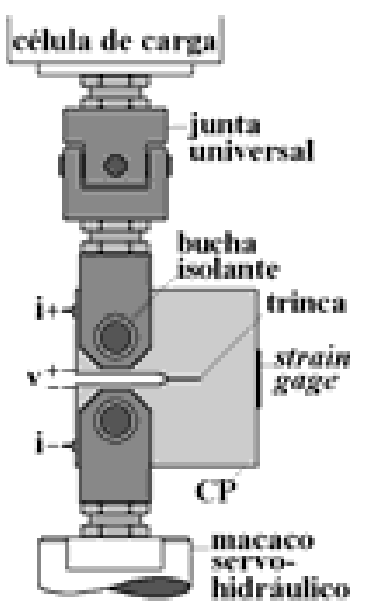

Figura 17 - Esquema da fixação do corpo de prova na máquina de teste

\subsection{Metodologia do Teste}

Para a realização do teste de propagação de trinca por fadiga utilizou-se o método $d a / d N$ e os equipamentos descritos acima. Seguiu-se a norma ASTM E 64700/2000 como referência para o pré-trincamento, mudanças de carga, verificação de validade do teste, cálculos do fator de intensidade de tensão, assim como para toda a planilha de monitoramento e cálculos do teste. Os tópicos da norma seguidos no procedimento experimental se encontram no Apêndice 3.

\subsubsection{Preparação do Corpo de Prova}

Foi usinado para o teste um corpo de prova do tipo Forma de Disco de aço carbono 4340. Sua superfície inicial era retificada. O corpo de prova foi medido com um paquímetro e encontraram-se as seguintes dimensões: 


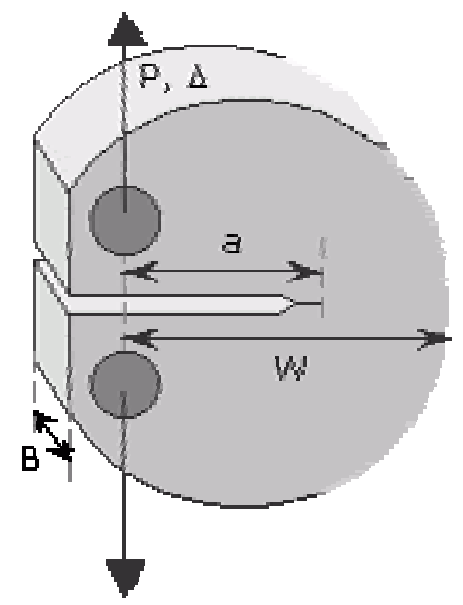

Figura 18 - Corpo de prova utilizado no teste

\begin{tabular}{|c|c|c|}
\hline \multicolumn{2}{|c|}{ Dimensões do Corpo de Prova } \\
\hline $\mathrm{B}=$ & 4,50 & $\mathrm{~mm}$ \\
\hline $\mathrm{w}=$ & 55,74 & $\mathrm{~mm}$ \\
\hline $\mathrm{a}_{0}=$ & 9,31 & $\mathrm{~mm}$ \\
\hline
\end{tabular}

Tabela 1 - Dimensões do corpo de prova

Como a medição de $\mathbf{a}_{0}$ é difícil de ser realizada, o seu valor foi calculado através da medição de outras dimensões. O valor da dureza Vikers (HV5) do material foi obtida experimentalmente no Laboratório de Ensaios Mecânicos do ITUC e foi igual a 209 HV5. Entretanto, estimou-se em seguida a tensão de ruptura considerando que HV5 = 210 pela correlação:

$$
S_{R}=3,4 H V 5
$$

$E$ chegou-se a $S_{R}=714 \mathrm{MPa}$. $O$ limite de escoamento $S_{E}$ foi estimado como sendo $84 \%$ de $\mathbf{S}_{\mathbf{R}}$.

Após a estimativa dos limites de ruptura e escoamento, poliram-se os dois lados do corpo de prova a fim de se obter uma superfície espelhada para que fosse possível medir o tamanho da trinca. O polimento se deu manualmente variando-se o número da lixa de 220 até 1200, e em seguida passando-se a pasta de diamante 
diluída em álcool hidratado $92,8^{\circ} \mathrm{GL}$. Tomou-se o cuidado para que em cada mudança de lixa o corpo de prova fosse girado de $90^{\circ}$, a fim de obter um polimento mais uniforme. O último passe do polimento foi executado na direção perpendicular ao caminho de propagação da trinca.

\subsubsection{Planilha de Monitoramento e Cálculo do Teste}

Foi desenvolvida uma planilha eletrônica para desempenhar as seguintes funções:

1) Calcular a/w e $f(a / w)$, que é uma função da geometria do corpo de prova, pela expressão.

$$
f\left(\frac{a}{w}\right)=\frac{2+\left(\frac{a}{w}\right)}{\left(1-\frac{a}{w}\right)^{1,5}}\left[0,76+4,8\left(\frac{a}{w}\right)-11,58\left(\frac{a}{w}\right)^{2}+11,43\left(\frac{a}{w}\right)^{3}-4,08\left(\frac{a}{w}\right)^{4}\right]
$$

2) Calcular $\mathbf{\Delta P}$ pela equação abaixo:

$$
\Delta P=\frac{\Delta K_{I} B \sqrt{W}}{f(a / w)}
$$

Onde a variação de $\Delta \mathrm{K}$ é imposta pela norma.

3) Calcular a carga mínima, média e máxima, assim como a amplitude de variação da força, seguindo o $\mathbf{R}$ escolhido para o teste.

4) Calcular $\mathbf{K}_{\text {Imax }}$ para a estimativa da zona plástica a frente da ponta da trinca.

5) Calcular o tamanho da zona plástica pela estimativa:

$z_{p}=\frac{1}{2 \pi} \frac{K_{I_{\max }}^{2}}{S_{E}^{2}}$

6) Entrada dos pontos de medição (tamanho da trinca a). 
7) Entrada do número de ciclos $\mathbf{N}$ nos respectivos pontos.

8) Calcular a taxa de propagação da trinca $\Delta a / \Delta N$.

9) Estimar o número de ciclos previstos para a medição seguinte baseado na última taxa de propagação.

10) Calcular o valor de $\mathrm{d} \Delta K_{I} / \Delta \mathrm{K}_{\mathrm{I}}$ para assegurar $\mathbf{\Delta K}$ aproximadamente constante.

\subsubsection{Montagem do Sistema}

Para os devidos fins, realizaram-se os seguintes passos:

1) Instalou-se na máquina de teste MTS devidamente alinhada o aparato experimental composto pela célula de carga, juntas bipartidas, junta universal, garras e cabeça de suporte INSTRON.

2) Aplicou-se uma pré-carga de 10X o valor máximo da força no teste, observando o limite máximo da célula de carga, com a finalidade de ajustar os anéis bipartidos para enrijecer o sistema e evitar a fadiga dos componentes. Esta pré-carga foi aplicada utilizando-se um dispositivo auxiliar em lugar do corpo de prova.

3) Posicionou-se o atuador da máquina o mais próximo possível da metade do seu curso total, na posição inicial do teste, pois, dessa forma estamos trabalhando na zona ótima de utilização do equipamento.

4) Fixou-se o corpo de prova nas garras centralizando-os com os alinhadores de papel.

5) Configurou-se o programa entrando com os dados abaixo:

a) Ajuste dos limites de segurança do teste; 
b) Taxa de crescimento da amplitude do carregamento em N/s (envelope time);

c) Carga média em N;

d) Amplitude em N;

e) Freqüência em cpm (ciclos por minuto);

6) Posicionou-se o mecanismo de medição de forma que o zero do micrômetro alinhasse a cruz de medição em cima do entalhe usinado do corpo de prova.

\subsubsection{Metodologia de Medição}

O tamanho da trinca foi medido oticamente com o sistema descrito acima. Segundo o item 8.8 da norma ASTM E $647^{42}$ seria necessário conseguir medir pelo menos $0,1 \mathrm{~mm}$ para que o teste fosse válido, sendo assim o sistema disponível era suficiente. A norma também sugere que sejam utilizados alguns meios que não foram executados, pois além de alguns deles não estarem disponíveis, como a malha de poliéster, julgou-se, para um primeiro teste que os meio eram suficientes.

Para iluminar a trinca foi utilizada uma lâmpada estroboscópica, pois ao colocar os equipamentos em freqüências muito próximas, foi possível observar a ponta da trinca se movimentando lentamente e assim estimar a parada do teste. Além disso, ao parar o teste ligava-se uma luz incandescente e com o corpo de prova submetido à carga média verificava-se se realmente a trinca havia chegado ao comprimento previsto para o próximo ajuste de carga, caso não tivesse chegado, o teste era reiniciado e novamente eram feitos monitoramentos até que o objetivo fosse alcançado. Com isso, anotava-se o número de ciclos que o software de máquina fornecia colocava-se na planilha eletrônica. 


\subsubsection{Freqüência}

No inicio do teste ou reinicio depois de uma parada maior que uma hora, eram impostas ao sistema freqüências baixas, como $600 \mathrm{cpm}(10 \mathrm{~Hz})$ para permitir que o óleo esquentasse. Após esse período inicial de transiente de temperatura, a freqüência era aumentada. Na maior parte do tempo a freqüência de trabalho era $1100 \mathrm{cpm}(18 \mathrm{~Hz})$, contudo às vezes era possível trabalhar a $1200 \mathrm{cpm}(20 \mathrm{~Hz})$ e até $2100 \mathrm{cpm}(35 \mathrm{~Hz})$.

\subsubsection{Limites e Controle do Teste}

Durante todo o procedimento foram mantidos limites de segurança bem apertados no sistema, que se ultrapassados, o sistema hidráulico desligaria, assim a possibilidade de sobrecarga sobre o corpo de prova foi diminuída, mas não eliminada.

O osciloscópio fui utilizado como controle do sistema de medição de carga da própria máquina, ou seja, os dados eram comparados para haver mais segurança e confiabilidade no que era lido nos equipamentos.

Seria muito melhor ter um sistema de medição para os dois lados do corpo de prova para assegurar que a trinca estaria crescendo igualmente nos dois lados e para obter medidas redundantes, contudo esse equipamento não estava disponível para utilização. Por isso foi adotada uma inspeção visual pelo menos 5 vezes por dia a fim de verificar a simetria da trinca.

\subsubsection{Calibração da Máquina de Testes}

Após a certificação de todos os alinhamentos da máquina e com o corpo de prova somente colocado, sem carga nenhuma aplicada sobre o mesmo, foi dado o comando para calibrar a medida de força. 


\subsubsection{Abertura da Pré-Trinca}

Para a abertura da pré-trinca, utilizou-se um $\mathbf{\Delta K}=\mathbf{2 0} M P a \sqrt{m}$ (que é adotado usualmente neste tipo de teste) e propagou-se a trinca por $3 \mathrm{~mm}$, ajustando-se a carga em intervalos de $\boldsymbol{\Delta a}=\mathbf{2 5 0} \boldsymbol{\mu m}$. Para certificar que o $\mathbf{\Delta} \mathbf{K}$ do final da fase de prétrincamento não excedesse o $\Delta \mathbf{K}$ do início do teste ${ }^{42}$ e esse fosse aproximadamente constante, diminuiu-se o intervalo $\Delta \mathbf{a}$ para $\mathbf{5 0} \boldsymbol{\mu m}$ entre as medições de $\mathbf{a}=12,310$ a $12,790 \mathrm{~mm}$. Pelo item 8.3.1 da norma ASTM E 647, o tamanho mínimo da pré-trinca para o corpo de prova analisado é de $3,480 \mathrm{~mm}$.

\subsubsection{Propagação da Trinca}

\subsubsection{K-Decrescente}

O método utilizado para o para a variação do $\Delta \mathbf{K}$ na primeira fase do teste foi K-Decrescente (K-Decreasing Procedure) da norma ASTM E 647. No item 8.6 da mesma norma, podemos observar que este método não é recomendado para crescimento maior que $10^{-8} \mathrm{~m} /$ ciclo, entretanto foi utilizado a fim achar o valor de $\Delta \mathbf{K}_{\mathrm{th}}$.

Após a abertura da pré-trinca iniciou-se o experimento. Estipulou-se que as tomadas do número de ciclos $\mathbf{N}$ seriam feitas em intervalos de $\mathbf{\Delta a}=\mathbf{5 0} \boldsymbol{\mu m}$. Este valor foi determinado tendo em vista alguns fatores. São eles:

- Manter $\Delta \mathrm{K}$ e, consequentemente, o tamanho da zona plástica à frente da trinca aproximadamente constante;

- As incertezas inerentes ao mecanismo e procedimento de medição;

- A flexibilidade do sistema que faz com que o corpo de prova se desloque nas direções vertical e horizontal (que é mais crítica, pois dificulta a medição e atribui uma incerteza maior ao resultado da medição); 
- Maximizar o número de medições em um mesmo $\Delta \mathbf{K}$ para diminuir a incerteza no valor médio da taxa $d a / d N$ relativa ao $\Delta \mathbf{K}$ corrente.

Sendo assim, posicionou-se a cruz de medição $\mathbf{5 0} \boldsymbol{\mu m}$ a frente da última tomada de $\mathbf{N}$. Propagou-se a trinca até que esta "tocasse" novamente a cruz de medição, entrando-se com o valor de $\mathbf{N}$ instantâneo na tabela que calculava automaticamente a taxa $\Delta a / \Delta N$. E a cada parada, visto o crescimento da trinca, eram ajustadas novamente as cargas para que os parâmetros pré-estipulados pelo teste fossem mantidos. Este procedimento foi repetido, em média, 15 vezes para coletarmos um número significativo de pontos da curva $d a / d N \mathbf{x} \mathbf{\Delta} \mathbf{K}$, para um determinado $\mathbf{\Delta} \mathbf{K}$ aproximadamente constante.

\subsubsection{K-Crescente}

O método seria utilizado para o para a variação do $\Delta \mathbf{K}$ na segunda fase do teste seria K-Crescente (K-Encreasing Procedure) da norma ASTM E 647.

Após achar o valor de $\Delta \mathbf{K}_{\mathrm{th}}$, começar-se-ia aumentar o valor de $\boldsymbol{\Delta} \mathbf{K}$ a fim de traçar o resto da curva, procedimento esse que é bem mais simples que o anterior, visto que não há efeitos de transiente na mudança de cargas, pois a zona plástica induzida no teste não afeta a próxima fase de carregamento. Além do mais, a fase final do sistema K-decrescente é muito sensível a qualquer sobrecarga, pois $\Delta \mathrm{K}$ é muito próximo de $\Delta \mathbf{K}_{\mathrm{th}}$.

Os dados de $\mathrm{K}$ crescente e decrescente seriam comparados e analisados ao fim do experimento, pois assim se tem resultados redundantes diminuindo a possibilidade de grandes erros nos resultados. 


\section{ANÁLISE DOS RESULTADOS}

Devido a inúmeras dificuldades encontradas e resolvidas no laboratório, somente foi possível levantar parte de uma curva $d a / d N \times \Delta \mathrm{K}$, justamente a parte mais difícil que é quando $\Delta \mathrm{K}$ decresce. Contudo, com os dados medidos, é possível realizar uma análise do teste, dos procedimentos adotados, sugerir melhorias para o processo, e vislumbrar a continuidade do trabalho. Neste experimento foi utilizado $R=0,1$ $\left(P_{\min } / P_{\max }\right)$

\subsection{Incertezas nas Medições}

Certamente a maior fonte de incerteza encontrada no teste realizado é a medição ótica do crescimento da trinca pelos vários motivos listados e comentados a seguir:

a) Polimento do corpo de prova:

Apesar de haver extremo cuidado ao polir o corpo de prova, como a operação foi feita manualmente (pois o serviço era cobrado para nós alunos de graduação) em alguns pontos existiam riscos ou pontos onde era impossível fazer a medida, pois a ponta da trinca ficava escondida.

b) Não redundância de medidas com outros métodos:

A queda de potencial e a flexibilidade são meios mais eficazes desde que bem calibrados para fazer essa medição. Na verdade a medida ótica deveria ser a auxiliar a esses métodos supracitados.

c) Mudança de posição do sistema de um dia para o outro: 
Invariavelmente, mesmo se re-alinhando o sistema a trinca parecia ter crescido $50 \mu \mathrm{m}$ de um dia para o outro, fazendo com que as primeiras medições do dia fossem ruins.

d) Deslocamento do corpo de prova na direção horizontal:

Este deslocamento é crítico pelo fato de ser da ordem de grandeza do incremento $\Delta \mathbf{a}$ da trinca a ser medido. Além disso, este variou ao longo do teste devido às mudanças no carregamento e o tamanho da trinca.

e) Potência da luz estroboscópica:

Em freqüências altas ficou difícil o monitoramento do crescimento da trinca, pois a luz estroboscópica neste regime não tinha intensidade luminosa suficiente para dar uma boa resolução da ponta da trinca. Em função disso, precisou-se diminuir a freqüência do equipamento e achar uma submúltipla da freqüência do teste.

f) O suporte do mecanismo de medição ótico:

O suporte não era ideal por ser muito esbelto e não proporcionar estabilidade para o mecanismo de medição. Além disso, pelo falto de ser simplesmente apoiado no piso, este era facilmente movido de sua posição.

g) Erros de paralaxe.

\subsection{Outras Incertezas}

Além das incertezas da medição, podemos encontrar outros parâmetros que influenciam negativamente o resultado do teste. Observou-se pelo programa de controle da máquina, no seu osciloscópio interno, que a amplitude do carregamento não era constante, variando da ordem de 3,5\%, em média, da carga máxima corrente. O osciloscópio externo confirmou este erro na aplicação das cargas. 
A carga mínima aplicada no teste foi de aproximadamente $0,4 \%$ da capacidade da célula de carga e a máxima cerca de $13 \%$. A incerteza na leitura da carga é inversamente proporcional à carga aplicada. No entanto não se fez a estimativa quantitativa deste erro.

Essas medidas da célula de carga são enviadas para o computador de controle do teste que usa este sinal para compensar a diferença entre a força aplicada e a esperada. O erro desta compensação torna-se ainda maior pelo motivo do parágrafo acima.

\subsection{Análise dos Dados}

Desenvolveu-se um uma rotina em MatLab (Apêndice 2) para traçar os gráficos (Apêndice 4) de interesse do teste.

A nuvem de pontos esta dividida por faixas de valores conforme a divisão especificada abaixo:

\begin{tabular}{|c|c|c|}
\hline Marcas & Cor & Descrição \\
\hline Diamante & Preto & $\begin{array}{c}\text { Medições do número de ciclos N } \\
\text { válidas para traçar a curva da/dN. }\end{array}$ \\
\hline Circulo & Magenta & $\begin{array}{c}\text { Região onde a trinca está sofrendo } \\
\text { influência da zp do } \Delta \text { KI anterior mais } \\
2 \text { vezes a zp atual. }\end{array}$ \\
\hline Hexagrama & Azul & Inicio da pré-trinca \\
\hline Hexagrama & Verde & Final da pré-trinca \\
\hline Cruz & Vermelha & Ajusta após sobrecarga acidental \\
\hline Quadrado & Cyan & Região onde não podemos garantir \\
& qualquer confiabilidade na medição \\
\hline
\end{tabular}

Tabela 2 - Identificação dos pontos do teste 
A seguir temos os gráficos em escala reduzida;

1 - Gráfico a x N

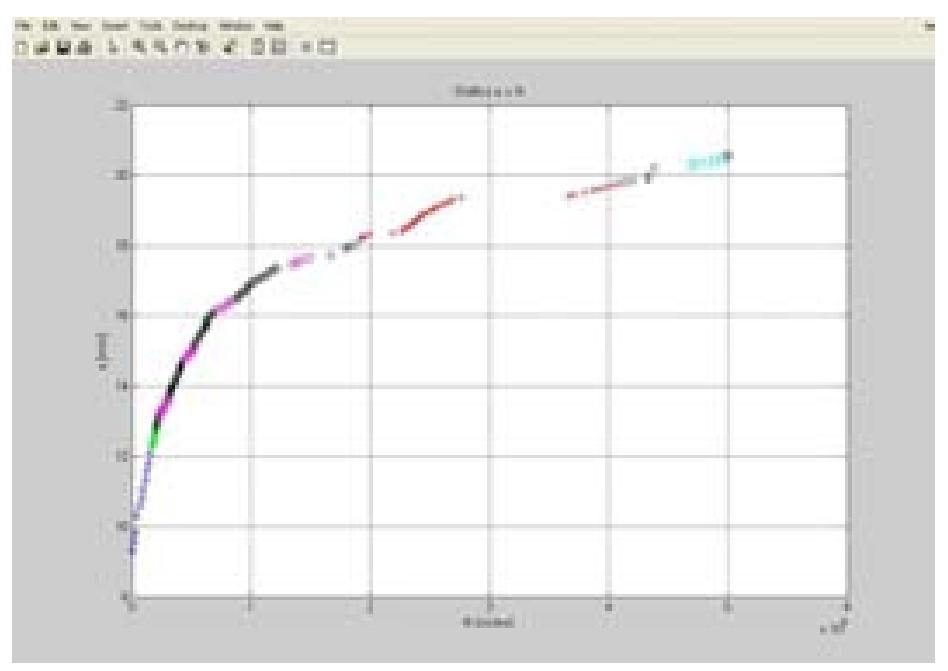

Figura 19 - Gráfico a X N

Conforme o esperado, a curva que descreve o aumento da trinca com o número de ciclos cresce monotonicamente, pois como $\Delta \mathrm{K}$ diminui à medida que o teste avança a trinca precisa de mais ciclos para crescer o mesmo $\Delta \mathbf{a}$. Existe uma descontinuidade na faixa de dados entre 3 milhões e 4 milhões de ciclos devido à falta de medição do tamanho a em relação ao numero de ciclos $\mathbf{N}$.

Pode-se observar na zona do ajuste que há um crescimento mais rápido do tamanho da trinca. Isso se deve ao fato de ter-se aumentado o valor de $\mathbf{\Delta K}$ para transpor a zona plástica devido a uma sobrecarga acidental ocorrida no teste.

Cabe ressaltar que após a sobrecarga, para o $\Delta \mathbf{K}$ corrente, a trinca parou por completo. Verificou-se essa parada após 800.000 ciclos. Contudo, não parece ter sido causada por ter-se encontrado o $\Delta \mathbf{K}_{\text {th. }}$ No mesmo $\Delta \mathrm{K}$, a trinca estava crescendo a uma taxa razoavelmente rápida. Verificou-se o corpo de prova e observou-se que havia uma deformação ao redor da ponta da trinca maior que esperado. Para transpor essa zona 
plástica residual foi necessário aumentar o $\Delta \mathbf{K}$ em duas faixas, isto é de aproximadamente $14 \mathrm{MPa} \sqrt{m}$ para $17 \mathrm{MPa} \sqrt{m}$.

\section{2 - Gráfico da/dN x a}

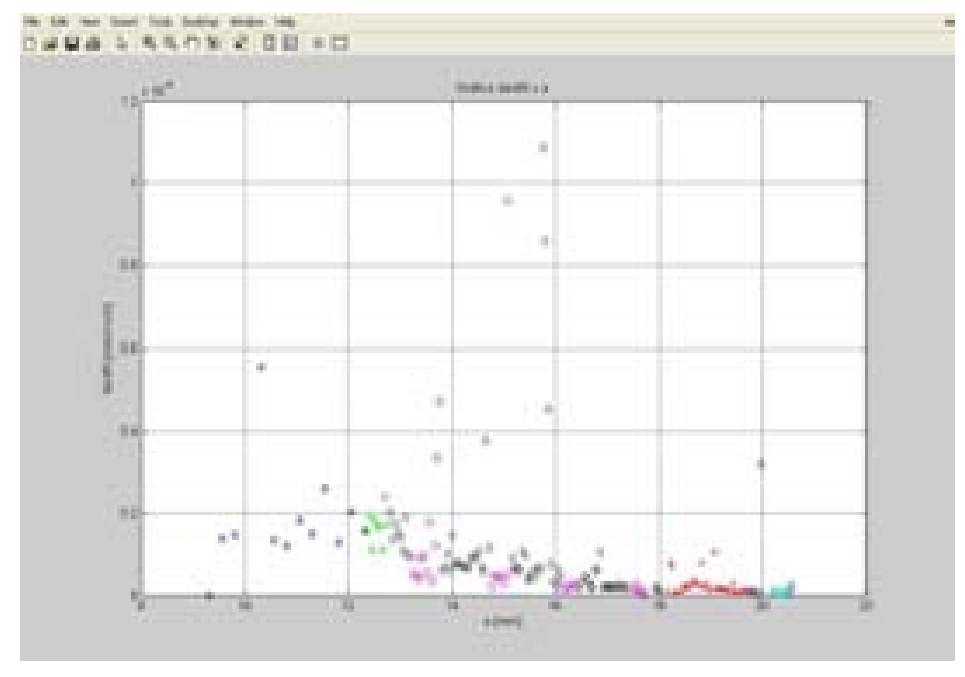

Figura 20 - Gráfico da/dN X a

Neste gráfico podemos observar a variação da taxa de propagação da trinca da/dN em relação ao seu tamanho a. Apesar da nuvem de pontos estar muito dispersa, podemos destacar algumas características identificáveis.

Pode-se observar que a maioria dos pontos segue uma tendência semelhante. De maneira geral da/dN decresce com o tamanho da trinca. Isto era esperado, pois foi imposto pela metodologia sugerida pela norma ASTM E 647.

Um aspecto muito interessante foi verificado ao observar os pontos durante o ajuste do teste após a sobrecarga acidental. Pode-se verificar claramente o efeito da sobrecarga no corpo de prova, pois se foi obrigado a aumentar o $\Delta \mathbf{K}$, mas à taxa $\mathbf{d a} / \mathbf{d N}$ não se elevou aos níveis atingidos anteriormente para $\Delta \mathbf{K}$ parecidos. A anotação número 1 no zoom retirado do gráfico $\mathbf{d a / d N} \mathbf{x}$ a global. 


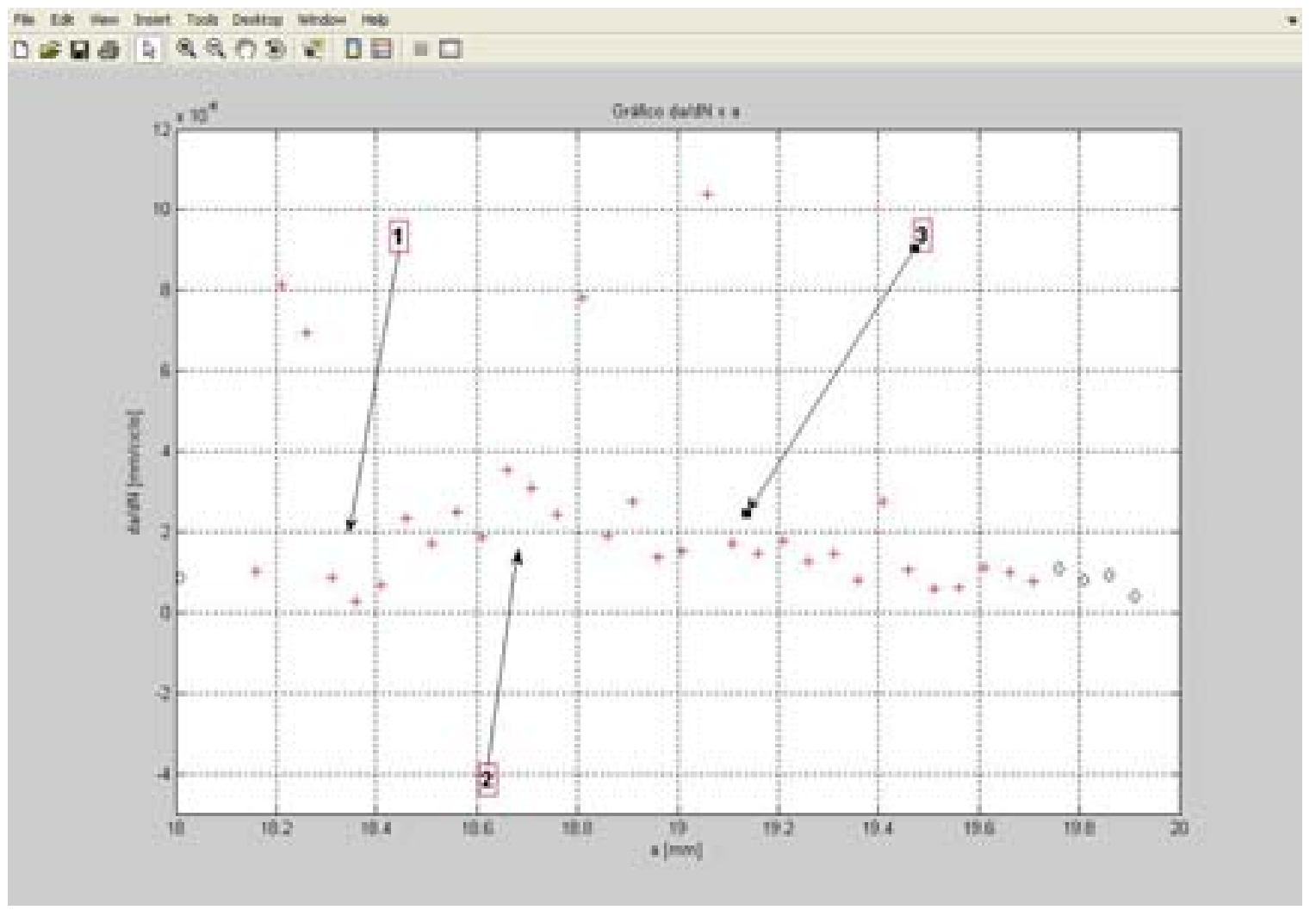

Figura 21 - Gráfico da/dN X a

A anotação número 2 coincide com a queda de aproximadamente $17 \mathrm{MPa} \sqrt{m}$ para $15,5 \mathrm{MPa} \sqrt{m}$, observa-se que a taxa da/dN nesta região começou a crescer em direção a um valor esperado para o $\Delta \mathbf{K}$ imposto pela tabela (Apêndice 1) e ao diminuirse o valor de $\Delta \mathrm{K}$ a curva volta a seguir a tendência global de decrescimento, conforme se pode observar na região 3 .

\section{3 - Gráfico da/dN x $\Delta K$}

Analisando o gráfico observa-se que as regiões sobre influência da zona plástica do carregamento anterior, após a redução no $\Delta \mathbf{K}$, de fato sofrem retardo na taxa de propagação da trinca da/dN. De maneira geral os pontos medidos se localizavam em média numa região abaixo dos pontos validados do teste.

Esperava-se um aumento da faixa de incerteza à medida que $\Delta \mathrm{K}$ diminuísse devido à sensibilidade do sistema é que baixa para pequenas cargas. 


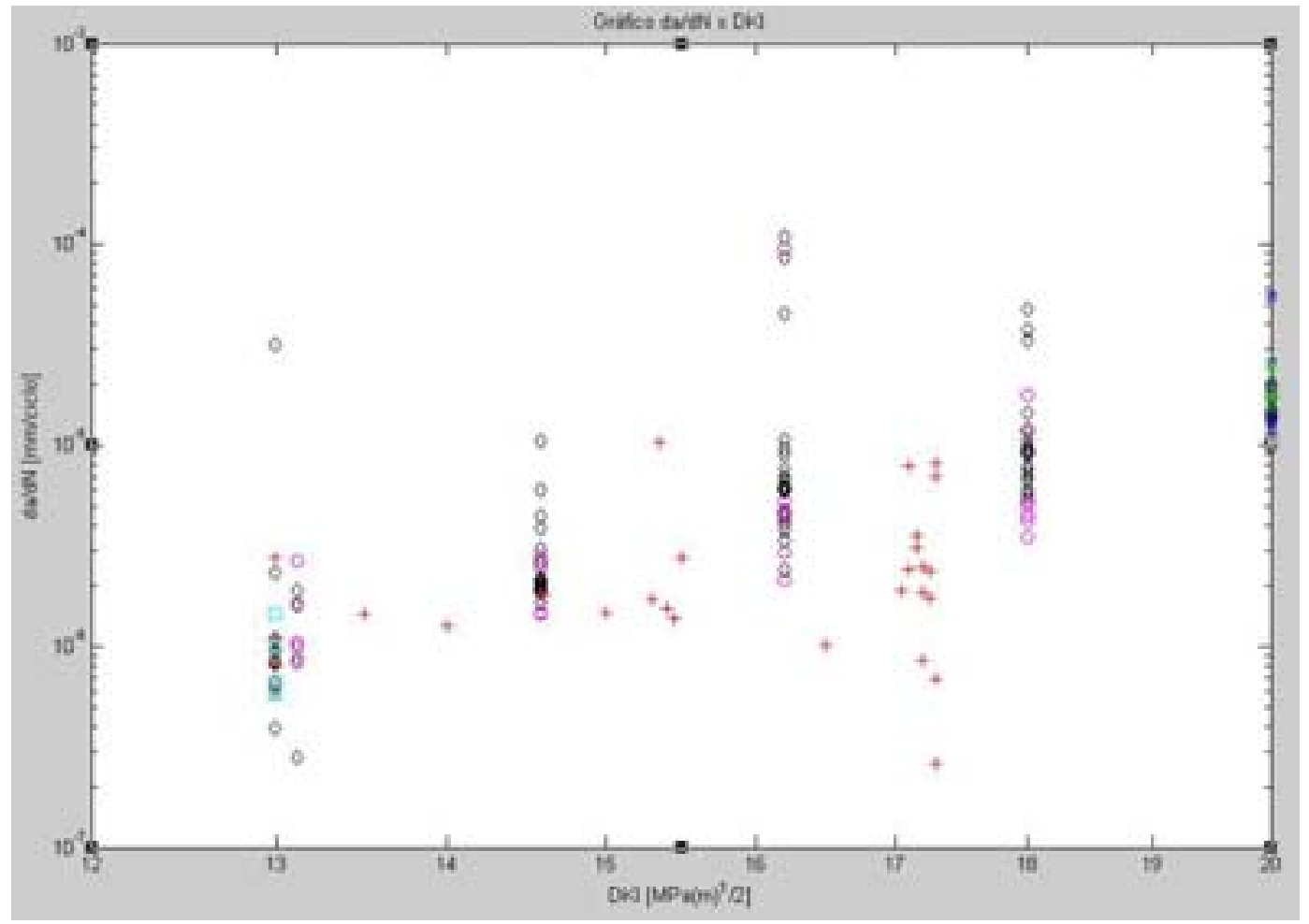

Figura $22-$ Gráfico da/dN X $\Delta \mathrm{K}$

Cabe ressaltar que os pontos do ajuste do teste após a sobrecarga acidental se encontram todos abaixo dos valores esperados de da/dN caso não houvesse a sobrecarga.

\section{CONCLUSÃO}

Pode-se observar em todos os gráficos que a dispersão dos pontos medidos é, em alguns casos, da ordem de grandeza da variação da taxa de propagação da/dN em relação à $\Delta \mathbf{K}$. Com isso concluímos que o método experimental não foi realizado sistematicamente e com o rigor que esse tipo de procedimento necessita para obter resultados quantitativos que descrevam o comportamento da trinca sob uma determinada gama de carregamentos. Certamente a inexperiência dos experimentalistas foi um dos fatores que contribuiu para a imprecisão nas medidas. 
Além disso, pelo fato de não ter-se conseguido levantar uma curva completa da/dN $\times \Delta \mathbf{K}, \quad$ o objetivo do trabalho foi alcançado parcialmente. Contudo os experimentalistas adquiriram o conhecimento necessário para conduzir um teste à fadiga da/dN medido com instrumento ótico. E conseguiram identificar inúmeras fontes de incertezas no processo de medição.

Conclusões adicionais puderam ser tiradas e ficaram muito claras durante a execução do teste e análise dos resultados. Como citado na revisão teórica, a zona plástica influencia muito no retardo das trincas. Devido a uma sobrecarga acidental tornou-se necessário ultrapassar esta zona aumentando $\Delta \mathbf{K}$, que por causa do incidente fez com que a trinca parasse.

Outro fato que corrobora com a afirmação acima é que, em linhas gerais, os pontos logo após a diminuição de $\Delta \mathbf{K}$ também tendem a ter taxas de propagação menores que os que não estão sobre a influencia da zona plástica anterior.

Além disso, pode-se afirmar que o cuidado com o corpo de prova é imprescindível tanto no polimento quanto no manuseio, pois nas medidas óticas o acabamento superficial é crucial.

E que a medida ótica, desde que feita com muito cuidado serve de referência para meios analógicos de medição, pois existem incertezas inerentes ao método, mas que podem ser minimizadas.

Cumpriu se um objetivo secundário do teste que era criar condições para que o laboratório voltasse a ser operacional. 


\section{BIBLIOGRAFIA}

1 - $\quad$ Abelkis,P.R., - "Effect of Transport Aircraft Wing Loads Spectrum Variation on Crack Growth” ASTM STP 714, pp.143-169, 1980.

2 - $\quad$ Barsom,J.M., Rolfe,S.T., - "Fracture and Fatigue Control in Structures", ASTM 1999.

3 - Broek,D., - “Elementary Engineering Fracture Mechanics”, Nijhoff, 1985.

4 - Broek,D., - "The Practical Uses of Fracture Mechanics”, Kluwer 1989.

5 - $\quad$ Bunch,J.O., Tramnell,R. \& Tanouye,P., - "Structural Life Analysis Methods Used on the B-2 Bomber", ASTM STP 1292, pp.220-247, 1986.

6 - Castro,J.T.C. \& Meggiolaro,M.A., - "Previsão da Vida Residual de Estruturas Trincadas”, Anais do COTEQ 97, pp.263-268, IBP 1997.

7 - Castro,J.T.P. \& Meggiolaro,M.A., - "Fadiga sob Cargas Reais de Serviço", em publicação, v.1, pp.329-501

8 - Castro,J.T.P. \& Meggiolaro,M.A., - "Fadiga sob Cargas Reais de Serviço", em publicação, v.2, pp.-507-770

9 - $\quad$ Castro,J.T.P., Giassoni,A. \& Kenedi,P.P., - "Fatigue Propagation of Semi and Quart-Elliptical Cracks in Wet Welds”, RBCM V.20, PP.263-277, 1998.

10 - Castro.J.T.P., - "A Circuit to Measure Crack Closure", Experimental Techniques, v.17, n.2, pp.23-25, 1993.

11 - Chang,J.B. \& Engle,R.M., - "Improved Damage-Tolerance Analysis Methodology" J. of Aircraft v.21, pp.722-730, 1984.

12 - Crandall,S.H., Dahl,N.C., Lardner,T.J., - "An Introduction to the Mechanics of Solids", McGraw Hill, 1978.

13 - Dahl,W. \& Roth,G., - "On the Influence of Overloads on Fatigue Crack Propagation in Structural Steels", Aachen Technical University, 1979.

14 - de Koning,A.U., ten Hoeve,H.J. \& Hendriksen,T.K., - "The Description of Crack Growth on the Basis of the Strip-Yield Model for Computation of Crack Opening Loads, the Crack Tip Stretch and Strain Rates", National Aerospace Laboratory Report (NLR), 1997.

15 - Dugdale,D.S., - "Yielding of Steel Sheets Containing Slits", J. of Mech. And Physics of Solids, v.8, pp.100-104, 1960.

16 - Duggan,T.V. \& Byrne,J., - "Fatigue as a Design Criterion”, Macmillan 1977. 
17 - Elber, W., - "Fatigue Crack Closure under Cyclic Tension", Engineering Fracture Mechanics v.2(1), pp.37-45, 1970.

18 - Elber, W., - "The Significance of Fatigue Crack Closure", Damage Tolerance of Aircraft Structures, ASTM STP 486, pp.230-242, 1971.

19 - Engle,L. \& Klingele,H., - "An Atlas of Metal Damage”, Prentice Hall 1981.

20 - Finney,J.M., - "Sensitivity of Fatigue Crack Growth Prediction Using Wheeler Retardation to Data Representation", J. of Testing and Evaluation v.17(2), pp.75-81, 1989.

21 - Forman,R.G. \& Mettus,S., - "Behavior of Surface and Corner Cracks Subjected to Tensile and Bending Loads in Ti6A14V Alloy", ASTM STP 1131, pp.519-546, 1992.

22 - Forman,R.G., Kearney,V.E. \& Engle,R.M., - "Numerical Analysis of Crack Propagation in a Cyclic-Loaded Structure", J. Basic Eng., v.89, n.3, pp.459-464, 1967.

23 - Forman,R.G., Shivakumar,V., Mettu,S.R. \& Newman,J.C., - "Fatigue Crack Growth Computer Program NASGRO Version 3.0, Reference Manual”, NASA 2000.

24 - Gallagher,J.P. \& Hughes,T., - "Influence of Yield Strength on Overload Affected Fatigue Crack Growth Behavior in 4340 Steel", Wright Patterson Air Force Laboratory, 1974.

25 - Gallagher,J.P., - "A Generalized Development of Yield Zone Models”, Wright Patterson Air Force Laboratory, 1974.

26 - Hall,L.R., Shah,R.C. \& Engstrom,W.L., - "Fracture and Fatigue Crack Growth Behavior of Surface Flaws and Flaws Originating at Fastener Holes", Air Force Flight Dynamics Lab., AFFDL-TR-74-47, 1974.

27 - Inglis,C.E., - "Stress in a Plate Due to the Presence of Cracks and Sharp Corners”, Phil. Trans. Royal Society Series A, v.215, pp.119-233, 1913.

28 - Kujawski,D., - "Enhanced Model of Partial Crack Closure for Correlation of Rratio Effects in Aluminum Alloys", Int. J. Fatigue, v.23, pp.95-102, 2001.

29 - Lang,M. \& Marci,G., - "The Influence of Single and Multiple Overloads on Fatigue Crack Propagation”, Fatigue and Fract. of Eng. Mat. Structures v.22, pp.257-271, 1999.

30 - Lankford,J. \& Davidson, D.L., - "The Effect of Overloads upon Fatigue Crack Tip Opening Displacement and Crack-Tip Opening/Closing Loads in Aluminum Alloys", Advances in Fracture Research, v.2, pp.899-906, 1981.

31 - Lawson,L., Chen,E.Y. \& Meshii,M., - "Near-Threshold Fatigue: a Review", Int. J. Fatigue v.21, pp.S15-S34, 1999. 
32 - McEvily,A. \& Ritchie,R.O., - "Crack Closure and the Fatigue Crack Propagation Threshold as a Function of Load Ratio", Fatigue Fract. Eng. Mater. Struct. v.21, pp.847855, 1998.

33 - McMillan,J.C. \& Pelloux,R.M.N., - "Fatigue Crack Propagation under Program and Random Loads", Fatigue Crack Propagation, ASTM STP 415, pp.505-535, 1967.

34 - Meggiolaro,M.A. \& Castro,J.T.P., - "Estimativas da Curva de Propagação de Trinca", PUC-Rio 2003.

35 - Meggiolaro,M.A., Castro,J.T.P., - "An Evaluation of Elbertype Crack Retardation Models”, II Sem. Internacional de Fadiga, SAE\#2001-01-4063, pp.207-216, 2001.

36 - Meggiolaro,M.A., Castro,J.T.P., - "Comparing Overload-Induced Retardation Models on Fatigue Crack Propagation", 56 Congresso da ABM, pp.1719-1729, 2001.

37 - Meggiolaro,M.A., Castro,J.T.P., - "Comparison of Load Interaction Models in Fatigue Crack Propagation”, 16 COBEM, v.12, pp.247-256, ABCM, 2001.

38 - Metals Handbook, 9th edition, v.12, "Fractography", ASM 1987.

39 - Miranda,A.C.O., Meggiolaro,M.A., Castro,J.T.P., Martha,L.F., - "Evaluation of Fatigue Crack Growth Retardation and Arrest in Bifurcated Cracks", submetido ao $58^{\circ}$ Congresso Annual da ABM, Rio de Janeiro, RJ, 2003.

40 - Newman,J.C., - "A Carck Opening Stress Equantion for Fatigue Crack Growth", Int. J. of Fracture, v.24, pp.R131-R135, 1984.

41 - Newman,J.C., Crews,J.H., Bigelow,C.A. \& Dawicke,D.S., - "Variations of a Global Constraint Factor in Cracked Bodies under Tension and Bending Loads", STM STP 1244, pp.21-42, 1995.

42 - norma E647, ASTM Standards v.03.01

43 - Paris,P.C. \& Erdogan,F., - "A Critical Analysis of Crack Propagation Laws”, J. Basic Engineering, v.85, pp.528-534, 1963.

44 - Paris,P.C., Gomez,M.P., Anderson,W.E., - "A Rational Analytic Theory of Fatigue", The Drend in Engineering, v.13, pp.9-14, 1961.

45 - Paris,P.C., Tada,H. \& Donald,J.K., - "Service Load Fatigue Damage - a Historical Perspective”, Int. J. of Fatigue v.21, pp.S35-S46, 1999.

46 - Priddle,E.K., Walker,F.E., - "Effect of Grain-Sized on Occurrence of Cleavage Fatigue Failure in 316 Stainless-Steel”, J. Mater. Sci., v.11, n.2, pp.386-388, 1976.

47 - Rice,R.C., ed., - "Fatigue Design Handbook", SAE 1998.

48 - Schijve,J., - "Fatigue of Structures and Materials”, Kluwer 2001. 
49 - Schijve,J., - "Four Lectures on Fatigue Crack Growth", Engineering Fracture Machanics, v.11, pp.176-221, 1979.

50 - Sippel,K.O., Weisgerber,D., - "Flight by Flight Crack Propagation Test Results with Several Load Spectra and Comparison with Calculation According to Different Models", ICAF Symposium, Darmstadt, 1977.

51 - Starke,E.A. \& Williams,J.C., - "Microstructure and the Fracture Mechanics of Fatigue Crack Propagation", Fracture Mechanics: Perspectives and Directions, ASTM STP 1020, pp.184-205, 1989.

52 - Suresh,S. \& Shih,C.F., - "Plastic Near-tip Fields for Branched Cracks", Int. J. Fracture, v.30, pp.237-259, 1986.

53 - Suresh,S., - "Fatigue of Materials”, 2nd Edition, Cambridge 1998.

54 - ten Hoeve,H.J. \& de Koning,A.U., - "Implementation of the Improved Strip Yield Model into NASGRO Software - Architecture and Detailed Design Document", NLR, 1995.

55 - von Euw,E.F.G., Hertzberg,R.W. \& Roberts,R., - "Delay Effects in Fatigue Crack Propagation", ASTM STP 513, pp.230-259, 1972.

56 - Walker,K., - "Effects of Environment and Complex Load History on Fatigue Life", ASTM STP 462, pp.1-14, 1970.

57 - Wasén,J., Heier,E., - "Fatigue Crack Growth Thresholds, the Influence of Young's Modulus and Fracture Surface Roughness", Int. J. of Fatigue v.20, pp.737-742, 1998.

58 - Wheeler,O.E., - "Spectrum Loading and Crack Growth", J. of Basic Engineering, pp.181-186, 1972.

59 - Willenborg,J., Engle,R.M. \& Wood,H.A., - "Crack Growth Retardation Model Using an Effective Stress Concept", Wright Patterson Air Force Laboratory, 1971. 


\section{Apêndice I}

\section{Tabela de Dados}

\begin{tabular}{|c|c|c|c|c|c|}
\hline Vermelho & \multicolumn{5}{|c|}{ Dados de entrada ou medidos. } \\
\hline Preto & \multicolumn{5}{|c|}{ Parâmetros calculados. } \\
\hline & \multicolumn{5}{|c|}{ Região de pré-trincamento onde $\Delta \mathrm{a}=\mathbf{2 5 0} \mathbf{\mathrm { mm }}$. } \\
\hline & \multicolumn{5}{|c|}{ Região de pré-trincamento onde $\Delta \mathrm{a}=\mathbf{5 0} \mathrm{mm}$. } \\
\hline & \multicolumn{5}{|c|}{ Região onde a trinca está sofrendo influência da $\mathrm{zp}$ do $\Delta \mathrm{K}_{\mathrm{l}}$ anterior mais 2 vezes a zp atual. } \\
\hline Azul & \multicolumn{5}{|c|}{ Região de reajuste do teste após a aplicação de uma sobrecarga acidental no corpo de prova. } \\
\hline & \multicolumn{5}{|c|}{ Região onde as medições foram muito dificultadas por arranhões e/ou marcas no corpo de prova. } \\
\hline Preto & \multicolumn{5}{|c|}{ Medições do número de ciclos $\mathbf{N}$ válidas para traçar a curva da/dN. } \\
\hline & \multicolumn{5}{|c|}{ Saltos no $\Delta$ a maiores que $250 \mathrm{~mm}$ na fase de pré-trinca ou maiores que $50 \mathrm{~mm}$ na fase de teste. } \\
\hline a $[\mathrm{mm}]$ & $\mathbf{N}$ [ciclos] & $\Delta \mathrm{a} / \Delta \mathrm{N}[\mathrm{mm} /$ ciclos $]$ & $\Delta \mathrm{K}_{\mathrm{l}}\left[\mathrm{MPa}(\mathrm{m})^{1 / 2}\right]$ & $\mathrm{K}_{\operatorname{lmax}}\left[\mathrm{MPa}(\mathrm{m})^{1 / 2}\right]$ & zp $[\mathrm{mm}]$ \\
\hline 9,310 & 0 & 0,00000000 & 20,000 & 22,222 & 0,218 \\
\hline 9,560 & 17971 & 0,00001391 & 20,000 & 22,222 & 0,218 \\
\hline 9,810 & 34946 & 0,00001473 & 20,000 & 22,222 & 0,218 \\
\hline 10,310 & 43952 & 0,00005552 & 20,000 & 22,222 & 0,218 \\
\hline 10,560 & 62742 & 0,00001330 & 20,000 & 22,222 & 0,218 \\
\hline 10,810 & 83539 & 0,00001202 & 20,000 & 22,222 & 0,218 \\
\hline 11,060 & 97273 & 0,00001820 & 20,000 & 22,222 & 0,218 \\
\hline 11,310 & 114127 & 0,00001483 & 20,000 & 22,222 & 0,218 \\
\hline 11,560 & 123754 & 0,00002597 & 20,000 & 22,222 & 0,218 \\
\hline 11,810 & 143084 & 0,00001293 & 20,000 & 22,222 & 0,218 \\
\hline 12,060 & 155462 & 0,00002020 & 20,000 & 22,222 & 0,218 \\
\hline 12,310 & 171366 & 0,00001572 & 20,000 & 22,222 & 0,218 \\
\hline 12,360 & 174559 & 0,00001566 & 20,000 & 22,444 & 0,223 \\
\hline 12,410 & 177108 & 0,00001962 & 20,000 & 22,000 & 0,214 \\
\hline 12,460 & 181634 & 0,00001105 & 20,000 & 22,222 & 0,218 \\
\hline 12,510 & 184361 & 0,00001834 & 20,000 & 22,444 & 0,223 \\
\hline 12,560 & 187360 & 0,00001667 & 20,000 & 22,000 & 0,214 \\
\hline 12,610 & 190370 & 0,00001661 & 20,000 & 22,222 & 0,218 \\
\hline 12,660 & 194875 & 0,00001110 & 20,000 & 22,444 & 0,223 \\
\hline 12,710 & 196954 & 0,00002405 & 20,000 & 22,000 & 0,214 \\
\hline 12,760 & 199861 & 0,00001720 & 20,000 & 22,222 & 0,218 \\
\hline 12,810 & 202331 & 0,00002024 & 20,000 & 22,444 & 0,223 \\
\hline 12,860 & 206006 & 0,00001361 & 20,000 & 22,000 & 0,214 \\
\hline 12,910 & 208859 & 0,00001753 & 20,000 & 22,222 & 0,218 \\
\hline 12,960 & 212161 & 0,00001514 & 20,000 & 22,444 & 0,223 \\
\hline 13,010 & 215666 & 0,00001427 & 20,000 & 22,000 & 0,214 \\
\hline 13,060 & 220269 & 0,00001086 & 20,000 & 22,222 & 0,218 \\
\hline 13,110 & 222915 & 0,00001890 & 20,000 & 22,444 & 0,223 \\
\hline 13,160 & 228027 & 0,00000978 & 20,000 & 20,000 & 0,177 \\
\hline 13,210 & 233321 & 0,00000944 & 18,000 & 20,200 & 0,180 \\
\hline 13,260 & 243115 & 0,00000511 & 18,000 & 19,800 & 0,173 \\
\hline
\end{tabular}




\begin{tabular}{|c|c|c|c|c|c|}
\hline 13,310 & 254264 & 0,00000448 & 18,000 & 20,000 & 0,177 \\
\hline 13,360 & 266194 & 0,00000419 & 18,000 & 20,200 & 0,180 \\
\hline 13,410 & 271650 & 0,00000916 & 18,000 & 19,800 & 0,173 \\
\hline 13,460 & 276901 & 0,00000952 & 18,000 & 20,000 & 0,177 \\
\hline 13,510 & 286320 & 0,00000531 & 18,000 & 20,200 & 0,180 \\
\hline 13,560 & 289114 & 0,00001790 & 18,000 & 19,800 & 0,173 \\
\hline 13,610 & 303520 & 0,00000347 & 18,000 & 20,000 & 0,177 \\
\hline 13,660 & 307680 & 0,00001202 & 18,000 & 20,200 & 0,180 \\
\hline 13,710 & 309177 & 0,00003340 & 18,000 & 19,800 & 0,173 \\
\hline 13,760 & 310235 & 0,00004726 & 18,000 & 20,000 & 0,177 \\
\hline 13,810 & 318382 & 0,00000614 & 18,000 & 20,200 & 0,180 \\
\hline 13,860 & 325575 & 0,00000695 & 18,000 & 19,800 & 0,173 \\
\hline 13,910 & 330549 & 0,00001005 & 18,000 & 20,000 & 0,177 \\
\hline 13,960 & 339012 & 0,00000591 & 18,000 & 20,200 & 0,180 \\
\hline 14,010 & 342461 & 0,00001450 & 18,000 & 19,800 & 0,173 \\
\hline 14,060 & 349109 & 0,00000752 & 18,000 & 20,000 & 0,177 \\
\hline 14,110 & 355760 & 0,00000752 & 18,000 & 20,200 & 0,180 \\
\hline 14,160 & 362144 & 0,00000783 & 18,000 & 19,800 & 0,173 \\
\hline 14,210 & 369341 & 0,00000695 & 18,000 & 20,000 & 0,177 \\
\hline 14,260 & 376869 & 0,00000664 & 18,000 & 20,200 & 0,180 \\
\hline 14,310 & 384351 & 0,00000668 & 18,000 & 19,800 & 0,173 \\
\hline 14,360 & 389958 & 0,00000892 & 18,000 & 20,000 & 0,177 \\
\hline 14,410 & 395281 & 0,00000939 & 18,000 & 20,200 & 0,180 \\
\hline 14,460 & 400545 & 0,00000950 & 18,000 & 19,800 & 0,173 \\
\hline 14,510 & 405197 & 0,00001075 & 18,000 & 20,000 & 0,177 \\
\hline 14,560 & 412396 & 0,00000695 & 18,000 & 20,200 & 0,180 \\
\hline 14,610 & 421332 & 0,00000560 & 18,000 & 19,800 & 0,173 \\
\hline 14,660 & 422661 & 0,00003762 & 18,000 & 20,000 & 0,177 \\
\hline 14,710 & 426978 & 0,00001158 & 18,000 & 18,000 & 0,143 \\
\hline 14,760 & 450452 & 0,00000213 & 16,200 & 18,180 & 0,146 \\
\hline 14,810 & 460962 & 0,00000476 & 16,200 & 17,820 & 0,140 \\
\hline 14,860 & 472175 & 0,00000446 & 16,200 & 18,000 & 0,143 \\
\hline 14,910 & 484329 & 0,00000411 & 16,200 & 18,180 & 0,146 \\
\hline 14,960 & 495437 & 0,00000450 & 16,200 & 17,820 & 0,140 \\
\hline 15,010 & 512502 & 0,00000293 & 16,200 & 18,000 & 0,143 \\
\hline 15,060 & 513024 & 0,00009579 & 16,200 & 18,180 & 0,146 \\
\hline 15,110 & 522352 & 0,00000536 & 16,200 & 17,820 & 0,140 \\
\hline 15,160 & 527864 & 0,00000907 & 16,200 & 18,180 & 0,146 \\
\hline 15,210 & 535061 & 0,00000695 & 16,200 & 17,820 & 0,140 \\
\hline 15,260 & 542878 & 0,00000640 & 16,200 & 18,000 & 0,143 \\
\hline 15,310 & 551133 & 0,00000606 & 16,200 & 18,180 & 0,146 \\
\hline 15,360 & 555835 & 0,00001063 & 16,200 & 17,820 & 0,140 \\
\hline 15,410 & 560968 & 0,00000974 & 16,200 & 18,000 & 0,143 \\
\hline 15,460 & 574171 & 0,00000379 & 16,200 & 18,180 & 0,146 \\
\hline 15,510 & 586271 & 0,00000413 & 16,200 & 17,820 & 0,140 \\
\hline 15,560 & 594673 & 0,00000595 & 16,200 & 18,000 & 0,143 \\
\hline 15,610 & 605674 & 0,00000455 & 16,200 & 18,180 & 0,146 \\
\hline 15,660 & 613002 & 0,00000682 & 16,200 & 17,820 & 0,140 \\
\hline 15,710 & 620983 & 0,00000626 & 16,200 & 18,000 & 0,143 \\
\hline 15,760 & 621443 & 0,00010870 & 16,200 & 18,180 & 0,146 \\
\hline
\end{tabular}




\begin{tabular}{|c|c|c|c|c|c|}
\hline 15,810 & 622025 & 0,00008591 & 16,200 & 17,820 & 0,140 \\
\hline 15,860 & 623124 & 0,00004550 & 16,200 & 18,000 & 0,143 \\
\hline 15,910 & 629728 & 0,00000757 & 16,200 & 18,180 & 0,146 \\
\hline 15,960 & 644468 & 0,00000339 & 16,200 & 17,820 & 0,140 \\
\hline 16,010 & 665199 & 0,00000241 & 16,200 & 18,000 & 0,143 \\
\hline 16,060 & 673356 & 0,00000613 & 16,200 & 18,180 & 0,146 \\
\hline 16,110 & 685368 & 0,00000416 & 16,200 & 16,200 & 0,116 \\
\hline 16,160 & 719153 & 0,00000148 & 14,580 & 16,362 & 0,118 \\
\hline 16,210 & 745655 & 0,00000189 & 14,580 & 16,038 & 0,114 \\
\hline 16,260 & 780345 & 0,00000144 & 14,580 & 16,200 & 0,116 \\
\hline 16,310 & 799513 & 0,00000261 & 14,580 & 16,362 & 0,118 \\
\hline 16,360 & 817407 & 0,00000279 & 14,580 & 16,038 & 0,114 \\
\hline 16,410 & 837800 & 0,00000245 & 14,580 & 16,200 & 0,116 \\
\hline 16,460 & 867807 & 0,00000167 & 14,580 & 16,038 & 0,114 \\
\hline 16,510 & 884199 & 0,00000305 & 14,580 & 16,200 & 0,116 \\
\hline 16,560 & 895480 & 0,00000443 & 14,580 & 16,362 & 0,118 \\
\hline 16,610 & 908426 & 0,00000386 & 14,580 & 16,038 & 0,114 \\
\hline 16,660 & 931465 & 0,00000217 & 14,580 & 16,200 & 0,116 \\
\hline 16,710 & 956766 & 0,00000198 & 14,580 & 16,362 & 0,118 \\
\hline 16,760 & 965132 & 0,00000598 & 14,580 & 16,038 & 0,114 \\
\hline 16,810 & 973423 & 0,00000603 & 14,580 & 16,200 & 0,116 \\
\hline 16,860 & 978138 & 0,00001060 & 14,580 & 16,362 & 0,118 \\
\hline 16,910 & 1003889 & 0,00000194 & 14,580 & 16,038 & 0,114 \\
\hline 16,960 & 1028212 & 0,00000206 & 14,580 & 16,200 & 0,116 \\
\hline 17,010 & 1051332 & 0,00000216 & 14,580 & 16,362 & 0,118 \\
\hline 17,060 & 1075195 & 0,00000210 & 14,580 & 16,038 & 0,114 \\
\hline 17,110 & 1101469 & 0,00000190 & 14,580 & 16,200 & 0,116 \\
\hline 17,160 & 1128623 & 0,00000184 & 14,580 & 16,362 & 0,118 \\
\hline 17,210 & 1147763 & 0,00000261 & 14,580 & 16,038 & 0,114 \\
\hline 17,260 & 1173254 & 0,00000196 & 14,580 & 16,200 & 0,116 \\
\hline 17,310 & 1196839 & 0,00000212 & 14,580 & 16,362 & 0,118 \\
\hline 17,360 & 1221927 & 0,00000199 & 14,580 & 16,038 & 0,114 \\
\hline 17,460 & 1342335 & 0,00000083 & 13,122 & 14,726 & 0,096 \\
\hline 17,510 & 1372945 & 0,00000163 & 13,122 & 14,434 & 0,092 \\
\hline 17,560 & 1391627 & 0,00000268 & 13,122 & 14,580 & 0,094 \\
\hline 17,610 & 1441665 & 0,00000100 & 13,122 & 14,726 & 0,096 \\
\hline 17,660 & 1489617 & 0,00000104 & 13,122 & 14,434 & 0,092 \\
\hline 17,710 & 1665768 & 0,00000028 & 13,122 & 14,580 & 0,094 \\
\hline 17,910 & 1790263 & 0,00000161 & 13,122 & 14,726 & 0,096 \\
\hline 17,960 & 1816758 & 0,00000189 & 13,122 & 14,434 & 0,092 \\
\hline 18,010 & 1873902 & 0,00000087 & 13,122 & 14,580 & 0,094 \\
\hline 18,160 & 1922757 & 0,00000102 & 16,500 & 18,333 & 0,149 \\
\hline 18,210 & 1928903 & 0,00000814 & 17,300 & 19,222 & 0,163 \\
\hline 18,260 & 1936096 & 0,00000695 & 17,300 & 19,222 & 0,163 \\
\hline 18,310 & 1994552 & 0,00000086 & 17,200 & 19,111 & 0,161 \\
\hline 18,360 & 2186792 & 0,00000026 & 17,300 & 19,222 & 0,163 \\
\hline 18,410 & 2260157 & 0,00000068 & 17,300 & 19,222 & 0,163 \\
\hline 18,460 & 2281456 & 0,00000235 & 17,250 & 19,167 & 0,162 \\
\hline 18,510 & 2310384 & 0,00000173 & 17,250 & 19,167 & 0,162 \\
\hline 18,560 & 2330417 & 0,00000250 & 17,200 & 19,111 & 0,161 \\
\hline
\end{tabular}




\begin{tabular}{|c|c|c|c|c|c|}
\hline 18,610 & 2357109 & 0,00000187 & 17,200 & 19,111 & 0,161 \\
\hline 18,660 & 2371284 & 0,00000353 & 17,150 & 19,056 & 0,161 \\
\hline 18,710 & 2387489 & 0,00000309 & 17,150 & 19,056 & 0,161 \\
\hline 18,760 & 2408179 & 0,00000242 & 17,100 & 19,000 & 0,160 \\
\hline 18,810 & 2414568 & 0,00000783 & 17,100 & 19,000 & 0,160 \\
\hline 18,860 & 2440855 & 0,00000190 & 17,050 & 18,944 & 0,159 \\
\hline 18,910 & 2459042 & 0,00000275 & 15,500 & 17,222 & 0,131 \\
\hline 18,960 & 2495227 & 0,00000138 & 15,450 & 17,167 & 0,130 \\
\hline 19,010 & 2527755 & 0,00000154 & 15,400 & 17,111 & 0,129 \\
\hline 19,060 & 2532561 & 0,00001040 & 15,350 & 17,056 & 0,129 \\
\hline 19,110 & 2561647 & 0,00000172 & 15,300 & 17,000 & 0,128 \\
\hline 19,160 & 2595741 & 0,00000147 & 15,000 & 16,667 & 0,123 \\
\hline 19,210 & 2623745 & 0,00000179 & 14,600 & 16,222 & 0,116 \\
\hline 19,260 & 2663011 & 0,00000127 & 14,000 & 15,556 & 0,107 \\
\hline 19,310 & 2697557 & 0,00000145 & 13,500 & 15,000 & 0,099 \\
\hline 19,360 & 2759240 & 0,00000081 & 12,991 & 14,434 & 0,092 \\
\hline 19,410 & 3662733 & 0,00000275 & 12,991 & 14,434 & 0,092 \\
\hline 19,460 & 3709829 & 0,00000106 & 12,991 & 14,434 & 0,092 \\
\hline 19,510 & 3794109 & 0,00000059 & 12,991 & 14,434 & 0,092 \\
\hline 19,560 & 3876088 & 0,00000061 & 12,991 & 14,434 & 0,092 \\
\hline 19,610 & 3921057 & 0,00000111 & 12,991 & 14,434 & 0,092 \\
\hline 19,660 & 3971883 & 0,00000098 & 12,991 & 14,434 & 0,092 \\
\hline 19,710 & 4035209 & 0,00000079 & 12,991 & 14,434 & 0,092 \\
\hline 19,760 & 4081070 & 0,00000109 & 12,991 & 14,434 & 0,092 \\
\hline 19,810 & 4142098 & 0,00000082 & 12,991 & 14,434 & 0,092 \\
\hline 19,860 & 4195842 & 0,00000093 & 12,991 & 14,434 & 0,092 \\
\hline 19,910 & 4322818 & 0,00000039 & 12,991 & 14,290 & 0,090 \\
\hline 19,960 & 4324387 & 0,00003187 & 12,991 & 14,290 & 0,090 \\
\hline 20,210 & 4382767 & 0,00000086 & 12,991 & 14,579 & 0,094 \\
\hline 20,293 & 4700139 & 0,00000099 & 12,991 & 14,290 & 0,090 \\
\hline 20,310 & 4728684 & 0,00000060 & 12,991 & 14,434 & 0,092 \\
\hline 20,360 & 4814995 & 0,00000058 & 12,991 & 14,579 & 0,094 \\
\hline 20,410 & 4890225 & 0,00000066 & 12,991 & 14,290 & 0,090 \\
\hline 20,477 & 4936274 & 0,00000145 & 12,991 & 14,434 & 0,092 \\
\hline 20,510 & 4986900 & 0,00000065 & 12,991 & 14,579 & 0,094 \\
\hline 20,560 & 5008590 & 0,00000231 & 12,991 & 14,290 & 0,090 \\
\hline
\end{tabular}


Apêndice II

\section{Rotina MatLab para Exibir a Nuvem de Pontos}

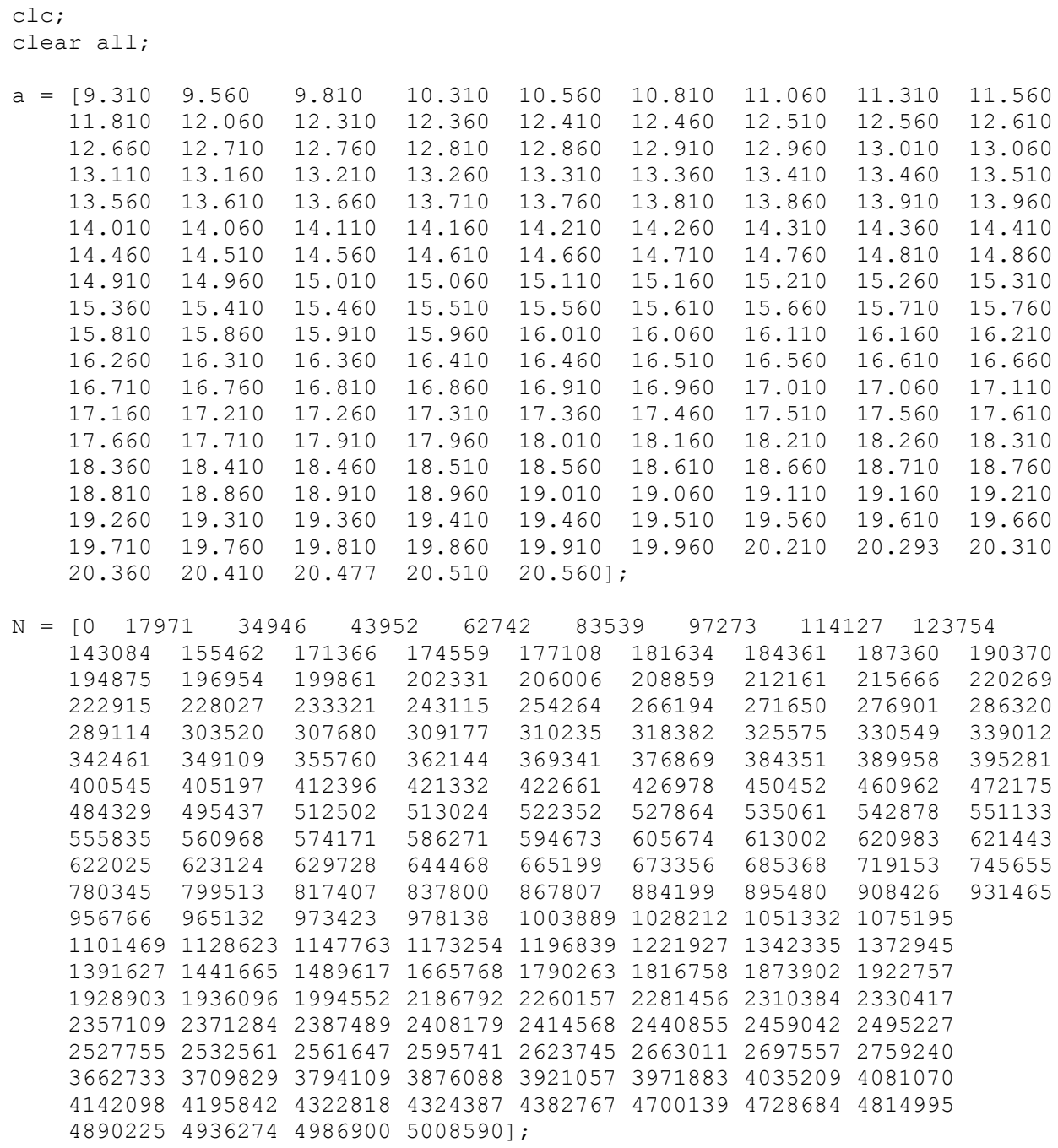
$\mathrm{N}=\left[\begin{array}{lllllllll}0 & 17971 & 34946 & 43952 & 62742 & 83539 & 97273 & 114127 & 123754\end{array}\right.$ $\begin{array}{lllllllll}143084 & 155462 & 171366 & 174559 & 177108 & 181634 & 184361 & 187360 & 190370\end{array}$ $\begin{array}{lllllllll}194875 & 196954 & 199861 & 202331 & 206006 & 208859 & 212161 & 215666 & 220269\end{array}$ $\begin{array}{lllllllll}222915 & 228027 & 233321 & 243115 & 254264 & 266194 & 271650 & 276901 & 286320\end{array}$ $\begin{array}{lllllllll}289114 & 303520 & 307680 & 309177 & 310235 & 318382 & 325575 & 330549 & 339012\end{array}$ $\begin{array}{lllllllll}342461 & 349109 & 355760 & 362144 & 369341 & 376869 & 384351 & 389958 & 395281\end{array}$ $\begin{array}{lllllllll}400545 & 405197 & 412396 & 421332 & 422661 & 426978 & 450452 & 460962 & 472175\end{array}$ $\begin{array}{lllllllll}484329 & 495437 & 512502 & 513024 & 522352 & 527864 & 535061 & 542878 & 551133\end{array}$ $\begin{array}{lllllllll}555835 & 560968 & 574171 & 586271 & 594673 & 605674 & 613002 & 620983 & 621443\end{array}$ $\begin{array}{lllllllll}622025 & 623124 & 629728 & 644468 & 665199 & 673356 & 685368 & 719153 & 745655\end{array}$ $\begin{array}{lllllllll}780345 & 799513 & 817407 & 837800 & 867807 & 884199 & 895480 & 908426 & 931465\end{array}$

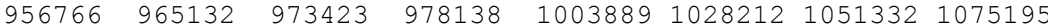 $\begin{array}{lllllllll}1101469 & 1128623 & 1147763 & 1173254 & 1196839 & 1221927 & 1342335 & 1372945\end{array}$ $\begin{array}{lllllllll}1391627 & 1441665 & 1489617 & 1665768 & 1790263 & 1816758 & 1873902 & 1922757\end{array}$ $\begin{array}{llllllll}1928903 & 1936096 & 1994552 & 2186792 & 2260157 & 2281456 & 2310384 & 2330417\end{array}$ 23571092371284238748924081792414568244085524590422495227 $\begin{array}{llllllllll}2527755 & 2532561 & 2561647 & 2595741 & 2623745 & 2663011 & 2697557 & 2759240\end{array}$

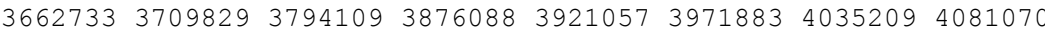 $4142098 \quad 4195842 \quad 4322818 \quad 4324387 \quad 4382767 \quad 470013947286844814995$ $4890225493627449869005008590]$;

$\begin{array}{ccccccc}\mathrm{dadN} & =[0 & 0.00001391 & 0.00001473 & 0.00005552 & 0.00001330 & 0.00001202 \\ 0.00001820 & 0.00001483 & 0.00002597 & 0.00001293 & 0.00002020 & 0.00001572 \\ 0.00001566 & 0.00001962 & 0.00001105 & 0.00001834 & 0.00001667 & 0.00001661 \\ 0.00001110 & 0.00002405 & 0.00001720 & 0.00002024 & 0.00001361 & 0.00001753 \\ 0.00001514 & 0.00001427 & 0.00001086 & 0.00001890 & 0.00000978 & 0.00000944 \\ 0.00000511 & 0.00000448 & 0.00000419 & 0.00000916 & 0.00000952 & 0.00000531 \\ 0.00001790 & 0.00000347 & 0.00001202 & 0.00003340 & 0.00004726 & 0.00000614 \\ 0.00000695 & 0.00001005 & 0.00000591 & 0.00001450 & 0.00000752 & 0.00000752 \\ 0.00000783 & 0.00000695 & 0.00000664 & 0.00000668 & 0.00000892 & 0.00000939 \\ 0.00000950 & 0.00001075 & 0.00000695 & 0.00000560 & 0.00003762 & 0.00001158 \\ 0.00000213 & 0.00000476 & 0.00000446 & 0.00000411 & 0.00000450 & 0.00000293 \\ 0.00009579 & 0.00000536 & 0.00000907 & 0.00000695 & 0.00000640 & 0.00000606 \\ 0.00001063 & 0.00000974 & 0.00000379 & 0.00000413 & 0.00000595 & 0.00000455 \\ 0.00000682 & 0.00000626 & 0.00010870 & 0.00008591 & 0.00004550 & 0.00000757 \\ 0.00000339 & 0.00000241 & 0.00000613 & 0.00000416 & 0.00000148 & 0.00000189 \\ 0.00000144 & 0.00000261 & 0.00000279 & 0.00000245 & 0.00000167 & 0.00000305 \\ 0.00000443 & 0.00000386 & 0.00000217 & 0.00000198 & 0.00000598 & 0.00000603 \\ 0.00001060 & 0.00000194 & 0.00000206 & 0.00000216 & 0.00000210 & 0.00000190 \\ 0.00000184 & 0.00000261 & 0.00000196 & 0.00000212 & 0.00000199 & 0.00000083\end{array}$




\begin{tabular}{|c|c|c|c|c|c|c|c|c|c|c|}
\hline & 0.000001 & & 000268 & 0.00000 & 100 & 0.0 & 000104 & 0.000000 & 028 & 000161 \\
\hline & 0.0000 & & 000087 & 0.00000 & 102 & & 0000814 & 0.0000 & 695 & 000086 \\
\hline & 0.000000 & 26 & 0000068 & 0.00000 & 235 & 0.0 & 0000173 & 0.000002 & 250 & 0000187 \\
\hline & 0.000003 & 353 & 0000309 & 0.00000 & 242 & 0.0 & 0000783 & 0.000001 & 190 & 0000275 \\
\hline & 0.000001 & 38 & 0000154 & 0.00001 & 040 & 0.0 & 0000172 & 0.000001 & 147 & 0000179 \\
\hline & 0.000001 & 27 & 0000145 & 0.00000 & 081 & 0.0 & 0000275 & 0.000001 & 106 & 0000059 \\
\hline & 0.000000 & 61 & 0000111 & 0.00000 & 098 & 0.0 & 0000079 & 0.000001 & 109 & 0000082 \\
\hline & 0.000000 & & 0000039 & 0.00003 & & 0.0 & 0000086 & 0.000000 & 099 & 0000060 \\
\hline & 0.000000 & 58 & 0000066 & 0.00000 & 145 & 0.0 & 0000065 & 0.000002 & 231]； & \\
\hline & $=[20.00$ & & $100 \quad 20$ & $00 \quad 20$. & & & $000 \quad 20$ & $100 \quad 20$. & & \\
\hline & 20.000 & 20.000 & 20.000 & 20.000 & 20. & 000 & 20.000 & 20.000 & 20.000 & 20.000 \\
\hline & 20.000 & 20.000 & 20.000 & 20.000 & 20. & 000 & 20.000 & 20.000 & 20.000 & 20.000 \\
\hline & 20.000 & 20.000 & 20.000 & 18.000 & 18. & 000 & 18.000 & 18.000 & 18.000 & 18.000 \\
\hline & 18.000 & 18.000 & 18.000 & 18.000 & 18. & 000 & 18.000 & 18.000 & 18.000 & 18.000 \\
\hline & 18.000 & 18.000 & 18.000 & 18.000 & 18. & 000 & 18.000 & 18.000 & 18.000 & 18.000 \\
\hline & 18.000 & 18.000 & 18.000 & 18.000 & 18. & 000 & 18.000 & 18.000 & 16.200 & 16.200 \\
\hline & 16.200 & 16.200 & 16.200 & 16.200 & 16. & 200 & 16.200 & 16.200 & 16.200 & 16.200 \\
\hline & 16.200 & 16.200 & 16.200 & 16.200 & 16. & 200 & 16.200 & 16.200 & 16.200 & 16.200 \\
\hline & 16.200 & 16.200 & 16.200 & 16.200 & 16. & 200 & 16.200 & 16.200 & 16.200 & 14.580 \\
\hline & 14.580 & 14.580 & 14.580 & 14.580 & 14. & 580 & 14.580 & 14.580 & 14.580 & 14.580 \\
\hline & 14.580 & 14.580 & 14.580 & 14.580 & 14. & 580 & 14.580 & 14.580 & 14.580 & 14.580 \\
\hline & 14.580 & 14.580 & 14.580 & 14.580 & 14. & 580 & 14.580 & 13.122 & 13.122 & .122 \\
\hline & 13.122 & 13.122 & 13.122 & 13.122 & 13. & 122 & 13.122 & 16.500 & 17.300 & .300 \\
\hline & 17.200 & 17.300 & 17.300 & 17.250 & 17. & 250 & 17.200 & 17.200 & 17.150 & 17.150 \\
\hline & 17.100 & 17.100 & 17.050 & 15.500 & 15. & 450 & 15.400 & 15.350 & 15.300 & \\
\hline & 14.600 & 14.000 & 13.500 & 12.991 & 12. & 991 & 12.991 & 12.991 & 12.991 & 12.991 \\
\hline & 12.991 & 12.991 & 12.991 & 12.991 & 12. & 991 & 12.991 & 12.991 & 12.991 & 12.991 \\
\hline & 12.991 & 12.991 & 12.991 & 12.991 & 12. & & & & & \\
\hline & $\operatorname{lax}=[22$ & $222 \quad 22$ & $22 \quad 22$ & $22 \quad 2$ & 22 & & 22222. & 22.2 & 22. & \\
\hline & 22.222 & 22.222 & 22.222 & 22.222 & 22. & 444 & 22.000 & 22.222 & 22.444 & 22.000 \\
\hline & 22.222 & 22.444 & 22.000 & 22.222 & 22. & 444 & 22.000 & 22.222 & 22.444 & 22.000 \\
\hline & 22.222 & 22.444 & 20.000 & 20.200 & 19. & 800 & 20.000 & 20.200 & 19.800 & 20.000 \\
\hline & 20.200 & 19.800 & 20.000 & 20.200 & 19. & 800 & 000 & .200 & 19.800 & 000 \\
\hline & 20.200 & 19.800 & 20.000 & 20.200 & 19. & 800 & .000 & 20.200 & 19.800 & 0.000 \\
\hline & 20.200 & 19.800 & 20.000 & 20.200 & 19. & 800 & .000 & 18.0 & 18.180 & 7.820 \\
\hline & 18.000 & 18.180 & 17.820 & 18.000 & 18. & 180 & .820 & 18.180 & 17.820 & 000 \\
\hline & 18.180 & 17.820 & 18.000 & 18.180 & 17. & 820 & 18.000 & 18.180 & 17.820 & 8.000 \\
\hline & .180 & 17.820 & 18.000 & 18.180 & 17. & 820 & 18.000 & 18.180 & 16.200 & .362 \\
\hline & .038 & 16.200 & & & & 200 & & .200 & 16.362 & \\
\hline & 16.200 & 16.362 & 16.038 & 16.2 & 16. & 362 & 5.038 & 16.200 & 16.362 & 5.038 \\
\hline & .200 & 16.362 & 16.038 & 16.2 & 16. & 362 & & & 14.434 & 1.580 \\
\hline & .726 & 14.434 & 14.5 & & 14 & 434 & 580 & & 19.222 & 222 \\
\hline & .111 & 19.222 & 19.222 & 19.167 & 19. & 167 & 9.111 & 19.1 & 19.056 & 9.056 \\
\hline & & 19.0 & & & & & & & & \\
\hline & 2 & 15.556 & & 14.4 & 14 & 434 & & 14. & 14.434 & 434 \\
\hline & 14.434 & 14.434 & 14.434 & 14.434 & 14. & 434 & 14.290 & 14.290 & 14.579 & 14.290 \\
\hline & & 14.579 & 14.290 & 14.434 & 14. & & $14.290]$ & & & \\
\hline $\mathrm{zp}=$ & $=[0.218$ & 0.218 & & & & & & & & \\
\hline & 0.218 & 0.218 & & & & & & & 0.214 & \\
\hline & 0.223 & 0.214 & 0 & & 0 . & & & $0.2 x+2$ & 0.214 & 18 \\
\hline & 0.223 & 0.177 & & & 0.1 & & & & 0.177 & 80 \\
\hline & 0.173 & 0.177 & & & 0.1 & & & & 0.177 & 80 \\
\hline & .173 & 0.177 & & & & & & & 0.177 & 0.180 \\
\hline & 0.173 & 0.177 & 0.180 & 0.17 & 0. & & 0.1 & 0.146 & 0.140 & 143 \\
\hline & .146 & 0.140 & & & 0.1 & & & & 0.143 & 46 \\
\hline & & 0.1 & & & & & & & & 46 \\
\hline & 0 & 0.14 & 0.1 & & 0.1 & & & & 0.118 & \\
\hline & .116 & 0.1 & & 0.1 & 0.1 & & & & 0.114 & \\
\hline & & 0.1 & & & & & & & 0.114 & \\
\hline & .118 & 0.114 & 0.116 & & 0.1 & & 0.096 & 0.092 & 0.094 & 0.096 \\
\hline & 0.092 & 0.094 & 0.096 & 0.092 & 0.0 & & 0.149 & 0.163 & 0.163 & 0.161 \\
\hline & & 0.163 & & & & & & & 0.161 & 0.160 \\
\hline & 0.160 & 0.159 & 0.131 & 0.13 & 0.1 & & 0.129 & 0.128 & 0.123 & 0.116 \\
\hline & 0.107 & 0.099 & 0.09 & 0.092 & 0.0 & & 0.092 & 0.092 & 0.092 & 0.092 \\
\hline & & 0.092 & 0.092 & 0.092 & 0.0 & & 0.090 & 0.094 & 0.090 & 0.092 \\
\hline & 0.094 & 0.090 & 0.092 & 0.094 & 0.0 & 901 & & & & \\
\hline
\end{tabular}

disp('Que gráfico deseja analisar?');

disp (' ') ;

disp('Opção $1-a \times N ; ')$;

disp(' '); 


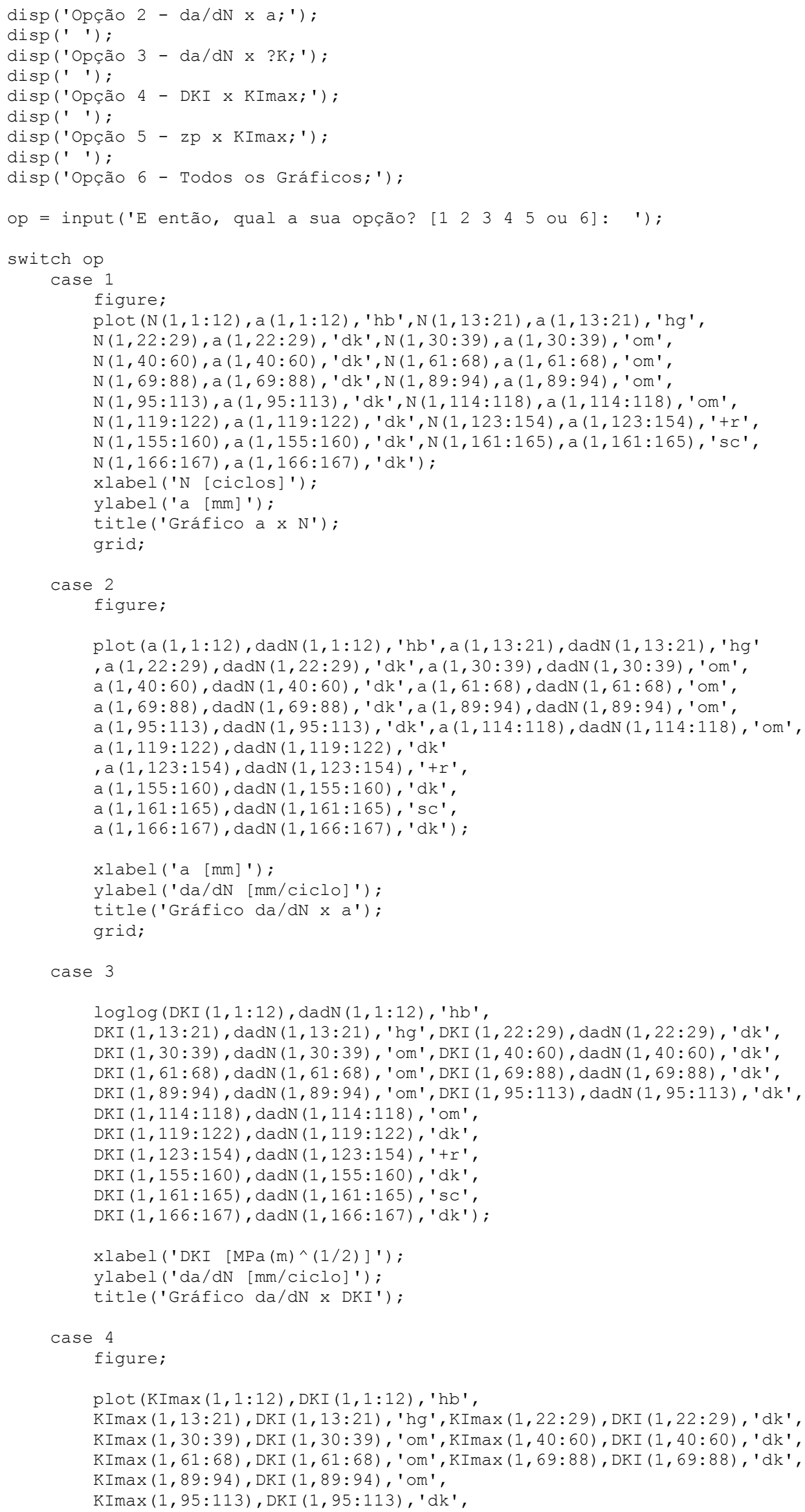


$\operatorname{KImax}(1,114: 118), \operatorname{DKI}(1,114: 118)$, 'om' , $\operatorname{KImax}(1,119: 122), \operatorname{DKI}(1,119: 122), \mathrm{Cdk}^{\prime}$, $\operatorname{KImax}(1,123: 154), \operatorname{DKI}(1,123: 154), '+r '$ $\operatorname{KImax}(1,155: 160), \operatorname{DKI}(1,155: 160),{ }^{\prime} \mathrm{dk}$ ', $\operatorname{KImax}(1,161: 165), \operatorname{DKI}(1,161: 165)$, 'sc', $\left.\operatorname{KImax}(1,166: 167), \operatorname{DKI}(1,166: 167), ' d k^{\prime}\right)$;

xlabel ('KImax $\left.\left[\mathrm{MPa}(\mathrm{m})^{\wedge}(1 / 2)\right]^{\prime}\right)$; ylabel ('DKI [MPa $\left.\left.(\mathrm{m})^{\wedge}(1 / 2)\right]^{\prime}\right)$; title('Gráfico DKI x KImax'); grid;

case 5

figure;

plot (KImax (1,1:12), zp (1,1:12), 'hb', $\operatorname{KImax}(1,13: 21), z p(1,13: 21)$, 'hg', $\operatorname{KImax}(1,22: 29), \mathrm{zp}(1,22: 29),{ }^{\prime} \mathrm{dk} \mathbf{\prime}^{\prime}, \operatorname{KImax}(1,30: 39), \mathrm{zp}(1,30: 39)$, 'om ', $\operatorname{KImax}(1,40: 60), \mathrm{zp}(1,40: 60),{ }^{\prime} \mathrm{dk}{ }^{\prime}, \operatorname{KImax}(1,61: 68), \mathrm{zp}(1,61: 68)$,' 'om',' $\operatorname{KImax}(1,69: 88), \mathrm{zp}(1,69: 88),{ }^{\prime} \mathrm{dk}$ ', $\operatorname{KImax}(1,89: 94), \mathrm{zp}(1,89: 94)$, 'om ', $\operatorname{KImax}(1,95: 113), \mathrm{zp}(1,95: 113), \mathrm{dkk}^{\prime}$, $\operatorname{KImax}(1,114: 118), \mathrm{zp}(1,114: 118)$, 'om' , $\operatorname{KImax}(1,119: 122), \mathrm{zp}(1,119: 122), \mathrm{dk}^{\prime}$, $\operatorname{KImax}(1,123: 154), \operatorname{zp}(1,123: 154)$, '+r', $\operatorname{KImax}(1,155: 160), \mathrm{zp}(1,155: 160), \mathrm{dkk}^{\prime}$ $\operatorname{KImax}(1,161: 165), \mathrm{zp}(1,161: 165)$, 'sc', $\left.\operatorname{KImax}(1,166: 167), \mathrm{zp}(1,166: 167), \mathrm{dk}^{\prime}\right)$;

xlabel ('KImax $\left.\left[\operatorname{MPa}(\mathrm{m})^{\wedge}(1 / 2)\right]^{\prime}\right)$; ylabel ('zp [mm]');

title('Gráfico zp x KImax'); grid;

case 6

figure (1);

plot (N (1, 1:12), a (1,1:12), 'hb', N(1,13:21), a (1,13:21), 'hg',

$\mathrm{N}(1,22: 29), \mathrm{a}(1,22: 29), \mathrm{dk}^{\prime}, \mathrm{N}(1,30: 39), \mathrm{a}(1,30: 39), \mathrm{I}^{\prime}$ ',

$\mathrm{N}(1,40: 60), \mathrm{a}(1,40: 60), \mathrm{d}^{\prime}$ ', $\mathrm{N}(1,61: 68), \mathrm{a}(1,61: 68)$, 'om', $\mathrm{N}(1,69: 88), \mathrm{a}(1,69: 88), \mathrm{dk}^{\prime}, \mathrm{N}(1,89: 94), \mathrm{a}(1,89: 94), \mathrm{com}^{\prime}$, $\mathrm{N}(1,95: 113), \mathrm{a}(1,95: 113), \mathrm{dk}^{\prime}, \mathrm{N}(1,114: 118), \mathrm{a}(1,114: 118)$, 'om' , $\mathrm{N}(1,119: 122), \mathrm{a}(1,119: 122),{ }^{\prime} \mathrm{dk} \mathrm{\prime}^{\prime}, \mathrm{N}(1,123: 154), \mathrm{a}(1,123: 154), \mathrm{r}^{\prime}$, $\mathrm{N}(1,155: 160), \mathrm{a}(1,155: 160), \mathrm{dk}^{\prime}, \mathrm{N}(1,161: 165), \mathrm{a}(1,161: 165), \mathrm{sc}^{\prime}$, $\left.\mathrm{N}(1,166: 167), \mathrm{a}(1,166: 167), \mathrm{dk}^{\prime}\right)$;

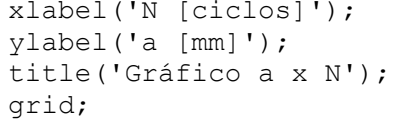

figure (3) ;

$\log \log (\operatorname{DKI}(1,1: 12), \operatorname{dadN}(1,1: 12)$, 'hb', $\operatorname{DKI}(1,13: 21), \operatorname{dadN}(1,13: 21)$, ' hg' ', DKI $(1,22: 29), \operatorname{dadN}(1,22: 29)$, 'dk' , $\operatorname{DKI}(1,30: 39)$, dadN (1,30:39) , ' om' , DKI (1,40:60), dadN (1, $40: 60)$, 'dk' ',

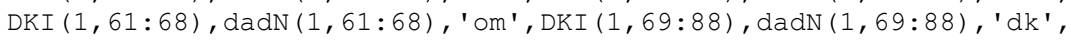

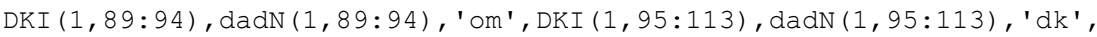




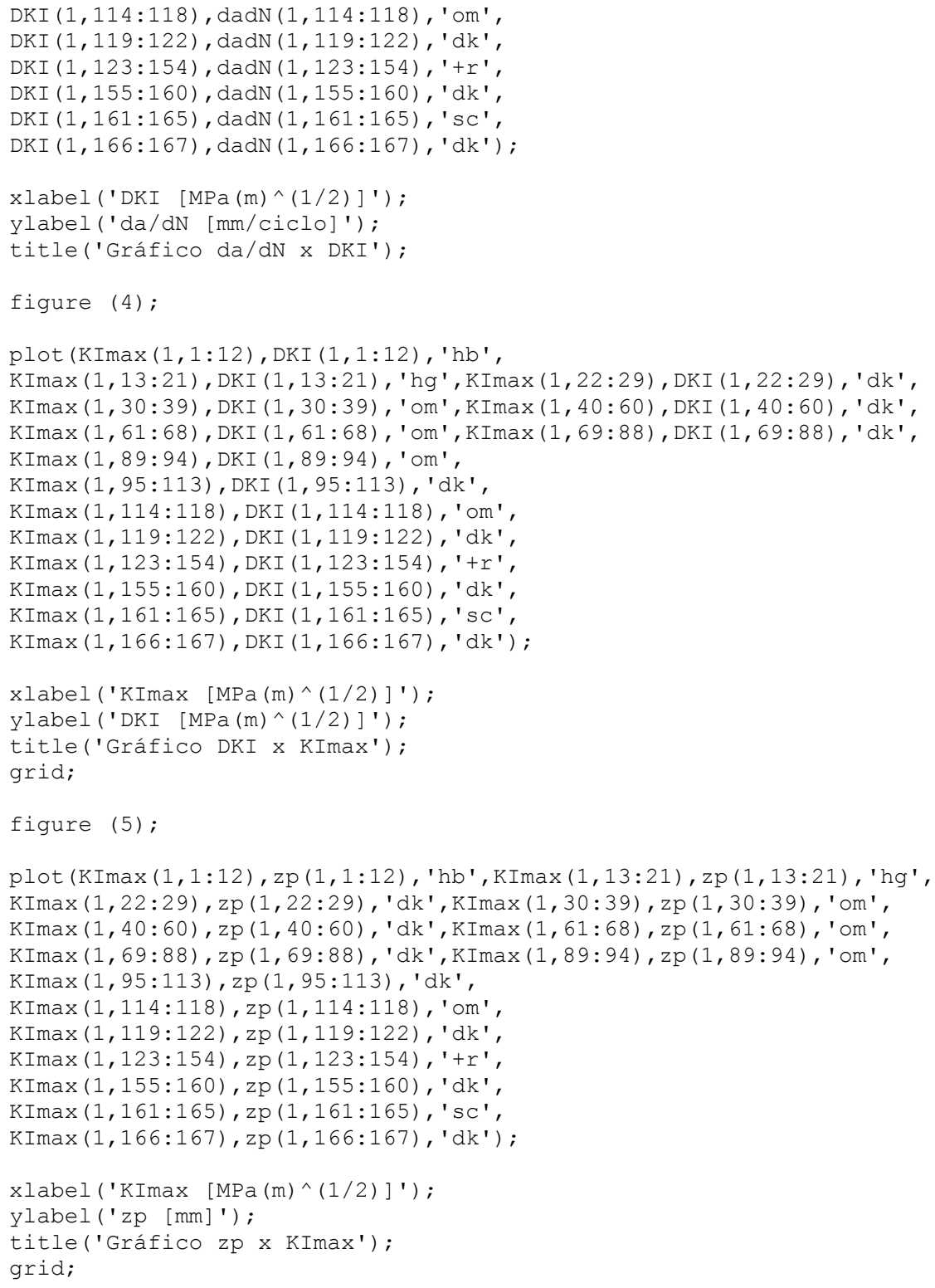




\section{Apêndice III}

\section{Tópicos da Norma ASTM E 647-2000 Utilizados}

$$
\begin{aligned}
& \Delta P=P_{\text {max }}-P_{\text {min }} \\
& R=\frac{P_{\text {min }}}{P_{\text {max }}} \\
& \Delta K=K_{\text {max }}-K_{\text {min }} \Rightarrow\left\{\begin{array}{c}
\Delta K=(1-R) K_{\text {max }}, R \geq 0 \\
\Delta K=K_{\text {max }}, R \leq 0
\end{array}\right.
\end{aligned}
$$

$\mathrm{K}_{\max }$ corresponde a carga $\mathrm{P}_{\max }$ aplicada assim como $\mathrm{K}_{\min }$ corresponde a carga $P_{\min }$ aplicada quando $R>0$, ou seja, carga trativa. Se $R \leq 0$, o que corresponde à compressão, toma-se $\mathrm{P}_{\min }=0$.

$\Delta \mathrm{K}_{\text {th }}-$ Valor assintótico de $\Delta \mathrm{K}$ para o qual da/dN se aproxima de zero. Para a maioria dos materiais $\Delta \mathrm{K}_{\text {th }}$ é igual ao $\Delta \mathrm{K}$ que resulta uma taxa de crescimento da trinca por fadiga de $10^{-10} \mathrm{~m} /$ ciclo.

\section{Pré-trincamento}

A importância do pré-trincamento é fornecer uma trinca de fadiga afiada de tamanho e geometria adequada, assegurando que:

1) o efeito do entalhe inicial usinado é removido do espécime K-calibrado;

2) os efeitos nos dados das taxas de crescimento da trinca subseqüentes causados por mudanças no formato da ponta da trinca ou pela história do carregamento de pré-trincamento sejam eliminados.

Conduzir o pré-trincamento por fadiga com o espécime totalmente tratado termicamente para as condições em que será testado. O equipamento de prétrincamento deve ter distribuição simétrica de forças com respeito ao entalhe usinado e 
$\mathrm{K}_{\max }$ durante o pré-trincamento é controlado dentro de $\pm 5 \%$. Qualquer freqüência de carregamento conveniente que permita a precisão a ser alcançada na força requerida pode ser usada para o pré-trincamento. O entalhe usinado mais a pré-trinca devem estar contidos dentro do envelope, mostrado na fig. 1, que tem como sua extremidade o final da pré-trinca de fadiga. Além disso, a pré-trinca não deve ser menor do que o maior valor entre os três: $0,10 \mathrm{~B}, \mathrm{~h}$ ou $1,0 \mathrm{~mm}$.

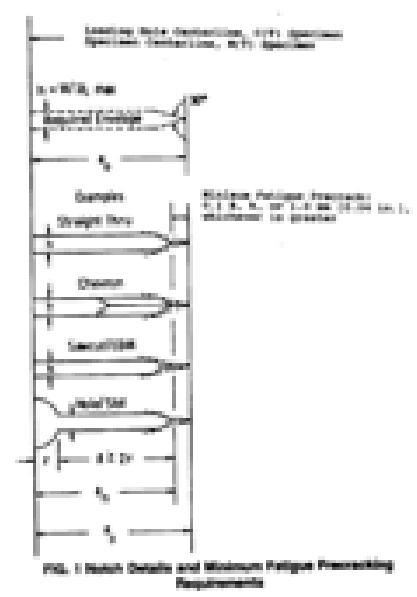

O $\mathrm{K}_{\max }$ final de pré-trinca não deve exceder o $\mathrm{K}_{\max }$ inicial cujos dados do teste começarão a ser obtidos. $\mathrm{O} \mathrm{K}_{\max }$ final de pré-trinca ocorre quando a trinca já está propagada de uma distância onde a Mecânica da Fratura Linear Elástica (MFLE) pode ser aplicada, no nosso caso, levando em consideração a exigência acima e a geometria do corpo de prova, quando a pré-trinca alcança uma distância de $3 \mathrm{~mm}$ a frente do entalhe usinado. Este $\mathrm{K}_{\max }$ não pode ser maior do que o $\mathrm{K}_{\max }$ que ocorre no início do teste onde serão obtidos os dados de propagação da trinca. Se necessário, forças correspondentes a valores de $\mathrm{K}_{\max }$ maiores podem ser usadas para iniciar trincas no entalhe usinado. Para estes casos, a força aplicada deve diminuir em degraus para atender à exigência de que $\mathrm{K}_{\max }$ de pré-trinca é menor ou igual a $\mathrm{K}_{\max }$ de inicio do teste na região de transição. Além disso, é recomendado que a redução em 
$P_{\max }$ para qualquer degrau não seja maior do que $20 \%$ do valor anterior e que um aumento mensurável da trinca ocorra antes de continuar com o próximo passo.

Para evitar efeitos de transientes nos dados do teste, aplicar a diminuição da força em cada degrau após a trinca ter crescido de um valor de no mínimo $3 / \pi\left(K_{\max }^{\prime} / \sigma_{Y S}\right)^{2}$, onde $K_{\max }^{\prime}$ é o valor terminal de $\mathrm{K}_{\max }$ referente ao passo anterior. Se $P_{\min } / P_{\max }$, durante o pré-trincamento, for diferente do usado durante o teste, ver as precauções descritas abaixo.

Se a força varia em diversas fases, deve-se fazer com que $\mathrm{P}_{\max }$ aumente em vez de diminuir, para impedir o retardamento da taxa de crescimento da trinca causado por efeitos de sobrecarga, sendo o retardo um efeito mais pronunciado do que a aceleração do crescimento da trinca associado com o aumento de $\mathrm{P}_{\max }$. Taxas de crescimento transientes da trinca também são oriundas de mudanças no $P_{\min }$ ou $R$. Um alongamento suficiente da trinca deve seguir a mudança na força para permitir que a taxa de crescimento atinja um valor estável. O tamanho do crescimento da trinca requerido depende da magnitude da mudança da forca e do material. Um aumento de $10 \%$ ou menos minimiza essa taxa de crescimento transiente.

Para o procedimento de teste com K-decrescente, a historia de carregamento prévia pode influenciar as taxas de crescimento no limiar de propagação apesar das precauções anteriores. É de boa prática iniciar trincas por fadiga com as menores intensidades de tensões possíveis. Taxas de crescimento de pré-trinca menores do que $10^{-8} \mathrm{~m} /$ ciclo são sugeridas. Uma força compressiva menor ou igual à força de prétrincamento pode facilitar o pré-trincamento por fadiga e diminuir a influência do procedimento de teste K-decrescente no comportamento da taxa de crescimento da trinca por fadiga subseqüente. 
Medir o tamanho da trinca nas superfícies da frente e traseira do espécime dentro de 0,10 mm ou 0,002 W, o que for maior. Para espécimes em que $\mathrm{W}>127 \mathrm{~mm}$, medir o tamanho da trinca dentro de $0,25 \mathrm{~mm}$. Se o tamanho das trincas medidas nas superfícies da frente e traseiras diferirem por mais de $0,25 \mathrm{~B}$, a operação de prétrincamento não é apropriada e os testes subseqüentes seriam inválidos sob este método de teste. 


\section{Apêndice IV}

\section{Gráficos}

\section{1 - Gráfico da/dN x $\Delta K$}

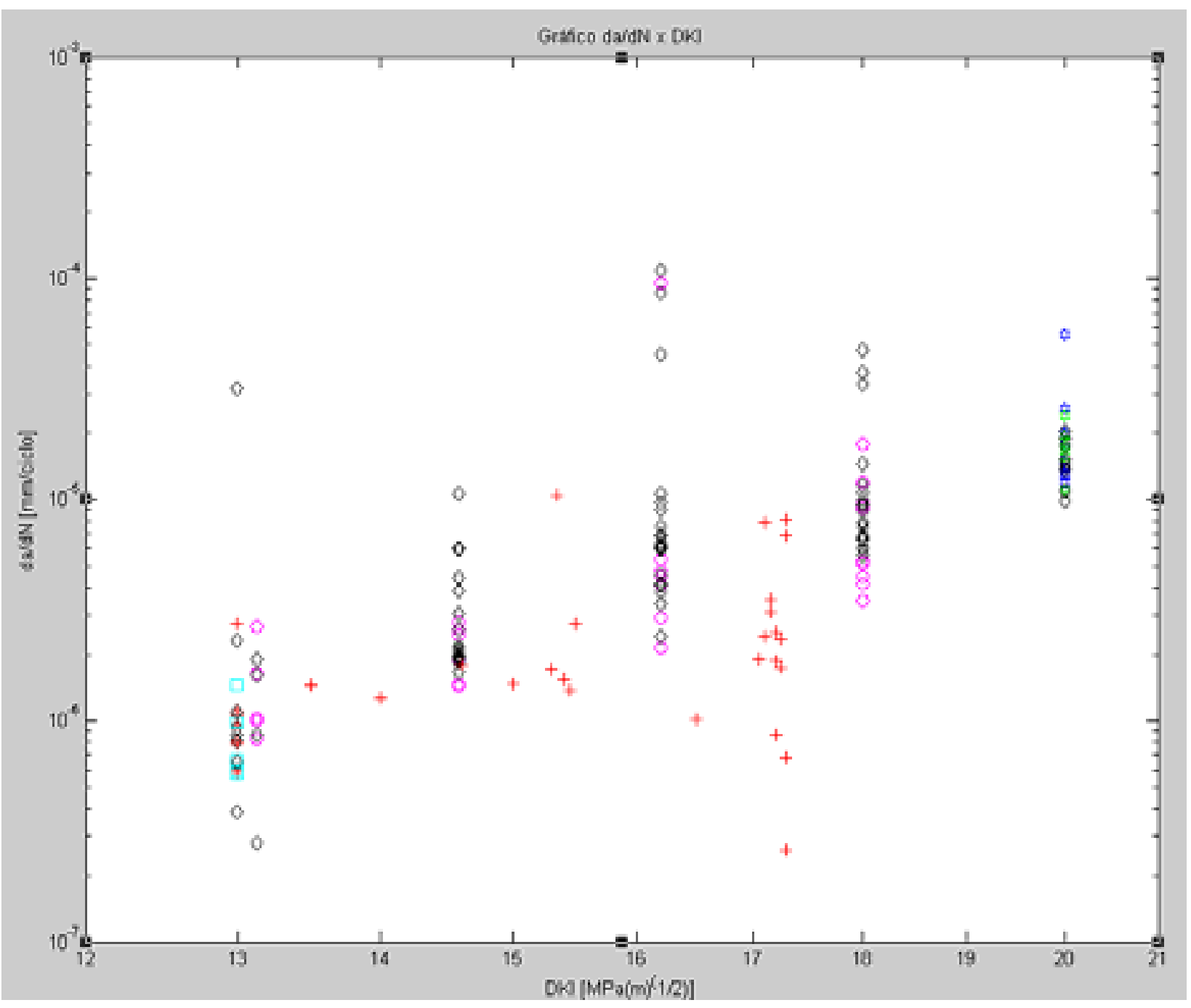




\section{2 - Gráfico da/dN x a}

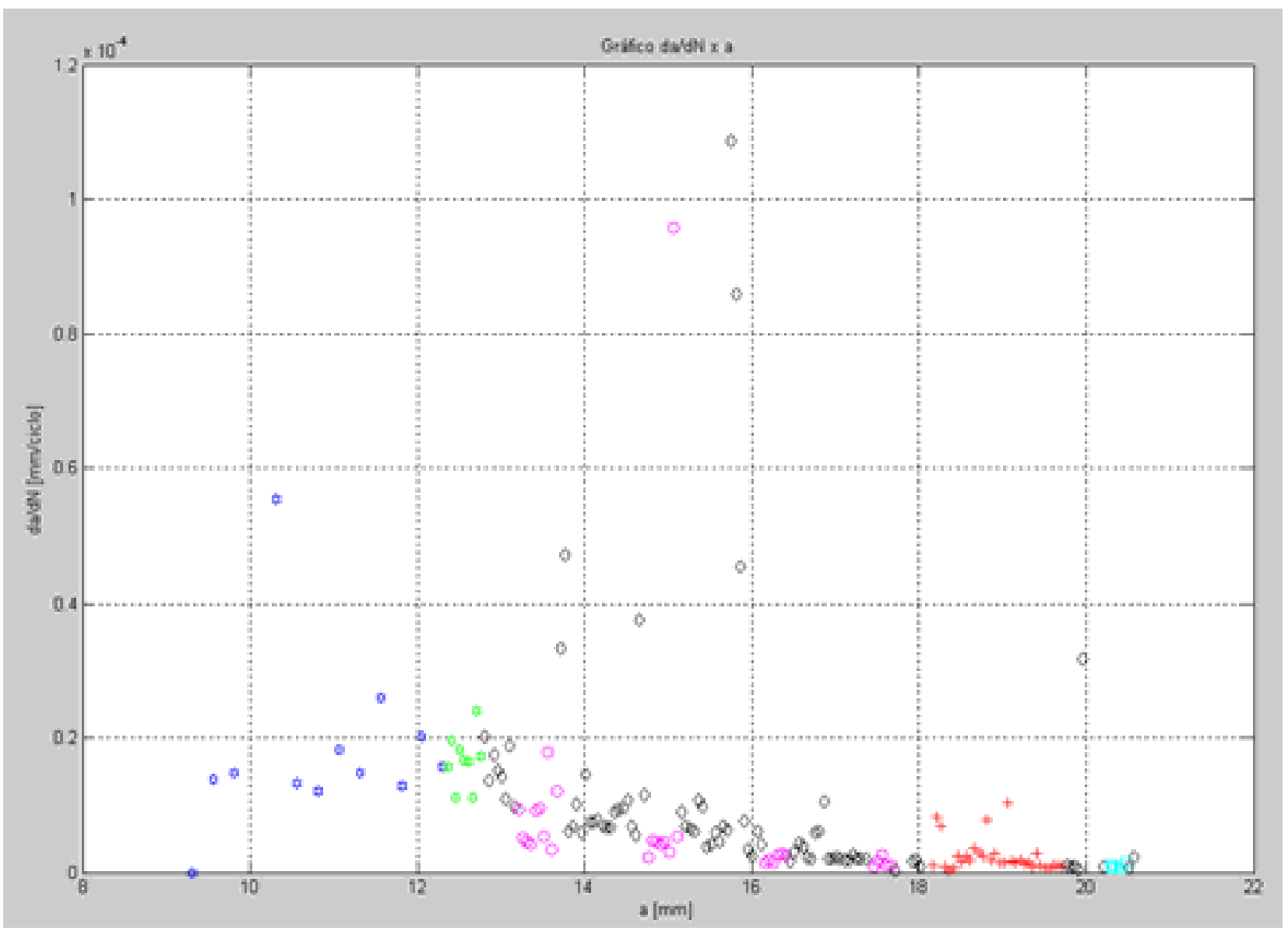




\section{3 - Gráfico a x N}

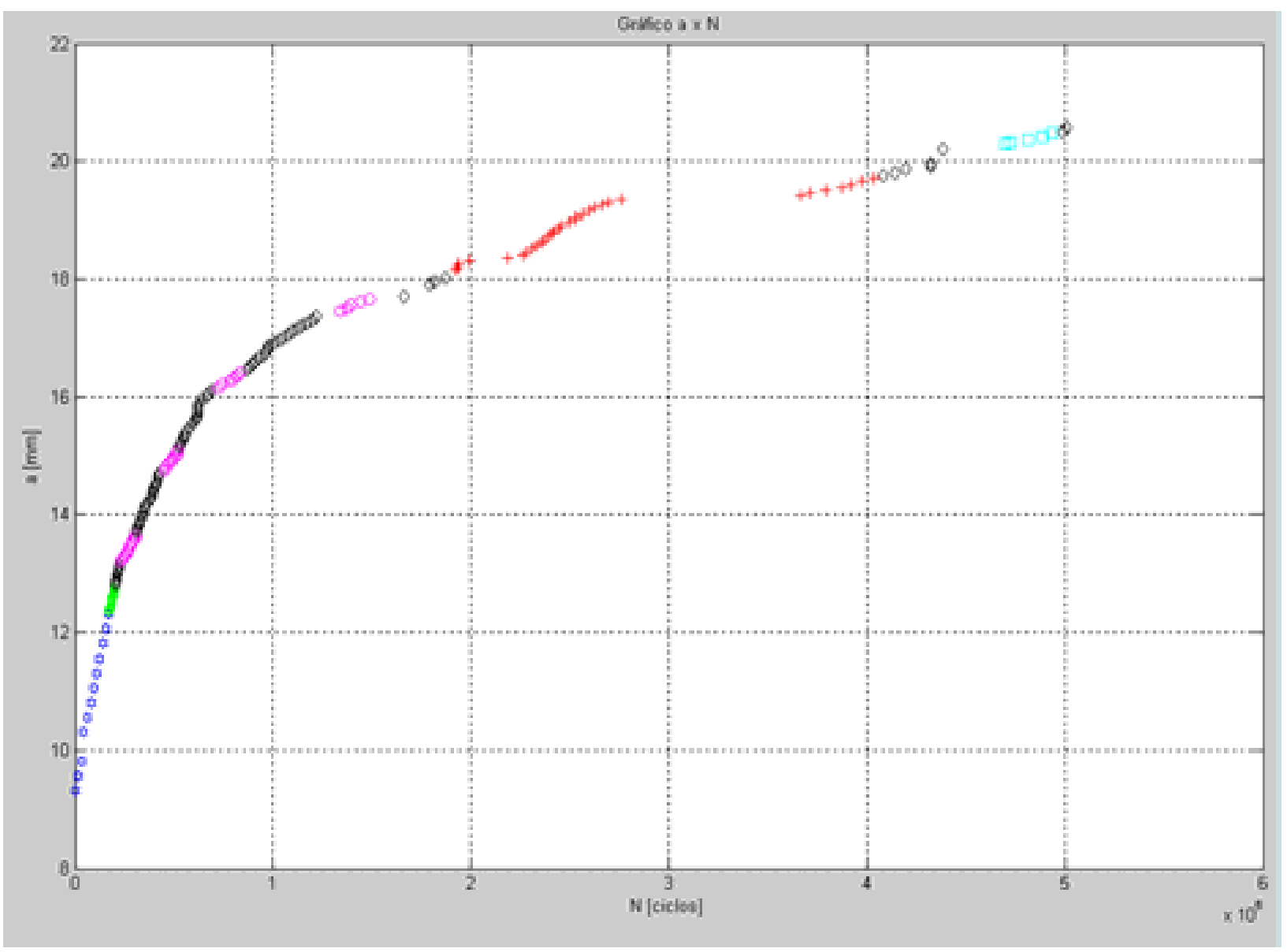

